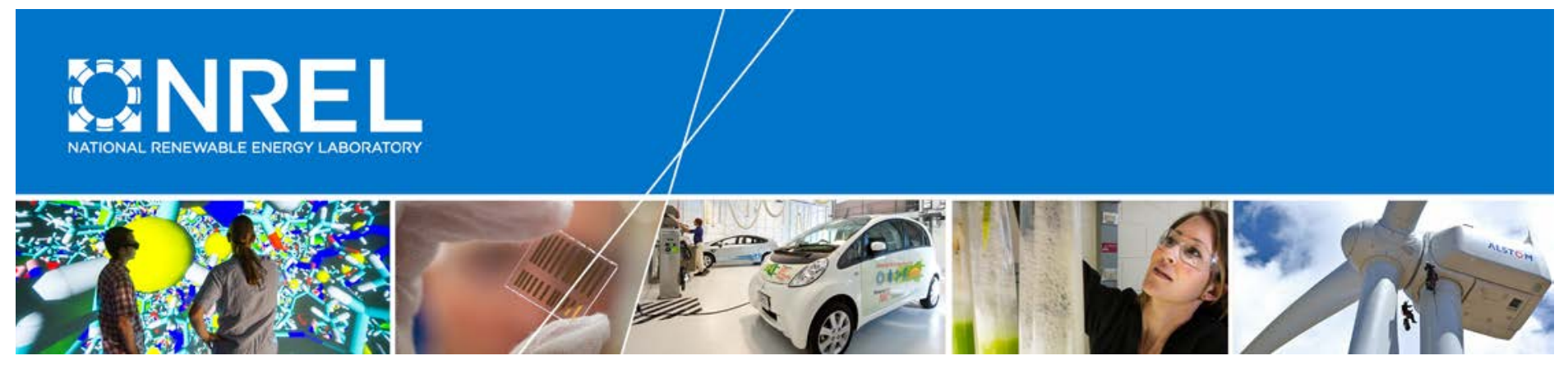

\title{
Energy Storage Annual Progress Report for FY15
}

Ahmad Pesaran, Chunmei Ban, Lei Cao, Peter Graf, Matt Keyser, Gi-Heon Kim, Shriram Santhanagopalan, Aron Saxon, Ying Shi, Kandler Smith, Robert Tenent, Chuanbo Yang, and Chao Zhang National Renewable Energy Laboratory

NREL is a national laboratory of the U.S. Department of Energy Office of Energy Efficiency \& Renewable Energy Operated by the Alliance for Sustainable Energy, LLC

This report is available at no cost from the National Renewable Energy Laboratory (NREL) at www.nrel.gov/publications.

Technical Report

NREL/MP-5400-65317

December 2016 


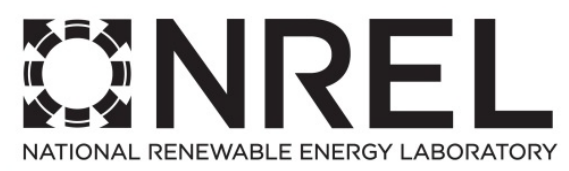

\title{
Energy Storage Annual Progress Report for FY15
}

\author{
Ahmad Pesaran, Chunmei Ban, Lei Cao, \\ Peter Graf, Matt Keyser, Gi-Heon Kim, \\ Shriram Santhanagopalan, Aron Saxon, \\ Ying Shi, Kandler Smith, Robert Tenent, \\ Chuanbo Yang, and Chao Zhang \\ National Renewable Energy Laboratory
}

Prepared under Task Numbers VTP26A01, VTP26A02, VTP26A03, VTP26300, VTP26700, FOVT2000, FOVT2100, and VTP26210

NREL is a national laboratory of the U.S. Department of Energy Office of Energy Efficiency \& Renewable Energy Operated by the Alliance for Sustainable Energy, LLC

This report is available at no cost from the National Renewable Energy Laboratory (NREL) at www.nrel.gov/publications.

National Renewable Energy Laboratory 15013 Denver West Parkway Golden, CO 80401 303-275-3000 • www.nrel.gov

\section{Technical Report}

NREL/MP-5400-65317

December 2016

Contract No. DE-AC36-08G028308 


\section{NOTICE}

This report was prepared as an account of work sponsored by an agency of the United States government. Neither the United States government nor any agency thereof, nor any of their employees, makes any warranty, express or implied, or assumes any legal liability or responsibility for the accuracy, completeness, or usefulness of any information, apparatus, product, or process disclosed, or represents that its use would not infringe privately owned rights. Reference herein to any specific commercial product, process, or service by trade name, trademark, manufacturer, or otherwise does not necessarily constitute or imply its endorsement, recommendation, or favoring by the United States government or any agency thereof. The views and opinions of authors expressed herein do not necessarily state or reflect those of the United States government or any agency thereof.

This report is available at no cost from the National Renewable Energy Laboratory (NREL) at www.nrel.gov/publications.

Available electronically at SciTech Connect http:/www.osti.gov/scitech

Available for a processing fee to U.S. Department of Energy and its contractors, in paper, from:

U.S. Department of Energy

Office of Scientific and Technical Information

P.O. Box 62

Oak Ridge, TN 37831-0062

OSTI http://www.osti.gov

Phone: 865.576.8401

Fax: 865.576.5728

Email: reports@osti.gov

Available for sale to the public, in paper, from:

U.S. Department of Commerce

National Technical Information Service

5301 Shawnee Road

Alexandria, VA 22312

NTIS http://www.ntis.gov

Phone: 800.553 .6847 or 703.605 .6000

Fax: 703.605.6900

Email: orders@ntis.gov 


\section{Foreword}

The Energy Storage Team within the Transportation and Hydrogen Systems Center and the Chemical and Materials Science Center at the National Renewable Energy Laboratory (NREL) performed the work detailed in this report under the Energy Storage Research and Development (R\&D) activity of the Vehicle Technologies Office (VTO), which is managed by David Howell of the U.S. Department of Energy (DOE) Office of Energy Efficiency and Renewable Energy (EERE), in support of the automotive and battery industries. In fiscal year 2015, NREL performed several R\&D projects under its Annual Operating Plan submitted to DOE on silicon anode materials, electrode coatings, battery modeling, computer-aided engineering of batteries (CAEBAT), improved computational efficiency of Multi-Scale Multi-Domain (MSMD) models in CAEBAT, medium-duty hybrid electric vehicle battery leasing and standardization, battery thermal testing, and battery life degradation modeling. A summary of each project was prepared and submitted to DOE VTO for inclusion in its Energy Storage FY15 Annual Progress Report. This report is a collection of the individual sections submitted to DOE.

This research and report would not have been possible without support and insight from many people. The authors wish to thank Brian Cunningham, Tien Duong, Peter Faguy, and David Howell from the Office of Vehicle Technologies at DOE for funding support and guidance. We also wish to thank Taeyoung Han of General Motors (GM) and his team for their contributions to the CAEBAT project summary. We also would like to express our gratitude to Marissa Rusinek for assembling and formatting this report.

Ahmad A. Pesaran

Manager, Energy Storage Group

National Renewable Energy Laboratory 


\section{Contents}

\section{Foreword}

Executive Summary

Battery Leasing \& Standardization for Medium-Duty Hybrid Electric Vehicle

Battery Thermal Analysis and Characterization Activities

Battery Multiscale Multidomain Framework \& Modeling

Computer Aided Engineering of Batteries - CAEBAT

Coupling Mechanical with Electrochemical-Thermal Models Batteries under Abuse

Significant Enhancement of Computational Efficiency in Multiscale Battery Modeling

Crash Propagation in Automotive Batteries: Simulations and Validation

Development of Industrially Viable Electrode Coatings

Atomic Layer Deposition for Stabilization of Silicon Anodes 


\section{Executive Summary}

The Energy Storage research and development (R\&D) subprogram within the DOE Vehicle Technologies Office (VTO) provides support and guidance for projects focusing on batteries for plug-in electric vehicles (PEVs) in support of the EV Everywhere Grand Challenge. PEVs could have a significant impact on the nation's goal of reducing dependence on imported oil and gaseous pollutant emissions. The Energy Storage program targets overcoming technical barriers to enable market success, including: (1) significantly reducing battery cost; (2) increasing battery performance (power, energy, durability); (3) reducing battery weight and volume; and (4) increasing battery tolerance to abusive conditions such as short circuit, overcharge, and crush.

The National Renewable Energy Laboratory (NREL) supports the VTO's Energy Storage program by evaluating the thermal performance of cells and packs, developing electrochemical-thermal models to accelerate the design cycle for developing batteries, investigating the behavior of lithium (Li)-ion batteries under abuse conditions such as crush, enhancing the durability of electrodes by coatings such as atomic layer deposition (ALD), synthesis of materials for higher energy density batteries, and conducting techno-economic analysis of batteries in various electric-drive vehicles.

This report describes the progress made by NREL on the research and development projects funded by the DOE VTO Energy Storage subprogram in FY15.

\section{Battery Leasing \& Standardization for Medium-Duty Hybrid Electric Vehicles}

- Collected information from stakeholders (medium-duty [MD] vehicle original equipment manufacturers [OEMs], fleet operators, and battery manufacturers and integrators) and performed market assessment of MD fleet vehicles

- Performed economic analysis and determined that, under certain assumptions, leasing an MD hybrid electric vehicle (HEV) battery can reduce the payback period of the vehicle to less than 3 years for the vehicle fleet owner, albeit at higher total cost of ownership to the fleet

- Identified drive-cycle characteristics from Class 6 MD HEV parcel delivery truck drive cycles in the NREL's Fleet DNA database and used them to derive battery requirements

- Simulated performance and life of a Class 6 MD HEV parcel delivery truck using NREL's Future Automotive Systems Technology Simulator (FASTSim) and Battery Lifetime Analysis and Simulation Tool (BLAST) models to identify an ideal battery size for fuel economy, 10-year life, and 12,000 to $22,000 \mathrm{mile} / \mathrm{year}$ typical operation

- Identified battery standardization strategies and quantified the cost/benefit of each strategy for annual battery pack sales ranging from 1,000 to 50,000 per year, using Argonne National Laboratory's (ANL's) Battery Performance and Cost (BatPaC) model.

\section{Battery Thermal Analysis and Characterization Activities}

- Obtained cells from various United States Advanced Battery Consortium (USABC) battery partners, including Johnson Controls Incorporated (JCI), LGCPI, SK Innovation, Leyden, Saft, and Seeo

- Obtained infrared thermal images of cells provided by USABC battery developers and identified any areas of thermal concern

- Used NREL's unique calorimeters to measure heat generation from cells and modules under various charge/discharge profiles to design the appropriate thermal management system

- Obtained thermal and electrical performance data of cells under HEV, plug-in hybrid electric vehicle (PHEV), and electric vehicle (EV) power profiles

- Determined that the energy efficiency of most titanate $\mathrm{Li}$-ion cells is above $96 \%$

- Presented results of cell thermal characterization and pack thermal evaluation at USABC/battery developers review meetings. 


\section{Battery Multiscale Multidomain Framework \& Modeling}

- Integrated the C++ MSMD/GHMSMD particle domain model (PDM) and electrode domain model (EDM) with open-source optimization software

- Explored several numerical procedures for PDM/EDM identification using synthetic/experimental data

- Evaluated a modified galvanostatic intermittent titration test (GITT) method for faster identification of solid-state diffusion dynamics for the MSMD-PDM multi-particle model

- Suggested a sequential optimization procedure to break the under-determined parameter estimation problem of the whole system into a sequence of fully determined fits to subsets of the parameters

- Prepared an initial draft of MSMD Identification Manual in support of the CAEBAT project.

\section{Computer Aided Engineering of Batteries - CAEBAT}

- GM and its partners successfully completed their CAEBAT-1 subcontract by developing a validated battery simulation software and delivering all their reporting requirements.

- ANSYS officially released the public version of its battery 3D multi-physics simulation tool in December 2014 (Fluent Version 16).

- The ANSYS Battery Design Tool (ABDT) was developed utilizing the ANSYS Workbench Framework.

- A direct thermal reduced order model (ROM) was developed and validated with full-field simulation.

- NREL developed a user defined function (UDF) for multiple particle/multiple active material models in support of the GM team.

- A semi-physics-based cycle life model was developed and validated with cycle life test.

- A battery pack-level model was validated compared to the full field simulation and the test data for a production-level battery pack, and comparisons are satisfactory.

- The three CAEBAT-1 subcontract teams (CD-adapco, EC Power, and GM) now have successfully completed their projects and released three different battery computer-aided design software tools to simulate the electrochemical-thermal performance of batteries.

\section{Coupling Mechanical with Electrochemical-Thermal Models Batteries under Abuse}

- We developed a representative-sandwich (RS) model to predict the mechanical deformation of Li-ion cells under indentation tests.

- The team developed an analytical method to estimate through-thickness mechanical properties of battery cell components.

- The team proposed a couple of approaches to predict the mechanical-electrical-thermal response during a crush event.

- We conducted systematic case studies investigating the role of mechanical failure and electrical contact area on the subsequent electrical and thermal responses during a mechanical abuse.

- This report highlights the comparison of the simulation results to experimental data, including results from the phenomenological models developed by our team members at Massachusetts Institute of Technology (MIT), the cell-level implementations by ANSYS, and the coupled models built at NREL using this information.

\section{Significant Enhancement of Computational Efficiency in Multiscale Battery Modeling}

- Developed GH-MSMD, a new quasi-explicit, modular, extendable, tightly coupled, nonlinear framework in both the $\mathrm{C}++$ and MATLAB platforms

- Demonstrated that the new GH-MSMD speeds up computations by 1,000 times

- Demonstrated implementation of GH-MSMD cell-domain model (CDM) in ANSYS/Fluent 
- Built a custom graphical user interface (GUI) in ANSYS/Fluent for GH-MSMD simulation preprocessing

- Compared options for an adaptive time-stepping algorithm in GH-MSMD versus the existing recursive method

- Constructed the MSMD standard input file structure, facilitating its multiscale simulation

- Refined the numerical method for the final version of the adaptive SVM (A-SVM) model

- Validated and benchmarked A-SVM against other electrode domain model (EDM) MSMD models in MATLAB

- Demonstrated that the A-SVM achieved 50x speed-up with accuracy better than $15 \mathrm{mV}$

- Developed a new time-domain ROM, Error-corrected Time-domain Series solution (ETS) for the solid-phase diffusion equation

- Evaluated the computational speed and the solution accuracy of the ETS

- Performed the first demonstration of wall-clock speed-up for POD/DEIM method for prototype electrolyte equation

- Initiated the MSMD integration with vehicle simulator software.

\section{Crash Propagation in Automotive Batteries: Simulations and Validation}

- We have developed the first-ever simulation tool that includes physics-based models for mechanical, electrochemical, and thermal response of a multi-cell unit.

- Several test cases were simulated to demonstrate versatility of the models from the single-cell case and cell strings to modules in different configurations.

- Experimental validation of mechanical models across these geometries was demonstrated and is summarized in this report.

- The cells within packaging volume of a module experienced about $60 \%$ less force under identical impact test conditions, so the packaging on the test articles is robust. However, under slow-crush simulations, we found that the maximum deformation of the cell strings with packaging is about twice that of cell strings without packaging.

- Thus, we have identified a sweet spot between balancing damage prevention during an impact test and forced deformation during a slow crush. This information will provide insight to pack assemblers to design better modules by providing sufficient spacing between cells within the modules/cell-strings. An alternate approach is to design packaging material with better elastic properties while maintaining adequate failure strength.

\section{Development of Industrially Viable Electrode Coatings}

- NREL and the University of Colorado at Boulder (CU-Boulder) demonstrated the ability to coat ALD alumina on flexible substrates using an in-line rotary reactor system at effective line speeds of approximately $300 \mathrm{ft} / \mathrm{min}$.

- The team developed a model system to assess the ability to coat porous materials using the in-line rotary reactor.

- We performed initial coating of battery electrode materials and are currently assessing coating performance at both NREL and ANL.

- NREL initiated new partnerships with ANL, Oak Ridge National Laboratory, and Lawrence Berkeley National Laboratory in support of their High Energy/High Voltage project to provide ALD coatings as required.

\section{Atomic Layer Deposition for Stabilization of Silicon Anodes}

- Developed a new polymeric hybrid inorganic-organic coating, cross-linked aluminum dioxybenzene, that is covalently bonded to the surface of silicon particles via molecular layer deposition 
- Resolved the chemistry of the hybrid coating during crosslinking reactions

- Demonstrated a high-performance and high-rate-capable lithium-ion Si anode enabled by this robust, conductive surface coating

- Characterized the morphology and structure evolution of both uncoated and MLD coated silicon anodes during cycling

- By applying new hybrid coating on conventional silicon electrodes, the coated electrode is enabled to provide sustainable cycling with capacities of nearly $1,500 \mathrm{mAh} \mathrm{g}^{-1}$ after 100 cycles and Coulombic efficiency in excess of $99 \%$. 


\section{Battery Leasing \& Standardization for Medium-Duty Hybrid Electric Vehicle}

\section{OBJECTIVES}

- Identify battery standardization and leasing strategies that will increase the adoption rate of fuel-efficient hybrid electric vehicles (HEVs) in Class 6 commercial medium-duty (MD) fleets for parcel delivery trucks by reducing the payback period for the HEV relative to a conventional MD vehicle.

\section{TECHNICAL BARRIERS}

- Long payback periods ( $>3$ years) of current MD HEVs limit their mass adoption in commercial vehicle fleets

- Low annual sales and production volumes for MD Class 3-6 vehicles

- Demanding duty cycles with annual mileages up to 30,000 miles per year impact the life of batteries.

\section{TECHNICAL TARGETS}

- Identify battery leasing strategies that achieve the payback period and evaluate the business case for a battery leasing company

- Identify battery standardization strategies that further reduce battery cost and thereby the incremental cost of the HEV powertrain.

\section{ACCOMPLISHMENTS}

- Collected information from stakeholders (MD vehicle original equipment manufacturers [OEMs], fleet operators, battery manufacturers and integrators) and performed market assessment of MD fleet vehicles

- Performed economic analysis and determined that, under certain assumptions, leasing an MD HEV battery can reduce the payback period of the vehicle to less than 3 years for the vehicle fleet owner, albeit at higher total cost of ownership to the fleet

- Identified drive cycle characteristics from Class 6 MD HEV parcel delivery truck drive cycles in the National Renewable Energy Laboratory's (NREL's) Fleet DNA database and used them to derive battery requirements

- Simulated performance and life of a Class 6 MD HEV parcel delivery truck using NREL's Future Automotive Systems Technology Simulator (FASTSim) and Battery Lifetime Analysis and Simulation Tool (BLAST) models to identify an ideal battery size for fuel economy, 10-year life, and 12,000 to 22,000 mile/year typical operation

- Identified battery standardization strategies and quantified the cost/benefit of each strategy for annual battery pack sales ranging from 1,000 to 50,000 per year, using Argonne National Laboratory's Battery Performance and Cost $(\mathrm{BatPaC})$ model. 


\section{INTRODUCTION}

Medium-duty HEVs used by commercial vehicle fleets are selling in limited numbers due to (i) present low fuel prices, and (ii) high incremental cost of the HEV technology, particularly the battery system, relative to a conventional powertrain. These two factors contribute to long payback times for the HEV technology. In the summer of 2014, MD HEV industry representatives contacted DOE's Vehicle Technologies Office (VTO) and NREL to investigate strategies that could make MD HEVs for delivery truck applications competitive with conventional MD vehicles.

Data from NREL's Fleet DNA project indicate that a conventional delivery truck achieves around 7 miles per gallon (mpg) on average, while the same vehicle with an HEV powertrain achieves $8.2 \mathrm{mpg}$ on average [1]. This has the following implications for an HEV with a $\$ 15,000$ net incremental cost (extra cost minus government incentives) to achieve simple payback compared to a conventional vehicle:

- At $\$ 2.50$ /gallon diesel fuel prices, an HEV delivery truck would need to drive 30,000 miles/year or more to pay for itself over its 10-year lifetime.

- At \$3.50/gallon diesel, the average forecast for 2018-2020 [2], the HEV delivery truck would need to

○ Drive 22,000 miles/year or more to pay for itself in 10 years, or

- Achieve a fuel efficiency of over $15 \mathrm{mpg}$ and drive 22,000 miles/year or more to pay for itself in 3 years.

In these scenarios, the payback period can be cut in half if the HEV incremental cost is reduced from $\$ 15,000$ to $\$ 7,500$, which may be possible with future cost reductions for batteries and other HEV technologies. The HEV payback period can also be strongly influenced by the business model of battery direct ownership versus battery leasing.

To shorten the payback period and increase HEV adoption rates in fleets, two focus areas for this analysis are to (i) evaluate the economics of a battery leasing business model for fleets, and (ii) reduce battery costs through standardization.

\section{APPROACH}

The team leveraged multiple toolsets including NREL's Fleet DNA database, the FASTSim vehicle simulator, and the BLAST suite; Argonne National Laboratory's BatPaC model; and Ricardo's Total Cost of Ownership (TCO) model. Major elements of the project included:

1. Assessment of the MD HEV delivery truck market

2. Interviews with stakeholders, including industry experts from MD vehicle OEMs, fleet operators, battery manufacturers, and integrators

3. Analysis of battery requirements

4. Evaluation of economics of battery leasing versus direct ownership

5. Identification of standardization strategies that show the most promise to reduce battery upfront cost and thus reduce the incremental cost of HEV technology in the MD commercial delivery truck space.

\section{RESULTS}

We have achieved the following progress:

\section{HEV Market Assessment and Battery Requirements Analysis}

Market analysis indicates production volumes of MD HEVs will remain relatively low through 2020. This study focuses on Class 6 trucks. The projected number of 2015 U.S. full-year new registrations of Class 6 trucks (all vocations) was 51,900 [3]. Based on several years of sales data from 2007 to 2013, HEVs represent a small portion of overall Class 6 truck annual sales — only around 900 vehicles per year [4-10]. With present 
market conditions, we forecast MD HEV annual production over the 2015 to 2020 timeframe will range from 1,000 to 4,400 vehicles per year.

The incremental cost of MD HEVs is still quite expensive due to low production/sales numbers and the need to cover non-recurring engineering (NRE) design costs. The typical incremental cost of a Class $6 \mathrm{HEV}$ is around $\$ 27,000$, however this is partly offset by federal, state, and local incentives totaling about $\$ 19,000$ (Table 1). Incremental cost of the technology is expected to come down in the future, but so are incentives. Based on this, net incremental costs are forecast to range from $\$ 15,000$ at present to $\$ 7,500$ in the future.

Table 1: Incremental Cost of HEV Drive Systems and Incentives in the MD Market Segment

\begin{tabular}{|l|c|c|c|c|}
\hline \multicolumn{1}{|c|}{ Application } & Incremental Cost & Battery Type & Typical Incentive Funding/ Voucher & References \\
\hline Class 6 package delivery truck & $\$ 35 k$ & Li-ion & $\$ 15 k$ & 8 \\
\hline Class 6 package delivery truck & $\$ 21 k$ & Li-ion & $\$ 15 k$ & 9 \\
\hline Class 5 package delivery truck & $\$ 12 k$ & Nickel metal hydride & $\$ 18 k$ & 4,10 \\
\hline Class 6 HEV & $\$ 12 k-\$ 40 k$ & Li-ion & $\$ 15 k-\$ 30 k$ & 4 \\
\hline
\end{tabular}

To determine battery design requirements, the team analyzed vehicle drive cycles from the NREL Fleet DNA database and selected a representative cycle for vehicle simulation. FASTSim vehicle simulations were run for some $60+$ hypothetical HEV designs. The simulations indicated a $45-\mathrm{kW}$ battery yields optimal fuel economy for the Class 6 truck. The BLAST simulation tool showed Li-ion battery lifetime to be a strong function of total energy, which impacts the depth of discharge experienced by the battery during the HEV drive cycles. To achieve a 10-year, 200,000-mile total lifetime requires a battery with total energy of 1.8 to $2.5 \mathrm{kWh}$.

\section{Preliminary Analysis of Battery Leasing Versus Direct Ownership}

A spreadsheet model was created to perform a preliminary analysis of battery leasing versus direct ownership from both the lessee's and lessor's perspectives. The analysis found that a battery leasing company (the lessor) could achieve a $10 \%$ return on equity (ROE) with a lease price of $\$ 177 /$ month. A $10 \%$ ROE implies that the net worth of the lease at year 10 is equal to the compounded value of the initial capital outlay at year 0 . Other assumptions included $\$ 5,100$ battery cost, 1.33 markup, 10-year battery life with linear depreciation, 39.3\% taxes on net revenues, and $\$ 100 /$ year/battery general and administrative costs. The lease price is sensitive to these baseline assumptions:

- Eliminating the corporate income tax reduces the lease price from $\$ 177 /$ month to $\$ 132 /$ month.

- Reducing the battery cost by $15 \%$ reduces the lease from $\$ 177 /$ month to $\$ 151 /$ month.

- Reducing the battery markup from 1.33 to 1.1 reduces the lease from $\$ 177 /$ month to $\$ 166 /$ month.

The analysis furthermore found that a $15 \%$ ROE for the lessor is not viable as it raises the battery lease price too high, from $\$ 177 /$ month at $10 \%$ ROE to $\$ 260 /$ month at $15 \%$ ROE.

For the fleet owner (the lessee), monthly fuel savings of operating an HEV compared to a conventional vehicle range from $\$ 50 /$ month at 12,000 miles/year and $\$ 2.50 /$ gal fuel to $\$ 175 /$ month at 30,000 miles/year and $\$ 3.50$ /gal fuel. Under the battery leasing arrangement, the lessee also no longer has to pay upfront the $\$ 5,100 \mathrm{x}$ 1.33 markup cost of the battery, but still may bear other HEV incremental costs for the electric motor and inverter. As an example, avoiding the upfront battery cost generates an additional $\$ 189 /$ month savings over the 3 -year period in simple terms. (Other HEV incremental costs, heavily dependent on future HEV production volumes, NRE costs, and government incentives can reduce this savings by $10 \%$ to $100 \%$.)

To summarize, the business model for the battery leasing company allows it to achieve a reasonable $10 \% \mathrm{ROE}$ over 10 years. The fleet owner benefits over the initial 3 years can range from $\$ 40 /$ month to $\$ 170 /$ month. The downside is that the fleet owner does not own the battery after 3 years. 


\section{Evaluation of Battery Standardization Strategies}

Building off of recent analysis of battery standardization for commercial plug-in HEV and electric vehicle designs [10], Ricardo performed an analysis of battery standardization strategies for commercial Class $6 \mathrm{HEV}$ batteries using the BatPaC model from Argonne National Laboratory. Eight categories of strategies were considered:

1. Module housings, bus bar, attachments

2. Module voltages

3. Electrode dimensions

4. Communications

5. Current collectors

6. Safety systems

7. Module stack interface, heating/cooling, heat conductors

8. Interface for power transfer.

Within each category, a relative cost curve was derived to estimate the impact of production volume on cost. In some categories, such as metal stampings for module housings, the cost versus production volume falls steeply due to high tooling costs. In other categories, such as printed circuit boards, the cost versus production volume falls only slightly, indicating cost is less sensitive to production volume due to highly automated production processes that can efficiently produce the device even at low numbers.

At low production volumes of 1,000 battery packs per year (Figure 1), all but one of the strategies (standardized communications interface) result in a battery cost increase. At around 10,000 battery packs produced per year, five of the strategies become viable (i.e., cost of implementing strategy approximately equal to savings), the most advantageous being standardizing module housings, bus bars, and attachments. This strategy is estimated to reduce battery pack cost by $17 \%$. At 50,000 battery packs produced per year, the standardized module housing, bus bar, and attachment strategy may reduce battery pack cost by $36 \%$. The results are further summarized in Table 2 .

It is apparent from this analysis that significant battery pack cost reductions are not achieved until annual production volumes reach 10,000 to 50,000 battery packs per year. But the annual production rate of all commercial MD delivery trucks - hybrids and non-hybrids - is presently only around 50,000 vehicles per year. This suggests two methods to achieve cost reductions:

1. Hybridize a significant portion, over $20 \%$ of commercial MD vehicles, which may require significant government incentives, or

2. Identify and use battery cells and modules that are already produced in significant volumes, over 50,000 packs per year, in some other application such as light-duty HEVs. 

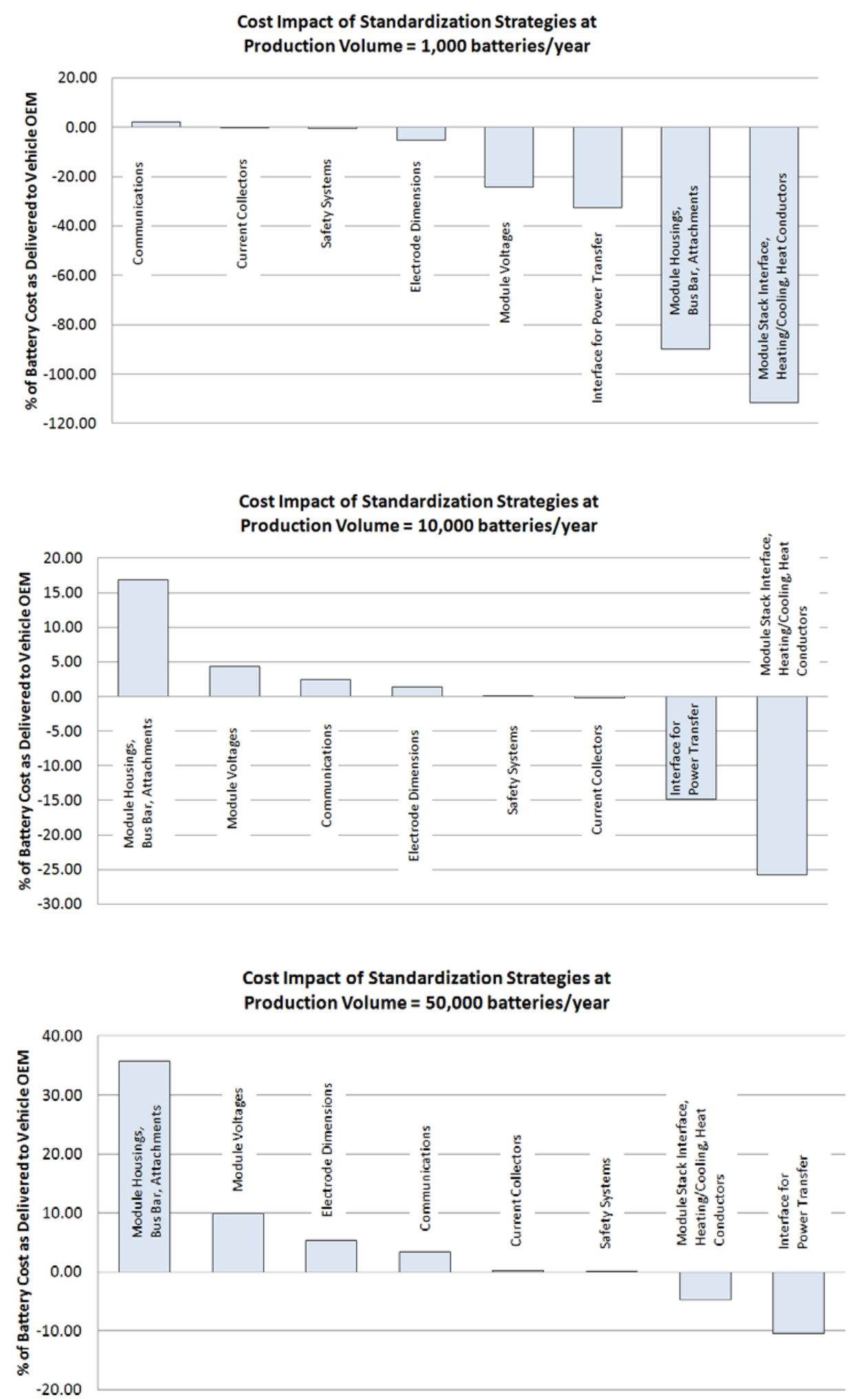

Figure 1: Impact of individual standardization strategies on battery cost (positive is cost reduction) 
Table 2: Percentage Cost Savings or Cost Increase from Each Standardization Strategy at Different Annual Battery Pack Production Volumes

\begin{tabular}{|c|c|c|c|c|c|}
\hline \multirow[t]{2}{*}{ Standardization Approach } & \multicolumn{5}{|c|}{$\begin{array}{l}\text { Cost Savings or Penalty (\% of delivered cost of battery to vehicle OEM) for indicated } \\
\text { Production Volumes (Batteries/Year) }\end{array}$} \\
\hline & 1,000 & 5,000 & 10,000 & 50,000 & 100,000 \\
\hline Module Housings, Bus Bar, Attachments & -89.80 & -0.20 & 16.84 & 35.75 & 39.34 \\
\hline Module Voltages & -24.12 & -0.19 & 4.40 & 9.90 & 11.60 \\
\hline Electrode Dimensions & -5.10 & -0.43 & 1.41 & 5.29 & 6.81 \\
\hline Communications & 2.22 & 2.30 & 2.41 & 3.42 & 5.05 \\
\hline Current Collectors & -0.26 & -0.23 & -0.20 & 0.24 & 1.17 \\
\hline Safety Systems & -0.39 & -0.04 & 0.03 & 0.12 & 0.17 \\
\hline Module Stack Interface, Heating/Cooling, Heat Conductors & -111.42 & -41.60 & -25.80 & -4.75 & 1.16 \\
\hline Interface for Power Transfer & -32.46 & -17.78 & -14.89 & -10.73 & -6.10 \\
\hline
\end{tabular}

Standardization Strategies that Produce a Cost Savings at Indicated Production Volume Standardization Strategies that Produce a Cost Increase at Indicated Production Volume

\section{CONCLUSIONS AND FUTURE DIRECTIONS}

Commercial MD Class 6 trucks are presently produced and sold at rates of around 50,000 vehicles per year. With present market conditions, HEVs are only expected to account for $2 \%-9 \%$ of this segment. But for battery costs to come down, battery packs must be produced at numbers of 10,000 to 50,000 per year or greater. Without significant government incentives to push hybridization, a possible path forward for MD vehicle OEMs to bring down battery costs is to build business arrangements with light-duty vehicle OEMs to purchase battery modules similar to those used in their light-duty HEVs, which are already produced at high volumes.

Presently, commercial MD HEVs achieve about $17 \%$ greater fuel economy compared to conventional MD vehicles. With further optimization, this could be improved to $25 \%-40 \%$, which is similar to light-duty HEVs. This improved fuel economy, if it can be achieved with low HEV incremental cost, would shorten the payback period for MD HEVs.

A preliminary analysis of the battery leasing business model indicates that it can indeed shorten the payback period for MD HEVs. A battery leasing company could achieve a reasonable $10 \%$ ROE. Whether the battery leasing strategy can shorten the payback period to less than 3 years greatly depends on the incremental cost of the HEV technology and government incentives.

An analysis methodology has been developed to evaluate the impact of a range of battery standardization strategies. The analysis models have been populated with vehicle duty cycles, battery requirements, and cost data, and preliminary analysis has been conducted on a range of strategies. In the remaining 3 months of the study, the team will review results with industry to obtain feedback on the analysis, refine the analysis, and establish best paths forward. A final technical report will be published in FY 2016.

Potential follow-on activities include:

- Link Argonne National Laboratory's BatPaC battery cost model to NREL's BLAST battery operation model to evaluate the relation between battery component chemistries, life and cost for different vehicle types (HEVs, PHEVs, and EVs)

- Evaluate strategies for reducing the cost, volume, and mass of the balance of system (beyond electrochemical components)

- Extend the library of battery life models in the Battery Ownership Model and BLAST to nickelmanganese-cobalt and mixed-oxide lithium manganese oxide for cathodes and titanate for anodes

- Use BLAST to perform battery technical target and requirement analysis for various heavy-duty electrified vehicles (similar to work for USABC for $21^{\text {st }}$ Century Truck)

- Evaluate the value of various standardization strategies of batteries for light duty PEVs. 


\section{FY 2015 PUBLICATIONS/PRESENTATIONS}

- Interviews with vehicle OEMs (step vans), battery manufacturers (lithium-ion), government vehicle purchase incentive program administrators, and hybrid-electric drive system component manufacturers and suppliers, September 2-28, 2015.

- J. Neubauer, A. Pesaran, "FY15 Milestone: Medium-Duty Hybrid Electric Vehicle Battery Leasing Scoping Analysis," December 2014 NREL-DOE Milestone Report, DOE-NREL AOP WBS 1.1.2.409.

- $\quad$ K. Kelly, K. Smith, J. Cosgrove, B. Prohaska, A. Pesaran, J. Paul, M. Wiseman, "Battery Ownership Model: Medium-Duty HEV Battery Leasing \& Standardization," September 2015 NREL-DOE Milestone Report, DOE-NREL AOP WBS 1.1.2.409.

\section{REFERENCES}

1. Burton, J., Walkowicz, K., Sindler, P., and Duran, A., "In-Use and Vehicle Dynamometer Evaluation and Comparison of Class 7 Hybrid Electric and Conventional Diesel Delivery Trucks," SAE Int. J. Commer. Veh. 6(2):545-554, 2013, doi:10.4271/2013-01-2468. SAE Paper No. 2013-01-2468.

2. Annual Energy Outlook 2014, U.S. Energy Information Administration.

3. Clinton, P., "Commercial Truck Registrations," Work Truck Magazine, September 3, 2015.

4. Lyden, S., "The Latest Developments in Hybrid-Electric Medium-Duty Trucks," TruckingInfo, March 2014.

5. Cornils, H., "Hybrid Solutions for MD Commercial Vehicles," ERC Symposium, University of Wisconsin, June 10, 2009.

6. Busdiecker, M., "Technology Potential of Commercial Vehicle Transmissions," Heavy-Duty Vehicle Efficiency Technical Workshop, San Francisco, October 22, 2013.

7. Parish, R., et al., "Demand Assessment of First-Mover Hybrid and Electric Truck Fleets,"

CALSTART High Efficiency Truck Forum (HTUF), October 2012.

8. California Air Resources Board, "Hybrid Truck \& Bus Voucher Incentive Project (HVIP), Making the Case for Hybrid and Electric Trucks and Buses," https://www.californiahvip.org/making-the-case, Accessed September 12, 2015.

9. California Air Resources Board, "Hybrid Truck \& Bus Voucher Incentive Project (HVIP), Hino Motors Model 195h Delivery Truck with Parallel Hybrid System, Package Delivery, California HVIP Voucher Amount," https://www.californiahvip.org/docs/HVIP_Year4_EligibleVehicles.pdf, accessed September 17, 2015.

10. Paul, J., Bogen, M, Liss, J, Holmes, J, Sohnen. 2014. "The Market Impact of Standardized Design in PEV Commercial Battery Pack Purchase and Disposal." California Energy Commission (CEC). Public Interest Energy Research (PIER) Project Number CEC-PIR-12-005. CEC document number not yet assigned, expected publication date: January 2016. 


\section{Battery Thermal Analysis and Characterization Activities}

\section{OBJECTIVES}

- Thermally characterize battery cells and evaluate thermal performance of battery packs delivered by USABC developers

- Provide technical assistance and modeling support to US Drive /USABC and developers to improve thermal design and performance of energy storage systems

- Quantify the impact of temperature and dutycycle on energy storage system life and cost.

\section{TECHNICAL BARRIERS}

- Decreased battery life at high temperatures

- High cost due to an oversized thermal management system

- Cost, size, complexity, and energy consumption of thermal management system

- Decreased performance at low temperatures

- Insufficient cycle life stability to achieve the 3,000 to 5,000 "charge-depleting" deep discharge cycles.

\section{TECHNICAL TARGETS}

- Quantify that battery operate from $-30^{\circ} \mathrm{C}$ to $52^{\circ} \mathrm{C}$ without degradation in performance or life

- Develop a high-power battery technology exceeding 300,000 cycles

- Minimizing cost of battery thermal management system

- Achieve 15 -year calendar life at $30^{\circ} \mathrm{C}$.

\section{ACCOMPLISHMENTS}

- Obtained cells from various USABC battery partners including Johnson Controls Incorporated (JCI), LGCPI, SK Innovation, Leyden, Saft, and Seeo

- Obtained infrared thermal images of cells provided by USABC battery developers and identified any areas of thermal concern

- Used NREL's unique calorimeters to measure heat generation from cells and modules under various charge/discharge profiles in order to design the appropriate thermal management system

- Obtained thermal and electrical performance data of cells under HEV, PHEV, and EV power profiles

- Determined that the energy efficiency of most titanate lithium ion cells is above $96 \%$

- Presented results of cell thermal characterization and pack thermal evaluation at USABC/battery developers review meetings. 


\section{INTRODUCTION}

The operating temperature is critical in achieving the right balance between performance, cost, and life for both Li-ion batteries and ultracapacitors. At NREL, we have developed unique capabilities to measure the thermal properties of cells and evaluate thermal performance of battery packs (air- or liquid-cooled). We also use our electrothermal finite element models to analyze the thermal performance of battery systems in order to aid battery developers with improved thermal designs.

\section{APPROACH}

Using NREL's unique R\&D 100 Award-winning calorimeters and infrared thermal imaging equipment, we obtain thermal characteristics (heat generation, heat capacity, and thermal images) of batteries and ultracapacitors developed by USABC battery developers and other industry partners. NREL supports the Energy Storage Technical Team by participating in various work groups such as the JCI, LGCPI, SK Innovations, Leyden, Saft, and Seeo USABC Working Groups.

\section{RESULTS}

\section{Calorimeter Testing}

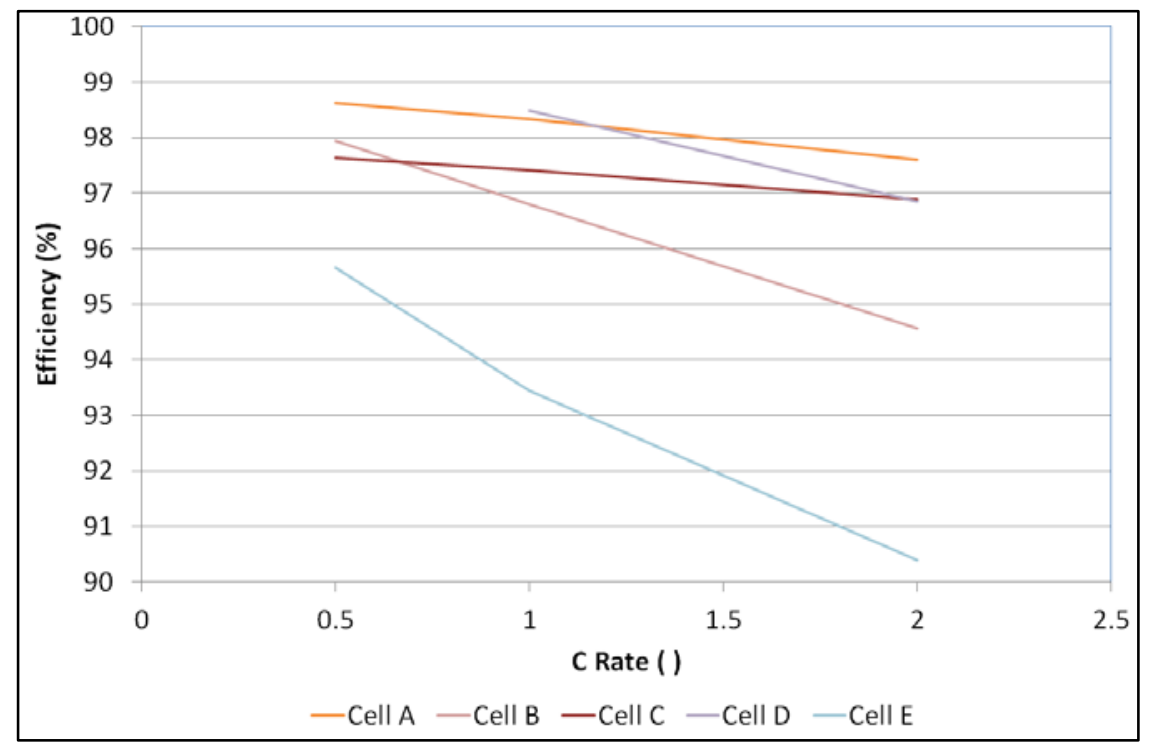

Figure 1: Efficiency of cells tested at $30^{\circ} \mathrm{C}$ in NREL's calorimeter during FY15
Figure 1 shows the efficiency of cells tested in FY15 at NREL at a calorimeter temperature of $30^{\circ} \mathrm{C}$. The lithium ion cells were fully discharged from $100 \%$ SOC to $0 \%$ SOC under $\mathrm{C} / 2, \mathrm{C} / 1$, and $2 \mathrm{C}$ currents. It should be noted that the cells in the figure are for both power and energy cells and have been developed for the HEV, PHEV, EV, and/or the 12 Volt Start/Stop programs within USABC. The figure shows that most of the lithium ion cells, A-D, are very efficient over this cycling regime typically greater than $94 \%$ for a $2 \mathrm{C}$ discharge. The range of efficiencies at a $2 \mathrm{C}$ discharge rate is between $90 \%$ and $98 \%$. An $8 \%$ difference in efficiency may not appear to be of concern; however, if a 50-kW pulse comes from the battery in an electrified advanced vehicle, then a $1 \%$ difference in efficiency results in an additional $500 \mathrm{~W}$ of heat for the pulse duration. Taking the example further, an $8 \%$ difference results in $4,000 \mathrm{~W}$ of additional heat. The efficiency differences between the cells will require the thermal management system to be tailored to the cell thermal characteristics so as not to affect the cycle life of the cells. Finally, Cell E shows a fairly low efficiency as compared to many of the other cells tested in FY15 and is an experimental chemistry. DOE and USABC are developing these new chemistries to realize energy density, power density, cycle life, and/or cost benefits. NREL's calorimeter is used to identify these outliers, but can also help determine if the inefficiency is due to chemistry or cell design.

During FY15, NREL tested a number of lithium titanate oxide (LTO) anode cells in our calorimeter. The efficiencies of these cells were typically the highest of the cells that we have tested over the past three years for DOE/USABC. Figure 2 shows the charge and discharge efficiency of an LTO cell under a full 
charge/discharge from $100 \% \Leftrightarrow 0 \%$ SOC. Of note, the charge efficiency of the cell is greater than the discharge efficiency-different from the typical graphite systems. The LTO anode has a very ordered structure with high surface area, which leads to the high efficiency under charge.

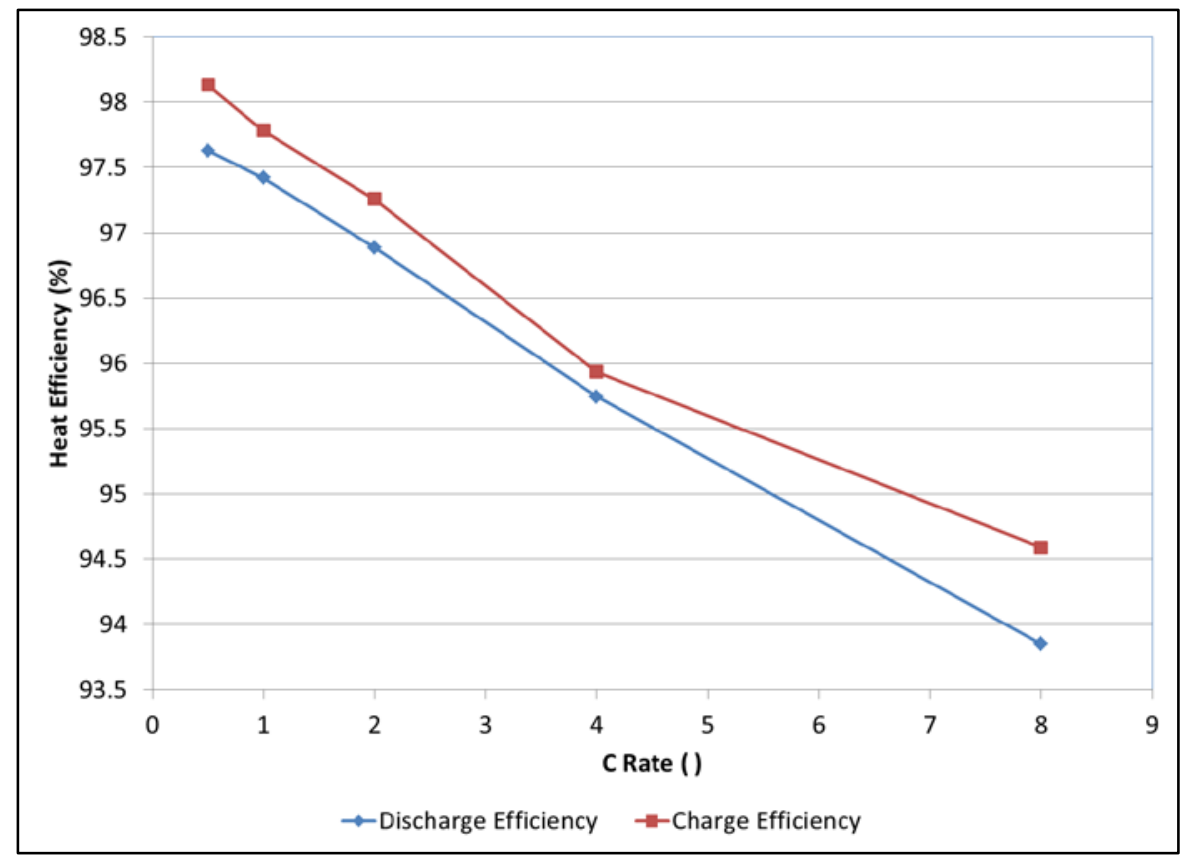

Figure 2: Efficiency of LTO cell tested at $30^{\circ} \mathrm{C}$ under a full charge/discharge

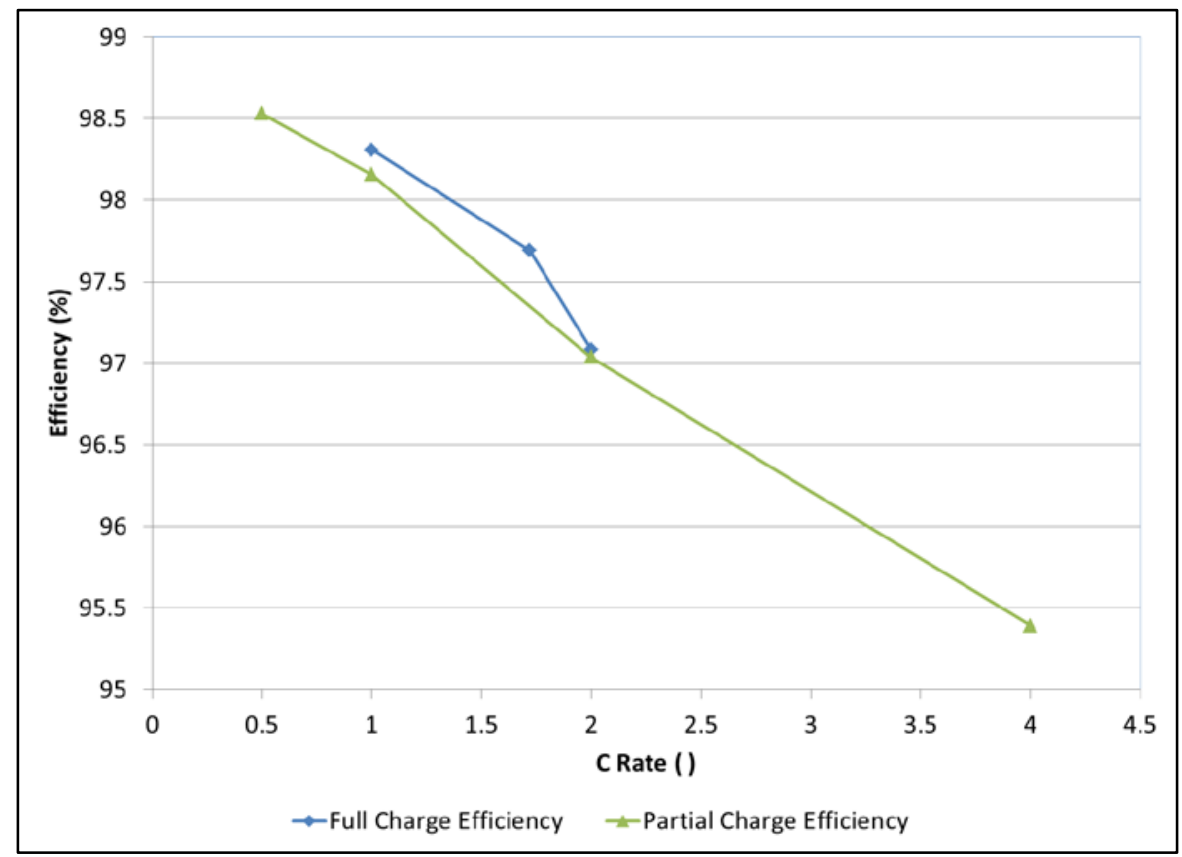

Figure 3 shows the charge efficiency of an LTO cell under a full charge from $0 \%$ to $100 \%$ SOC and also a partial charge from $20 \%$ to approximately $100 \%$ SOC. As can be seen from the graph, the full charge efficiency is slightly better than the partial charge efficiency-once again, an atypical result when compared to graphite systems. The reported efficiency numbers are an average over the entire test range and the LTO cells are very efficient in accepting lithium ions at low SOCs-thus, the charge efficiency over the full range is better than the partial range.

Figure 3: Efficiency of LTO cell tested at $30^{\circ} \mathrm{C}$ under a full and partial charge 


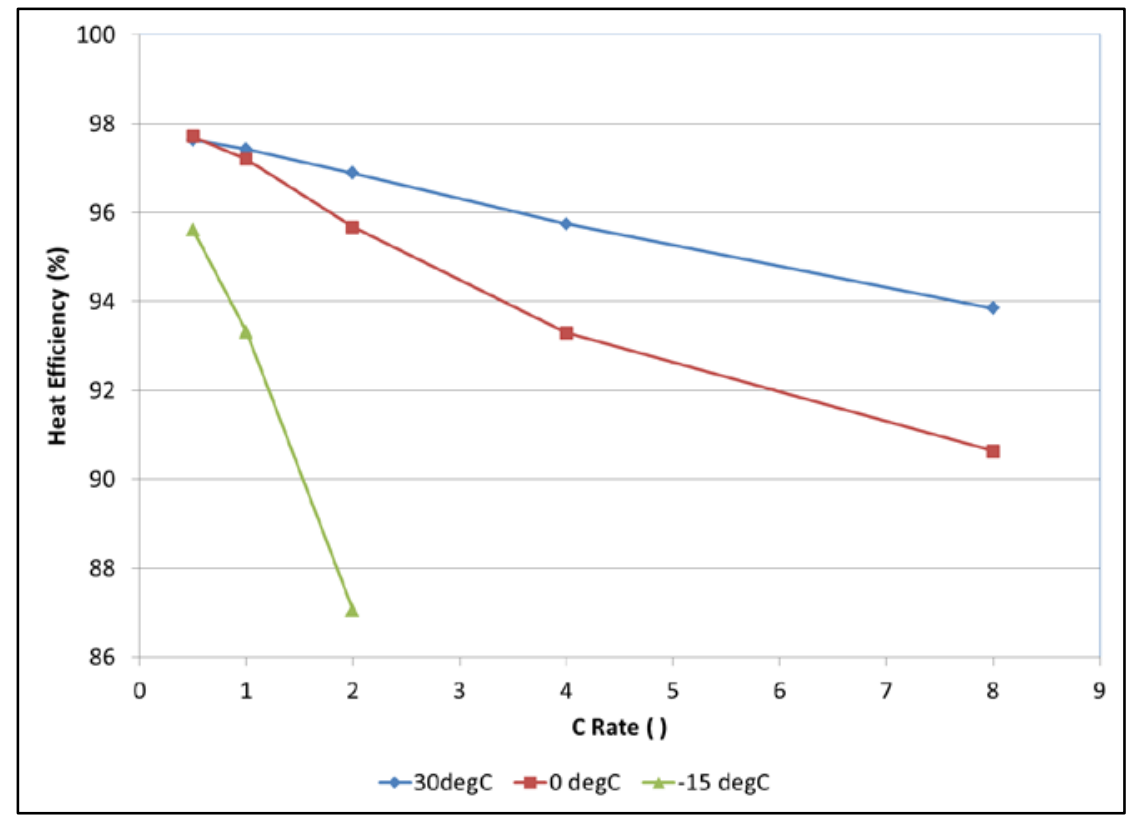

Figure 4: Efficiency of LTO cell at different temperatures under a partial discharge

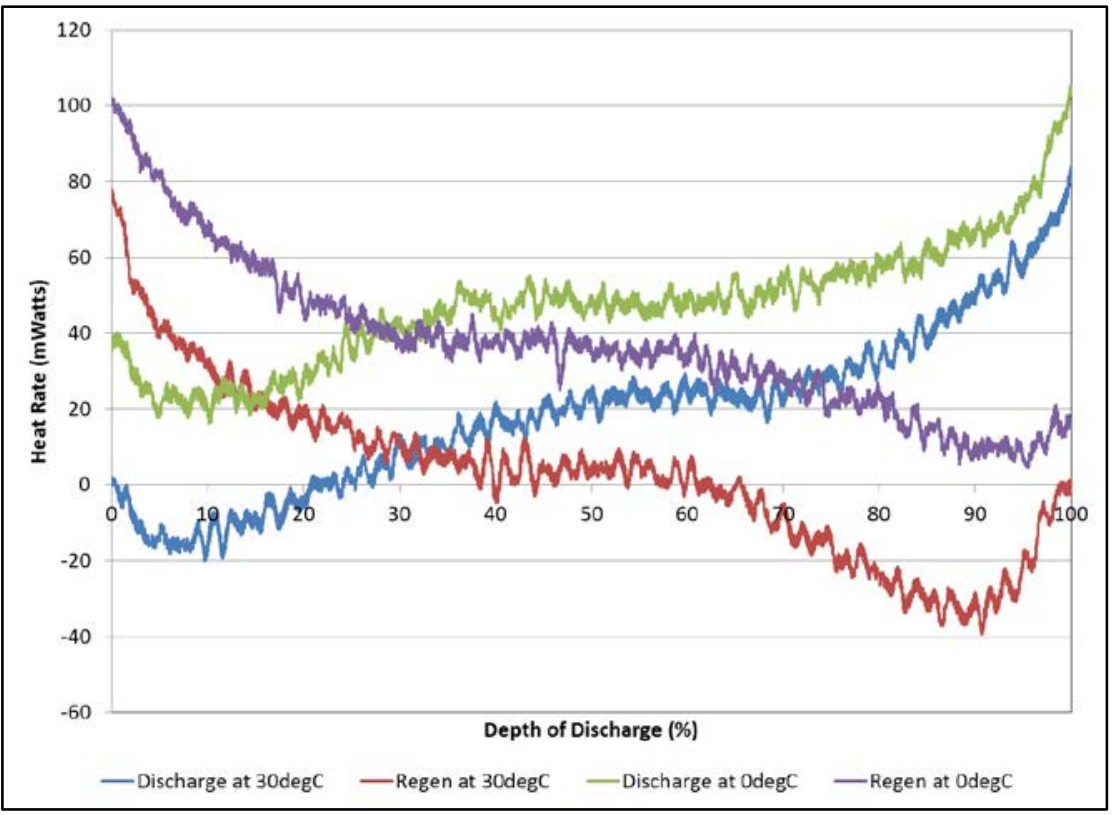

Figure 5: Entropic heating of LTO cell at $30^{\circ} \mathrm{C}$ and $0^{\circ} \mathrm{C}$
Figure 4 shows the efficiency of an LTO cell under a constant current discharge from approximately $100 \%$ to $20 \%$ SOC. As noted above, the efficiency of LTO cells are quite high when tested at $30^{\circ} \mathrm{C}-$ for the cell in Figure 4, above $97 \%$ at a $2 \mathrm{C}$ rate.

However, the cell decreases in efficiency as the temperature is lowered. The efficiency drops about $1.5 \%$ for a given discharge rate when the temperature is lowered from $30^{\circ} \mathrm{C}$ to $0^{\circ} \mathrm{C}$. In contrast, the efficiency drops precipitously to $87 \%$ at a $2 \mathrm{C}$ rate when the cell is tested at $-15^{\circ} \mathrm{C}$.

NREL's calorimeters are designed to be accurate enough to measure the electrochemical response from batteries under test. As car manufacturers progress from HEVs to PHEVs and EVs, the design of the battery pack will also change. For instance, an HEV battery pack is cycled within a very narrow band - typically within a window encompassing $10 \%$ of the overall energy window of the pack. In contrast, a PHEV and EV battery is typically cycled over a much wider range- 80 to $90 \%$ of the battery's capacity. Figure 5 shows the heat rates of an LTO cell tested at $30^{\circ} \mathrm{C}$ and $0^{\circ} \mathrm{C}$.

The battery in this figure was cycled from $100 \%$ SOC to $0 \%$

SOC at a very low current-minimizing the current decreases the joule heating of the cell and allows for the entropic heat signature to be assessed. As shown in the figure, the battery undergoes endothermic and exothermic heat generation over the cycling range. The primary differences in the heat signatures from $30^{\circ} \mathrm{C}$ to $0^{\circ} \mathrm{C}$ are primarily due to the resistance changes within the cell. The LTO cells do not have as many phase transitions as their graphite counterparts, which should positively affect the life of the cell. 


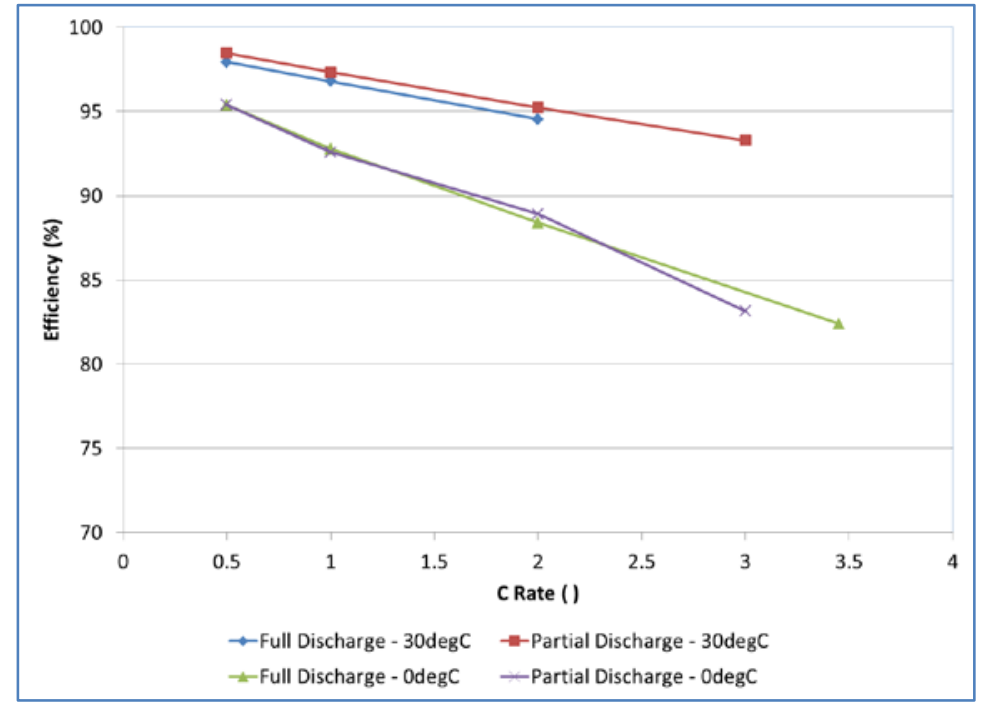

Figure 6: Efficiency comparison of PHEV/EV cell under full and partial discharge

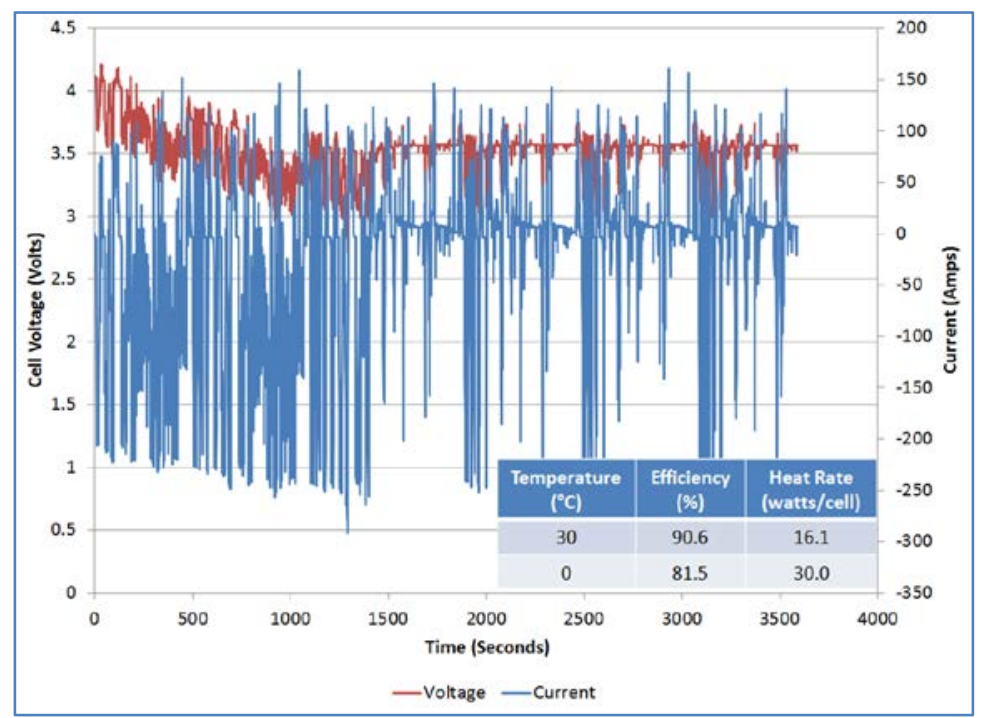

Figure 7: PHEV cell heat generation under US06 drive cycle
Over the past several years, our testing has shown that the difference in efficiency over the full SOC range as compared to the usage SOC range has decreased for PHEV and EV cells. NREL typically discharges cells under a constant current from $100 \%$ to $0 \%$ SOC for comparison purposes against other cells. However, cells are not typically used over their full capacity range due to life cycle limitations of the cell. Thus, NREL additionally tests the cells over their usage range for the cell-for a PHEV and $\mathrm{EV}$ cell; the usage range is approximately $95 \%$ to $20 \%$ SOC. As would be expected, the cells are less efficient over the full SOC range as compared to the partial SOC range. In recent testing, however, the gap in efficiency has decreased, as shown in Figure 6 . The cell was cycled over its full and usage range at $30^{\circ} \mathrm{C}$ and $0^{\circ} \mathrm{C}$. As can be seen from the figure, the efficiencies for a given temperature are fairly well matched. Battery manufacturers use the data from the calorimeter to ensure that the cell has the desired efficiency over the usage range while making trade-offs on other aspects of the cell design, such as low temperature operation, safety, cost, and ease of manufacturing.

When testing a cell to size the thermal management system, it is imperative to test the cell according to how it will be used. Figure 7 shows a PHEV cell undergoing a US06 charge depletion cycle followed by a US06 chargesustaining cycle. The average efficiency over this usage profile is approximately

$90.6 \%$ at $30^{\circ} \mathrm{C}$. However, the efficiency drops to $81.5 \%$ for the same profile as the temperature is lowered to $0^{\circ} \mathrm{C}$. The data provided by the calorimeter will allow the battery manufacturer and OEM to size the active thermal management system so as to limit the maximum operational cell temperature while ensuring that the battery pack meets their cycle life specifications.

\section{Infrared Imaging of Cells}

NREL performs infrared (IR) thermal imaging of battery manufacturers' cells to determine areas of thermal concern. We conduct IR thermal imaging under a set of prescribed procedures and environments to minimize the error from different sources such as reflective cell surfaces, radiation from surrounding surfaces, and cooling from the power cables attached to the cell. NREL combines the IR imaging equipment with a battery 
cycler to place the cells under various drive cycles, such as a US06 charge depleting cycle for a PHEV, to understand the temperature differences within the cell. We then make recommendations to the battery manufacturers and USABC on how to improve the thermal design of the cell to increase its cycle life and safety.

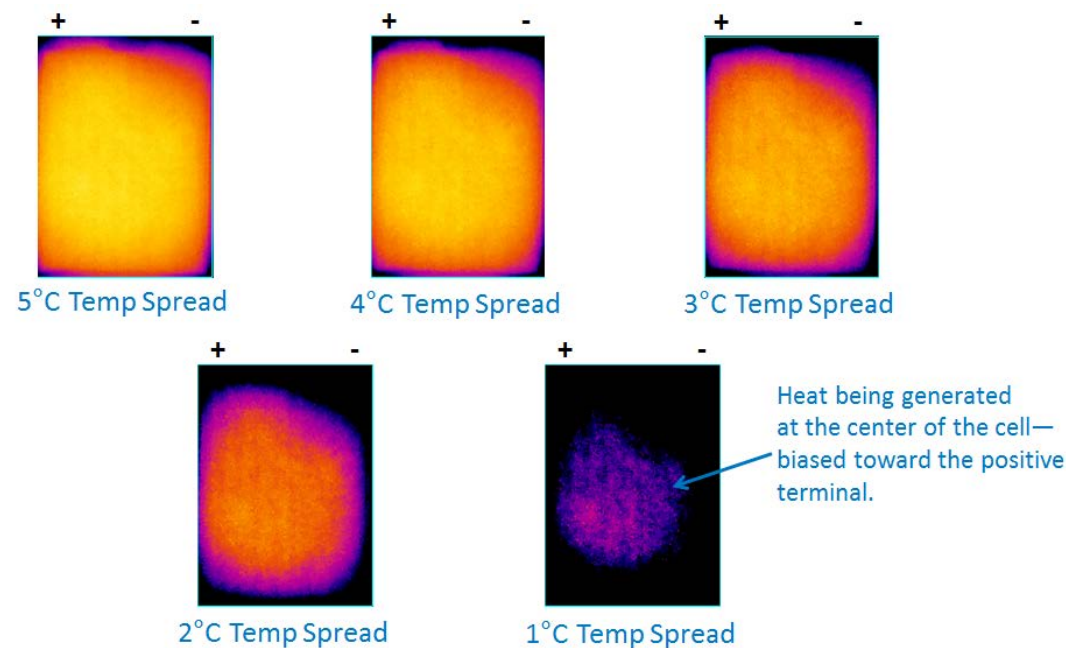

Figure 8: Infrared image of PHEV cell at the end of a $2 \mathrm{C}$ discharge
Figure 8 shows a PHEV cell at the end of a $2 \mathrm{C}$ discharge. Each IR image has a temperature spread associated with it-by decreasing the temperature spread from $5^{\circ} \mathrm{C}$ to $1^{\circ} \mathrm{C}$, a visual reference can be used to determine where the heat is preferentially generated within the cell. For this cell, the heat generation is biased towards the left center of the cell underneath the positive terminal. The heating may be a result of the aluminum used for the positive terminal as compared to copper for the negative terminal. We are also assessing the uniformity of the cell temperature across the surface. When the cell temperature is uniform and consistent, all areas within the cell age at the same rate, leading to a better cycle life. NREL is working with battery developers to understand how temperature non-uniformities affect the efficiency and cost of the cell over its life.

\section{CONCLUSIONS AND FUTURE DIRECTIONS}

NREL has thermally tested cells, modules, and/or packs from JCI, LG CPI, SK Innovations, Leyden, and Saft. We have provided critical data to the battery manufacturers and OEMs that can be used to improve the thermal design of the cell, module, pack, and their respective thermal management systems. The data included heat generation of cells under typical profiles for HEV, PHEV, EV, and 12 Volt Start/Stop applications, which is essential for designing the appropriately sized battery thermal management system. We found that the majority of the cells tested had a thermal efficiency greater than $94 \%$ when cycled under a $2 \mathrm{C}$ constant current discharge. During the thermal imaging of the cells, we identified areas of thermal concern and helped the battery developers improve the thermal design of their cells.

In FY16, NREL will continue to thermally characterize cells, modules, packs for USABC, DOE, and US Drive partnership.

\section{FY 2015 PUBLICATIONS/PRESENTATIONS}

1. 2010 DOE Annual Peer Review Meeting Presentation

2. Quarterly meeting presentations to the USABC battery working group and manufacturer

3. Presentation at the Global Automotive Management Council's Battery Congress, Michigan, June, 2015. 


\title{
Battery Multiscale Multidomain Framework \& Modeling
}

\section{OBJECTIVES}

- Develop a standard procedure for identifying model parameters for the multiscale multidomain (MSMD) battery model for simulating the performance of plug-in electric vehicle (PEV) batteries

- Develop an MSMD parameter identification manual in support of DOE's Computer Aided Engineering for Electric Drive Batteries (CAEBAT) project

\section{TECHNICAL BARRIERS}

- Lack of standard experimental procedure for extracting parameters for calibrating PEV battery models

\author{
Brian Cunningham (DOE Program Manager) \\ DOE Agreement \# 28883 Recipient: \\ National Renewable Energy Laboratory \\ Gi-Heon Kim (NREL - PI) \\ 15013 Denver West Parkway, M/S 1633 \\ Golden, CO 80401 \\ P 303-275-4437 \\ Email: gi-heon.kim@nrel.gov
}

Start Date: October 2014

Projected End Date: September 2015

- Identification of a physics-based battery model is known to be difficult. This anticipated difficulty for development of a physics-based constituent model comes from the fact that characterization of a battery is intrinsically solving an underdetermined problem.

\section{TECHNICAL TARGETS}

- Develop calibrated and validated battery models for accelerating the development of PEV battery simulation tools

- Support DOE's CAEBAT project by preparing a manuscript for the "MSMD Identification Manual."

\section{ACCOMPLISHMENTS}

- Integrated the C++ MSMD/GHMSMD particle domain model (PDM) and electrode domain model (EDM) with open-source optimization software

- Explored several numerical procedures for PDM/EDM identification using synthetic/experimental data

- Evaluated a modified galvanostatic intermittent titration test (GITT) method for faster identification of solid-state diffusion dynamics for the MSMD-PDM multi-particle model

- Suggested a sequential optimization procedure to break the under-determined parameter estimation problem of the whole system into a sequence of fully determined fits to subsets of the parameters

- Prepared an initial draft of MSMD Identification Manual in support of CAEBAT project

\section{INTRODUCTION}

In support of the U.S. Department of Energy's (DOE's) CAEBAT project, the National Renewable Energy Laboratory (NREL) developed the multi-scale multi-domain (MSMD) model, overcoming challenges in modeling the highly nonlinear multiscale response of battery systems. The MSMD model provides a high extent of flexibility and multiphysics expandability through its modularized architecture, as well as computational efficiency to enable the model to run on standard desktop PCs by providing selective, finer meshes for low hierarchical subdomains. As part of the first phase of CAEBAT, NREL supported GM and 
ANSYS to incorporate MSMD in the battery simulation software in the commercial offering of ANSYS (Fluent 16).

The GH-MSMD, a newly developed quasi-explicit nonlinear multiscale model framework, significantly improves the computational speed of the model while inheriting the modular architecture of the MSMD. However, acquisition of physics-based battery model parameters is known difficult. This difficulty comes from the fact that characterization of a battery is intrinsically solving an under-determined problem. Physics-based models require component material properties and design parameters as model inputs. On the other hand, traditional battery characterization tests such as GITT or EIS use certain math models for quantifying the property values from the measured data. Unfortunately, these circling-processes have been decoupled in practice. Model-based optimization has been limited by the lack of a fully-adaptive, fast-running, high-fidelity, flexible battery model. As part of the second phase of CAEBAT, NREL brings high fidelity fast-running models directly into battery system characterization step. For example, we directly use a high-fidelity particle domain model, discrete diffusion particle model (DDPM), as a reference tool model for thermodynamic, kinetic, transport, electrical, and geometrical characterizations of electrode particles.

\section{APPROACH}

The MSMD, a hierarchical multiscale modular framework, facilitates bottom-up identification. We suggest a sequential optimization procedure to break the under-determined parameter estimation problem of the whole system into a sequence of fully determined fits to subsets of the parameters. This sequential procedure is developed from the fact that the physicochemical processes in batteries occur in significant time scale segregation.

\section{RESULTS}

NREL brings high fidelity fast-running models directly into battery system characterization step. NREL's baseline Multi-Scale Multi-Domain (MSMD) model has been implemented in an open-source programing language platform, $\mathrm{C}++$, to expand access, and to increase flexibility. We suggested the standard model inputs and outputs, and the data structure. The MATLAB version codes were restructured and prototyped for porting, and the baseline MSMD has been ported into $\mathrm{C}++$ language. The MSMD, a hierarchical multiscale modular framework, facilitates bottom-up identification. The MSMD PDMs solve lithium transport in solid electrode particles, interfacial reaction kinetics, and charge conservation at the interfaces. The EDMs additionally consider polarization through electrolyte and composite matrices. In the extended cell-domain models (CDMs), additional polarization caused by non-uniform temperature and electric potential fields across cell volume is resolved.

\section{MSMD: Expandable Multiscale Multiphysics Modular Framework}

Physicochemical processes in lithium batteries occur in intricate geometries over a wide range of time and length scales. As the size of the battery increases to meet the system demands of high-energy and high-power energy storage in electric vehicle applications, macroscopic design factors in combination with highly dynamic environmental conditions significantly influence the electrical, thermal, electrochemical, and mechanical responses of a battery system. Without better knowledge of the interplays among interdisciplinary multiphysics occurring across varied scales in the battery systems, it is costly to design long-lasting, high-performing, safe, large battery systems. NREL pioneered the multiscale multidomain (MSMD) model, overcoming challenges in modeling the highly nonlinear multiscale response of battery systems. The model resolves the battery geometry into three coupled computational domains. The MSMD provides a high extent of flexibility and multiphysics expandability through its modularized architecture (Figure 1), as well as computational efficiency to enable the model to run on standard desktop PCs by providing selective, finer meshes for low hierarchical subdomains. Model domain separation for the physicochemical process interplay is carried out where the characteristic time or length scale is segregated. The MSMD particle-domain models (PDMs) solve collective response of electrically and ionically connected particle-batteries which are collocated in the electrode-domain. 
The EDMs solve collective behavior of PD-batteries, considering polarization through electrolyte and composite matrices. The CDMs of the MSMD solves single- or multi-cell battery response by resolving collective behavior of paired plate batteries, considering polarization caused by non-uniform temperature and electric potential fields across cell volume.

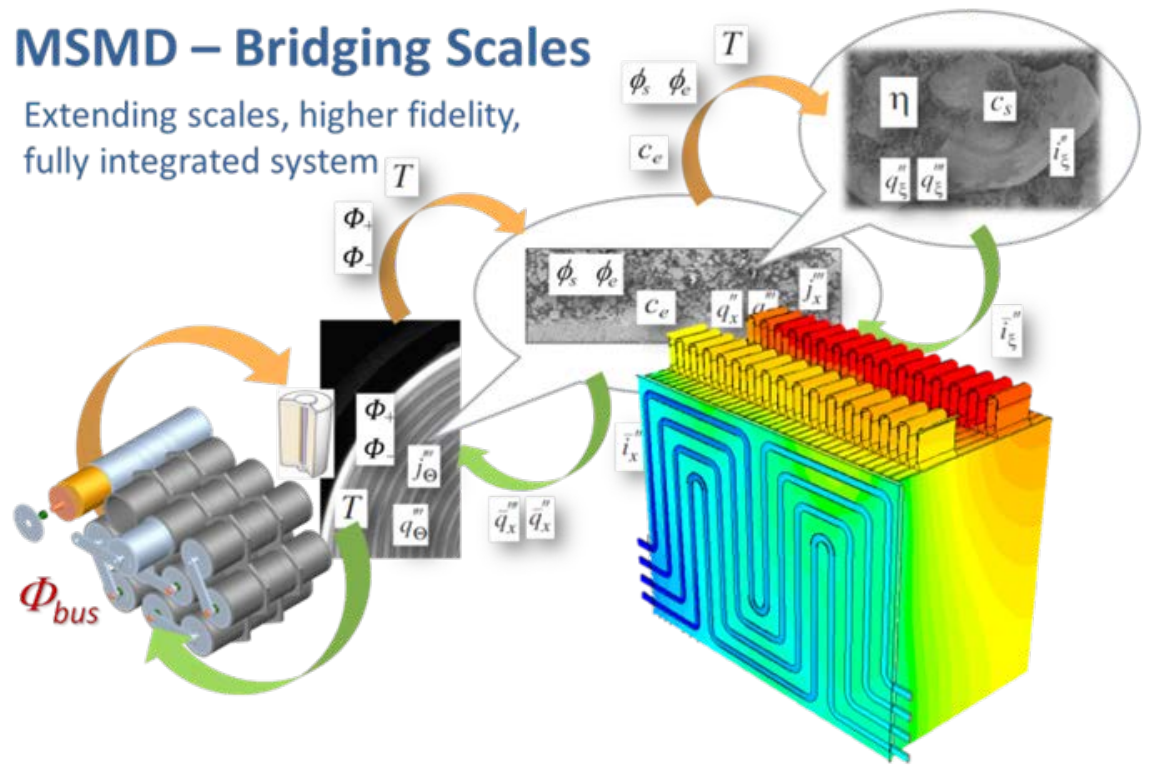

Figure 1. Modular multiscale model framework of MSMD

\section{Baseline Sub-Models}

$\underline{\text { PDM }}$ resolves lithium transport in solid electrode particles, interfacial reaction kinetics, and charge conservation at the interfaces. NREL has developed the discrete diffusion particle model (DDPM) as a baseline PDM for the MSMD multiscale model, to better address the impacts of particulate morphology, size distribution, surface modification, contact resistances, mixture composition of active particles. A system of particles is considered electronically continuous, but ionically discrete. An arbitrary number of quantized discrete particles can be given as a user input. The thermodynamic, kinetic, transport, electrical, and geometrical model parameters of each discrete particle can be independently determined.

$\underline{\text { EDM }}$ solves electronic and ionic charge conservation in composite electrodes and electrolytes, respectively, and species conservation in electrolytes. Assuming the existence of a local in-plane ensemble average in a finite volume of cell-domain, a one-dimensional porous electrode model is chosen for a baseline EDM.

CDM solves for temperature and electronic current in current collectors and other passive pathways across cell dimensions. An orthotropic cell composite model is a baseline CDM for the MSMD multiscale model. The battery cell composite has intricate stratified structures, and the assembly units of paired electrode layers are stacked or wound to build prismatic or cylindrical cells. Macroscopic designs for electrically and thermally configuring cell components greatly affect the physicochemical processes occurring in a battery. The numerical complexity of a model can be significantly reduced by treating the cell-composite as a homogeneous orthotropic continuum. For example, the single potential-pair continuum (SPPC) model treats the stratified cell-composite as homogeneous continuum with orthotropic transport properties, and resolves temperature and a pair of current collector phase potentials in the volume of the continuum with distinguished in-plane and transverse conductivities for heat diffusion and electrical current conduction. 


\section{MSMD Inputs}

MSMD (and GH-MSMD) accepts the two types of user-modifiable inputs: text-files and user-modifiable functions. Most of the model inputs are read in as text files with the extension "inp".

These inp files are:

- To define the battery

- To define usage

- To define the model setup.

Therefore, a user can choose materials, electrode designs, cell form-factors, battery use profiles, and submodel options for a MSMD battery simulation, by simply selecting a set of desired inp files from a text-file database without recompiling the model code. Occasionally, a user may want to use custom functions for the material properties. Then, "PROFUNC.cpp" can be edited. The case requires re-compilation of the model code.

INP files: The standard input file structure facilitates modular multiscale multiphysics simulation (Figure 2). These input files define a battery, a usage, and the numerics for model setup. The input file structure reflects the MSMD modularity. For example, if a user keeps the materials and the electrode design the same and only wants to change the cell form factor, the "cdparm.inp" needs to be replaced. If a user changes "edparm.inp" while keeping the others the same, the electrode design of a battery is changed. The files "posptcltbl.inp" and "negptcltbl.inp" define the positive and negative active materials, respectively.

\begin{tabular}{lccc} 
& PDM & EDM & CDM \\
\hline Define Battery & & & \\
\hline posptcltbl.inp, negptcltbl.inp & 0 & $\circ$ & 0 \\
edparm.inp & & $\circ$ & $\circ$ \\
cdparm.inp & & & $\circ$ \\
Define Usage & & & \\
ELprofl.inp & 0 & $\circ$ & $\circ$ \\
Setup Model & & & \\
setup.inp & $\circ$ & $\circ$ & $\circ$ \\
\hline
\end{tabular}

Figure 2: Standard MSMD input file structure

Property Functions: A group of functions is used to define the physicochemical properties of battery materials. The list includes:

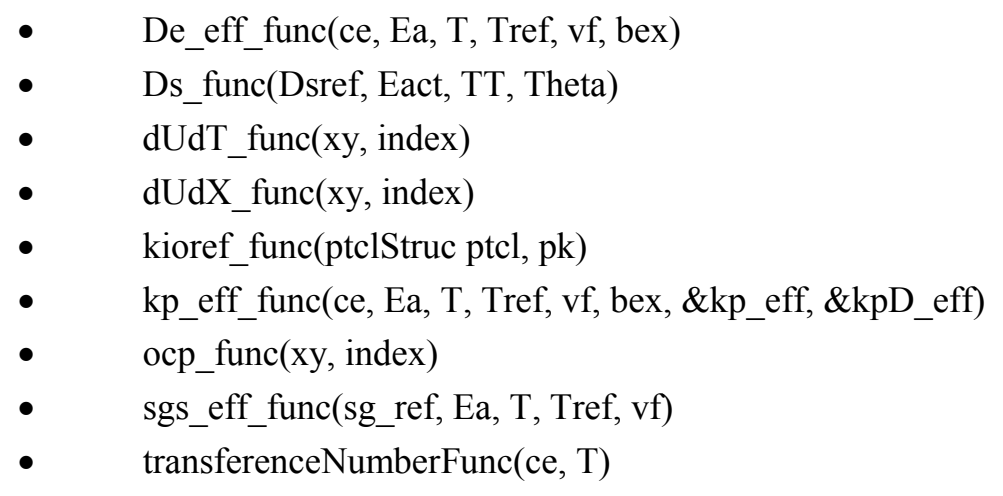




\section{Experimental Activity}

Test Cell Making: The following procedure uses LMO and graphite as examples. A cathode slurry is prepared with specific ratio using LMO, polyvinylidene fluoride (PVDF) as a binder, and carbon black as a conductive agent in an n-methyl pyrrolidone (NMP) solvent. An anode slurry is prepared in a similar way. When uniformly mixed, the slurry is spread onto a $15-\mu \mathrm{m}$-thick current collecting aluminum foil. After drying and pressing, electrode pieces are punched from the coated foil in coin cell or pouch cell format. For coin cells, the electrodes are assembled with lithium foil as counter electrodes in a glove box. For pouch cells, half cells are prepared in a similar way. Additionally, paired cathodes and anodes are assembled with lithium foil as reference electrodes in a three-electrode configuration. Electrolyte with $1.2 \mathrm{M} \mathrm{LiPF}_{6}$ is composed of ethylene carbonate (EC), diethyl carbonate (DEC), and dimethyl carbonate (DMC). Coating parameters like electrode dimension and solid loading level are measured and recorded. It should be noted that material properties including density, Brunauer-Emmett-Teller (BET) surface area, and particle size distribution are also necessary to subsequent modeling, thus it is suggested that these be acquired from vendors or manufacturers.

GITT Measurement: Coin cell tests are carried out with a battery tester. An environmental chamber maintains $20^{\circ} \mathrm{C}$ for at least 4 hours prior to testing. Coin cells are charged at $0.1 \mathrm{C}$ rate to a higher voltage limit and kept under that limit until the current drops below $0.05 \mathrm{C}$. In a time-effective manner, discharge is carried out in repeated two-step segments: low C-rate discharge at $0.05 \mathrm{C}$ for $30 \mathrm{~s}$ with 1 hour relaxation; high C-rate discharge at $0.1 \mathrm{C}$ for 1 hour with 4 hour relaxation. The segments are repeated until the voltage reaches the lower voltage limit. Open circuit potential (OCP) is recorded at the end of each resting period in every low Crate segment and GITT calculation uses the data in the same segments. The high C-rate discharge is used to reach certain state of charge stages faster.

EIS Measurement: Coin cells are charged at $0.1 \mathrm{C}$ rate under $20^{\circ} \mathrm{C}$ to corresponding voltage limit and kept at it until current drops below $0.05 \mathrm{C}$. After relaxation, the coin cells are discharged at $0.1 \mathrm{C}$ to reach $50 \%$ stage of charge. Four hours later, EIS tests from $1,000 \mathrm{kHz}$ to $0.005 \mathrm{~Hz}$ with $5-\mathrm{mV}$ amplitude are run on these cells.

\section{Test Matrix}

The list of these tests is suggested. MSMD model parameters are extracted from a defined test matrix, as shown in Table 1. The proposed tests are arranged in a consistent way such that the MSMD model framework is defined. With a bottom-up structure, parameters extracted from lower domains are independent of higher domain testing. Instead, the parameters are inputs to identify model parameters of higher domains.

Table 1. Suggested Test Matrix

\begin{tabular}{|c|c|c|c|}
\hline Domain Level & Cell Samples & Test & Objectives \\
\hline \multirow[t]{2}{*}{ Material } & $\begin{array}{l}\text { Cathode active } \\
\text { material }\end{array}$ & $\begin{array}{l}\text { BET test } \\
\text { Particle size analysis } \\
\text { Density Test }\end{array}$ & $\begin{array}{l}\text { Specific surface area } \\
\text { Powder particle size distribution } \\
\text { Ture and tape densities }\end{array}$ \\
\hline & $\begin{array}{l}\text { Anode active } \\
\text { material }\end{array}$ & $\begin{array}{l}\text { BET test } \\
\text { Particle size analysis } \\
\text { Density Test }\end{array}$ & $\begin{array}{l}\text { Specific surface area } \\
\text { Powder particle size distribution } \\
\text { Ture and tape densities }\end{array}$ \\
\hline Particle Domain & $\begin{array}{l}\text { Cathode Half } \\
\text { Cell }\end{array}$ & $\begin{array}{l}\text { Formation cycle } \\
\text { Constant-current discharge } \\
\text { GITT } \\
\text { EIS }\end{array}$ & $\begin{array}{l}\text { Formation loss } \\
\text { Crates performance } \\
\text { OCP curve and diffusion } \\
\text { Exchange current density and film } \\
\text { resistance }\end{array}$ \\
\hline
\end{tabular}




\begin{tabular}{|l|l|l|l|}
\hline Domain Level & Cell Samples & Test & Objectives \\
\hline & Anode Half Cell & $\begin{array}{l}\text { Formation cycle } \\
\text { Constant-current discharge } \\
\text { GITT } \\
\text { EIS }\end{array}$ & $\begin{array}{l}\text { Formation loss } \\
\text { Crates performance } \\
\text { OCP curve and diffusion } \\
\text { Exchange current density and film } \\
\text { resistance }\end{array}$ \\
\hline $\begin{array}{l}\text { Electrode } \\
\text { Domain }\end{array}$ & $\begin{array}{l}\text { Three Electrode } \\
\text { Cell }\end{array}$ & Formation cycle & $\begin{array}{l}\text { Formation loss, negative and positive mass } \\
\text { ratio } \\
\text { Model calibration (constant load) } \\
\text { Model calibration (dynamic load) }\end{array}$ \\
\hline Cell Domain & Full Cell & $\begin{array}{l}\text { Constant-current discharge } \\
\text { HPPC }\end{array}$ & $\begin{array}{l}\text { Formation cycle } \\
\text { Constant-current discharge } \\
\text { HPPC }\end{array}$ \\
\hline
\end{tabular}

\section{Numerical Procedures}

$\underline{\text { Method: }}$ Parameter estimation for battery identification is formulated here as a nonlinear least squares fitting problem of minimizing the least squares objective:

$$
F(p)=\sum_{i=1}^{N} \mid w_{i}\left(V^{\text {expt }}\left(t_{i}\right)-\left.V^{\text {calc }}\left(t_{i} ; p\right)\right|^{2}\right.
$$

with respect to the vector of parameter values p. Here, $V^{\text {expt }}\left(t_{\mathrm{i}}\right)$ is the voltage recorded at different time points $t_{\mathrm{i}}$ during our experiment (CCD, GITT, etc.), $V^{\text {calc }}(t ; p)$ is the course of voltages calculated at the same times by MSMD, and $w_{\mathrm{i}}$ are weights associated with each data point. Note the explicit dependence on the parameter values $p$. Our goal is to find the values of $p$ that minimize $F$. Note that it is likely true that for any given experimental device, there is a fixed value of $p$. However, because $p$ is not directly measurable, we must rely on numerical procedures to find $p$, and thus we rely on what the data can tell us about $p$. And quite frequently the data does not indicate a single set of best $p$ values. Our minimization is potentially an underdetermined problem.

That said, given a data set and an initial guess for $p$, there are a variety of algorithms for minimizing $F(p)$. For our work we use the Levenberg-Marquardt algorithm as implemented in the Fortran code MINPACK (from Argonne National Laboratory) and "wrapped" to be accessible from Python in the scipy numerical Python library. This algorithm is a combination of steepest descent and Newton's method, combining the robustness of the former with the efficiency of the latter. It is the "workhorse" method in this field. Analysis of the Jacobian matrix around the minimizer can provide estimates of confidence bounds on the estimated parameters, but we will not discuss this here. (Further details of the full probability distribution of the parameter values can be provided by Markov Chain Monte Carlo methods, especially in cases where the error cannot be assumed Gaussian. These methods are computationally expensive and will not be discussed further here, but we are actively pursuing this approach and connecting it to the traditional approaches as we move forward with our internal development.)

An important concept we recommend to overcome the underdetermined nature of the battery parameter estimation problem is the notion of sequential optimization. This simply means optimizing different sets of parameters at a time. Smaller subsets of parameters are more completely determined by the data. Once fixed, 
these allow the next subset of parameters to be determined by (perhaps different portion of) the data. The justification of such an approach is physical, not mathematical. We describe a particular case (fitting the particle domain model) below in the Examples section.

Another approach, simple yet powerful, is multi-start optimization. This simply means re-running the fitting procedure from a variety of starting parameter sets $p$. You may assume there is a single best $p$, but we have found that this procedure more often reveals that there are in fact many sets of parameters that can equally well describe the data. This is related to the sequential procedure. An "all-at-once" (as opposed to sequential) multistart fit reveals the underdetermined problem that the sequential procedure is meant to allay. However, statistics are subtle; it can sometimes be naïve to assume that a fixed value obtained from one stage of sequential fitting is known with sufficient confidence to fix it once and for all. Often it is better to let all the parameters remain free and discover the "space" of optimal parameter sets. Then perhaps a targeted fit of one of them can determine at the same time the values of those with which it is correlated.

Fitting Parameters: Referring to Chapter 3 regarding the MSMD inputs, there are a large number of quantities in the various MSMD input files. These can be divided into categories according to domain (PD, $\mathrm{ED}, \mathrm{CD}$, etc.) and according to role (design parameter, material parameter, environmental parameter, etc.). For the present purposes, we describe numerical fitting primarily at the particle domain level. Our goal here represents the "final stage" of the identification task and as such has several prerequisites, discussed in Chapter 5 regarding the MSMD "test matrix." In particular, we assume here the geometry information (cell size) and property functions (e.g. "ocp_func") have already been determined.

For this "final stage" of the MSMD battery identification task, we consider the following physical parameters;

- Reference exchange current density ("io_ref” in ptcltbl.inp). Assumed constant for each particle.

- Activation energy for exchange current density ("Eact_io" in ptcltbl.inp). Constant for each particle.

- Particle diffusion constant ("Ds_ref" in ptcltbl.inp). Assumed constant for each particle

- Activation energy for particle diffusion ("EactDs" in ptcltbl.inp). Constant for each particle.

- Particle radius $r_{\mathrm{i}}$. ("ptclxs" in ptcltbl.inp). Different for each particle.

- Particle volume fraction $f$. ("ptclvf" in ptcltbl.inp). Different for each particle.

- Surface to volume ratio: In principle this is known, but it appears to be very imprecisely known, so we treat it as a "virtual" parameter and allow it to vary.

This problem also has several constraints. First, the parameters are bound in physically realistic ranges (e.g., they are all positive). Second, the problem has two constraints relating particle radii $r_{\mathrm{i}}$ and particle volume fraction $f_{\mathrm{i}}$ :

$$
\begin{aligned}
& \sum_{i=1}^{n} f_{i}=1 \\
& \sum_{i=1}^{n} \frac{3}{r_{i}} f_{i}=s
\end{aligned}
$$

The first simply says the volume fractions sum to one. The second expresses our desire to maintain the same particle surface-to-volume ratio. We are able to use the two constraints to eliminate two otherwise free radii or volume fractions from the fit. We have chosen to eliminate the volume fractions for the first two particles.

At the electrode domain level most parameters are design parameters, but there are also several internal parameters that we must determine through numerical fitting to data. These include;

- Bruggeman tortuosity exponent for electrolyte diffusion in positive electrode, negative electrode, and separator ("pos_bex", "neg_bex", and "sep_bex" in "edparm.inp")

- Additional cell level ohmic resistance ("cel_Rohm" in "edparm.inp")

- Lithium loss fraction during formation (“cel_formationloss" in "edparm.inp"). 
Example: This example describes parameter identification for the cathode parameters of an experimental battery system of one of our industrial collaborators. In this study we seek to identify internal battery parameters over two data sets. The first is approximately 50 hours of pulse charging, and the second is constant current discharge at $0.5,0.1,1$, and $5 \mathrm{C}$ rates. The parameters of interest to identify are;

- io: exchange current density

- Ds: diffusivity

- $\quad$ Ri: particle sizes, $i=1$..number of particles

- Vi: particle volume fractions

- Eactio: activation energy for exchange current density

- EactDs: activation energy for diffusion coefficient

Surface-to-volume ratio: In principle, this is known, but as above it appears to be very imprecisely known, so we treat it as a "virtual" parameter and allow it to vary. One prescription is to determine these parameters by the sequential method described above. Here we describe a complementary multi-start approach to exploring the whole probability distribution of the parameters at once, without resorting to expensive Monte Carlo methods. For this, we have performed not one but many Levenberg-Marquardt local fits of constant current discharge to all the parameters, each fit starting from a different set of randomly chosen initial parameter values. Almost all of the starting conditions result in about the same quality of fit, but these "optimal" parameter values vary, and in interesting ways that reveal how they are related. This fact illustrates precisely the indeterminacy we refer to above. The actual experimental battery presumably has specific values for all these parameters. But the combination of data plus the MSMD model cannot tell us these precise but hidden values. It can only tell us the set of values that is consistent with the data, and in this case it tells us that there is an interesting correlation structure, revealed by the multi-start approach. Figure 3 is a "pair plot." It consists of a matrix of scatter plots. Each of these cells plots fitted values of one parameter (e.g., io) against another (e.g.,

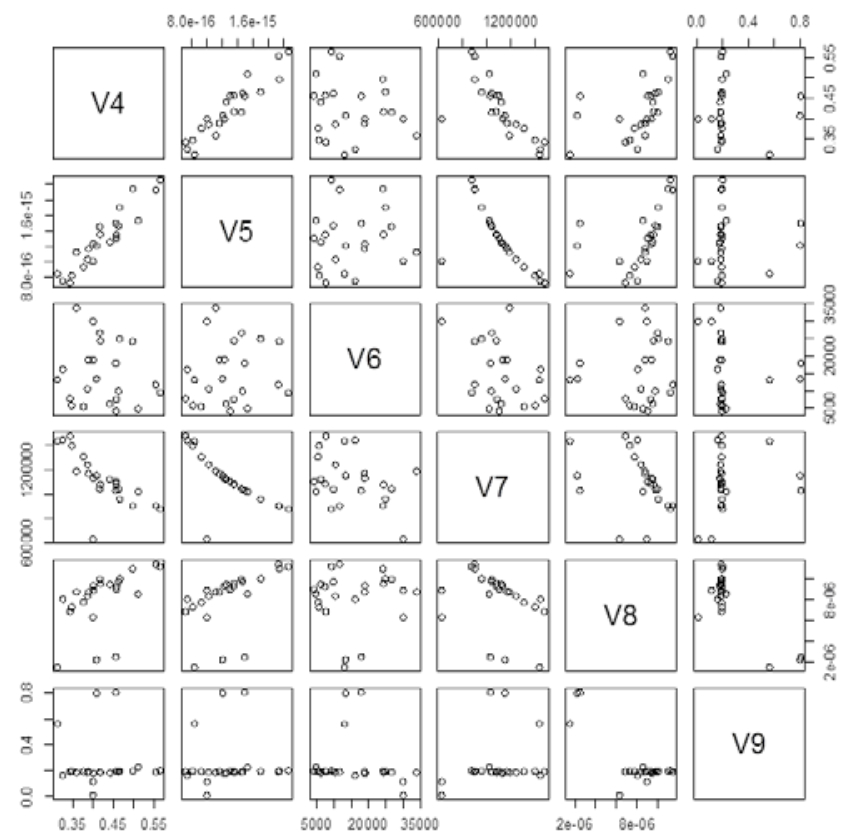

Ds). The plot reveals that the six parameters we fit are by no means all free-variables with respect to optimization. In fact, it is likely that there are only two free variables: 1 . one of $\mathrm{V} 4, \mathrm{~V} 5, \mathrm{~V} 7, \mathrm{~V} 8$, and V9.

Figure 3: From left to right (top to bottom) the parameters summarized are: io, Ds, Eactio, surface area, radius 1 , and volume fraction 1 . With respect to optimization there are only two or three free parameters: Cells labeled V4, V5, V7, and V8 are clearly correlated, so they represent only one actual choice by the optimizer. Except for outliers, V9 attains only one value. V6 appears uncorrelated with the other parameters. 


\section{CONCLUSIONS AND FUTURE DIRECTIONS}

In support of DOE's CAEBAT project, a document is being prepared to help model users identify the model inputs for running the MSMD and the GH-MSMD model simulations. The current version of the draft manuscript includes:

- Overview of the MSMD framework and the baseline submodels

- Review of conventional battery characterization test methods

- Standard input files

- To be commonly used in various existing and future submodel components

- To be easily databased for various lithium-ion chemistries and battery designs

- Test cell making and experimental guides

- List of tests

- Numerical procedure.

We will continue to develop sequential optimization procedure to break the under-determined parameter estimation problem of the whole system into a sequence of fully determined fits to subsets of the parameters. The procedure and the document will be updated for future publication. These developments will be performed under the third phase of the CAEBAT project.

\section{FY 2015 PUBLICATIONS/PRESENTATIONS}

- Annual Milestone Reports, September 2015 


\section{Computer Aided Engineering of Batteries - CAEBAT}

\section{OBJECTIVES}

The overall objective of the first phase of the ComputerAided Engineering of Electric Drive Vehicle Batteries (CAEBAT) project is to develop electrochemical-thermal software tools to accelerate the design and simulate the performance, life, and safety of electric-drive vehicle (EDV) batteries. As part of the CAEBAT-1 effort, NREL's objectives are:

- Support the U.S. vehicle, battery, and software industry with cost-shared subcontracts to develop battery modeling tools to simulate and design cells and battery packs to accelerate development of improved batteries for hybrid, plug-in hybrid, and electric vehicles

- Technically manage and monitor CAEBAT-1 subcontractors funded in 2011

- Oversee completion of the General Motors (GM) subcontract to deliver validated advanced lithium-ion battery systems using GM's six-step model verification and validation approach.

\section{TECHNICAL BARRIERS}

- Cost, life (calendar and cycle), high performance at all temperatures, and safety are barriers for widespread adoption of lithium-ion batteries in EDVs.

- Existing design tools are not practical for realistic battery pack design and optimization.

- Various cell physics sub-models exist, but they have not been integrated in a single framework in commercial code.

- Current engineering workstations do not have the computational power required to simulate packlevel thermal response coupled with electrochemistry. System-level analysis or reduced order modeling (ROM) is required to simulate integrated pack-level physics. However, ROM approaches for battery packs are not well understood.

\section{TECHNICAL TARGETS}

- Develop suites of software tools that enable automobile manufacturers, battery developers, pack integrators, and other end-users to design and simulate the electrochemical and thermal performance of cells and battery packs to accelerate development of battery systems that meet the requirements of EDVs

- To be useful to automotive engineers, battery cell and pack design tools should have the following analytical capabilities:

- Evaluate battery pack thermal management by predicting maximum intra- and inter-cell temperature difference under various drive-cycles 
- Ability to provide system simulations with ROM that allows for trade-off studies between the cooling cost and the battery pack warranty cost in the early stage of vehicle development.

- Ability for a real-time system simulations that can lead to battery management system (BMS) development and enhancement.

\section{ACCOMPLISHMENTS}

- GM and its partners successfully completed their CAEBAT-1 subcontract by developing a validated battery simulation software and delivering all their reporting requirements.

- ANSYS officially released the public version of its battery 3D multi-physics simulation tool in December 2014 (Fluent Version 16).

- The ANSYS Battery Design Tool (ABDT) was developed utilizing the ANSYS Workbench Framework.

- A direct thermal ROM was developed and validated with full-field simulation.

- NREL developed a user defined function (UDF) for multiple particle/multiple active material models in support of the GM team.

- Semi-physics-based cycle life model was developed and validated with cycle life test.

- A battery pack-level model was validated compared to the full field simulation and the test data for a production-level battery pack, and comparisons are satisfactory.

- The three CAEBAT-1 subcontract teams (CD-adapco, EC Power, and GM) now have successfully completed their projects and released three different battery computer-aided design software tools to simulate the electrochemical-thermal performance of batteries.

\section{INTRODUCTION}

In April 2010, the DOE Vehicle Technologies Office (VTO) announced a new program activity called Computer-Aided Engineering of Electric Drive Vehicle Batteries (CAEBAT) to develop software tools for battery design, R\&D, and manufacturing. The objective of CAEBAT is to incorporate existing and new models into battery design suites/tools with the goal of shortening design cycles and optimizing batteries (cells and packs) for improved performance, safety, long life, and low cost. The goal is to address the existing practices with which battery and pack developers operate: tediously experimenting with many different cell chemistries and geometries in an attempt to produce greater cell capacity, power, battery life, thermal performance and safety, and lower cost. By introducing battery simulation and design automation at an early stage in the battery design life cycle, it is possible to significantly reduce the product cycle time and cost, and thus significantly reduce the cost of the battery. When the project started three years ago, NREL had already developed an electrochemical-thermal model of lithium-ion cells with three-dimensional (3D) geometries. However, those tools were not integrated into a 3D computer-aided engineering (CAE) platform, which automotive engineers routinely use for other components. In many industries, including automotive and combustion engine development, CAE tools have been proven pathways to improve performance by resolving relevant physics in complex systems; shorten product development design cycles, thus reducing cost; and provide an efficient manner for evaluating parameters for robust design.

DOE VTO initiated the CAEBAT project to provide battery CAE tools to the industry. The goal of the CAEBAT activity is to "develop suites of software tools that enable automobile manufacturers, battery developers, pack integrators, and other end-users to simulate and design cells and battery packs in order to accelerate the development of energy storage systems that meet the requirements of the electric drive vehicle." The involvement of industry (automakers, battery developers, and software producers) in the CAEBAT activity was sought by soliciting active participation of the industry in developing cell and pack software suites for the design of batteries through competitive procurements. To oversee the successful execution of the CAEBAT program, NREL was assigned to coordinate the industry and academic activities on Cell-Level Modeling and Pack-Level Modeling. To engage serious involvement of industry, NREL, with guidance from 
DOE, issued a Request for Proposals (RFP) in FY10 to seek development of cell and pack battery design tools for a period of three years with $50 \%-50 \%$ cost sharing. The CD-adapco, GM, and EC Power teams were selected for award in early 2011. The three subcontract teams started technical work in July 2011. CD-adapco and EC Power completed their subcontracts and released the battery CAE tools to the public in 2014 as reported in the DOE FY2014 Annual Progress Report for the Energy Storage R\&D. CD-adpaco's battery simulation module in its STAR-CCM+ and EC Power's AutoLion have been licensed by more than 50 organizations. The GM subcontract was extended into FY 2015; thus, this final report focuses solely on the progress by the GM team.

The principal objective of the GM team was to produce an efficient and flexible simulation tool that predicts multi-physics battery responses for battery pack thermal management and predicts an optimum cell energy capacity in terms of electrical performance, cooling requirements, life, safety, and cost. The GM team led the four-year CAEBAT project, which is sponsored by the Energy Storage Research and Development (R\&D) activities of the VTO. The team is composed of GM researchers and engineers, ANSYS Inc. software developers, Professor Ralph E. White of the University of South Carolina and his ESim staff, and NREL. The team collaborated to develop a flexible modeling framework that supports multi-physics models and provides simulation process automation for robust engineering. The GM team's accomplishments included clarifying end-user requirements; physical validation of the models; cell aging and degradation models; and a new framework for multi-physics battery cell, module, and pack simulations. Many new capabilities and enhancements have been incorporated into ANSYS commercial software releases under the CAEBAT program. This is the last annual progress report for the CAEBAT-1 program.

\section{APPROACH}

The objective of GM's CAEBAT project was to develop a flexible, efficient software tool for multi-scale, multi-physics battery simulation based on the ANSYS Workbench framework. ANSYS is leveraging and enhancing its existing commercial products to provide both field-level (Fluent) and system-level (Simplorer) capabilities, including novel ROM methods and with other battery tools through the open architecture software interface.

Figure 1 shows the conceptual view of the ABDT Workbench infrastructure and architecture, which is the premise for ANSYS' software development. ABDT is the name adopted for the graphical user interface (GUI) layer that automates and customizes battery simulation workflow using ANSYS software products. In this vision, $\mathrm{ABDT}$ is the newly developed customization layer that ties the ANSYS building blocks together to provide a unified, intuitive simulation workflow. In software architecture terms, ABDT is a combination of an Addin, scripts, and templates. It was based initially on ANSYS Release 14.5, with updates to R15 and R16. The primary target for ABDT is automotive battery development or CAE engineers who are experts in neither battery physics nor simulation technologies. This community places a high value on process automation and ease of use. A secondary goal is to provide specialists with a convenient drill-through access to expert features such as electrochemistry sub-model details, numerical solution controls, and ROM algorithms. The essential role of the ABDT is to automate and integrate the ANSYS tools to make the various components emulate battery applications for cell and pack capabilities.

GM engineers generated the test database for validation of the nominal heat source model, as well as cell-level and pack-level electrical and thermal performance. ANSYS provided user-defined interfaces to utilize submodels developed by NREL that can represent multiple active materials and multiple particle sizes and shapes in the electrodes. ANSYS also created interfaces to enable these new tools to interface with current and future battery models developed by others. GM generated the test database for the physical validation of a 24cell module and a production-intent battery pack including electrical and thermal performance. GM validated the tools, obtaining satisfactory agreement with the test data. GM also successfully demonstrated thermal runaway simulations for a battery pack having an internal short circuit. With the expected rapid deployment of these design tools to the industry, the project results will accomplish the ultimate goal of accelerating the pace of battery innovation and development for future EDVs. 


\section{1}

\begin{tabular}{|l|l|l|}
\hline \multicolumn{2}{|c|}{ ANSYS BATTERY DESIGN TOOL (ABDT) } \\
\hline Field Simulation (CFD)
\end{tabular}

Figure 1. Battery simulation through ANSYS Battery Design Tool (ABDT)

\section{RESULTS}

The GM team continued developing and updating the cell- and pack-level battery simulation tools. New features were added to the ANSYS Fluent battery model that offer additional functionality and flexibility to the user.

\section{Direct Thermal ROM Automation Tool}

ROMs are typically faster to construct with a direct technique as the time-consuming step of computing the responses to a set of representative inputs is avoided or at least reduced. The inputs for a thermal ROM are volumetric heat sources as a function of time, applied uniformly to certain regions of the battery cell, and the outputs are temperatures as a function of time at all points of the field-solver mesh. The technique used in this work is based on Krylov-projection [1].

\section{Direct ROM Application and Results}

A small battery-model case file is provided with the ABDT deliverable software. This case file includes two battery cells, with a liquid cooling fin between the battery cells that contains nine micro-channels. Nine input heat sources are defined, and for each of these, the volume of the associated zone is defined as an output parameter. A pictorial comparison of the temperature field for the 1.8-million cell discretization is shown in Figure 2. Typically, errors of less $1 \mathrm{~K}$ are obtained for batteries heated to a few hundreds of degrees, with only a handful of basis vectors. The ROMs generated by the Krylov method are particularly good for slowly varying inputs, and they always match the steady-state responses perfectly. For particularly rapidly varying inputs, larger discrepancies between the ROM and full-order models will be observed.

Similar results for a battery pack made up of 20 battery cells placed between air cooling channels are shown in Figure 3. In this case, a coarser discretization was used, so that in this example the order of the full model is about 417,000 elements. 


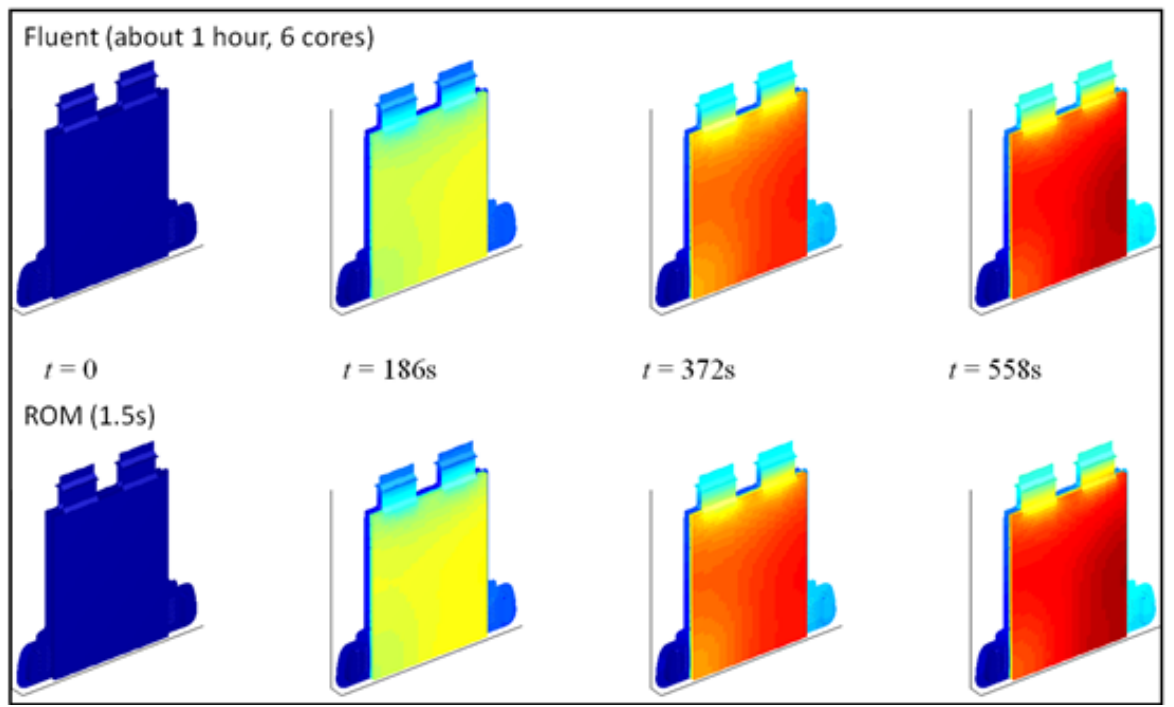

Figure 2. Comparison of transient simulation results (1.8 million unknowns)

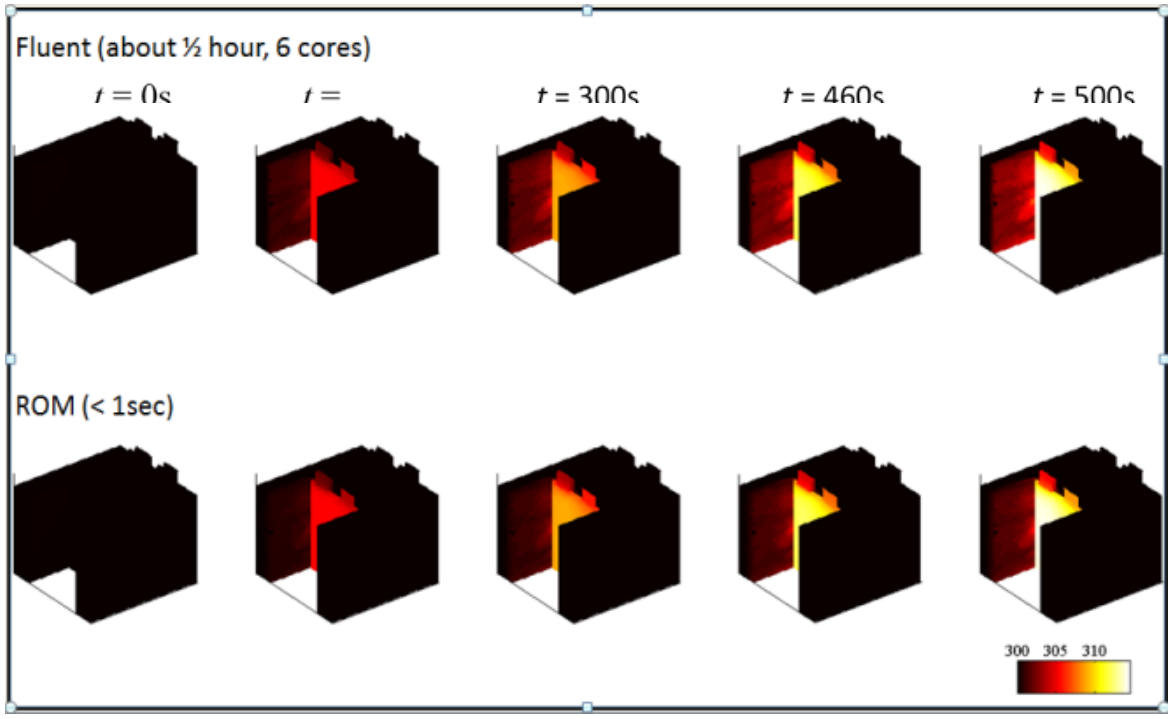

Figure 3. Comparison of transient simulation results (0.41 million unknowns)

\section{ROM Summary}

The system modeling with thermal Linear Time Variant (LTI)ROM for battery modules, under fixed mass flow rate cooling, approximates the battery module's volume averaged temperatures and the battery cell temperatures at specified locations of the battery cell quite well.

The Linear Parameter Varying (LPV) ROMs of mid/end cell units produced good approximations to temperature responses of the battery module. The amount of time it takes to generate the LPV training data is significantly reduced by the use of mid/end-cell units as compared to direct LPV approach. The divide-andconquer approach to system modeling with mid/end cell LPV ROMs mimics well the thermal behavioral of the battery module under varying mass flow rate cooling scenarios and reduces the calculation time by orders of magnitude when compared to field simulations. The ECM is used in Simplorer to calculate the battery cell's voltage and heat generation. A careful cascade of the (tightly) coupled ECM and thermal ROMs was achieved 
in Simplorer. The direct thermal ROM can approximate the battery cell temperature field of a module with fixed coolant mass flow rate. The Krylov-projection method is an effective ROM method for thermal battery modeling. The most attractive feature of this method is the shorter and simpler ROM construction procedure compared to the black-box methods.

\section{Validation for Production Intent Battery Pack}

The GM team has attempted to validate a battery pack that is planned to be implemented into a future GM hybrid vehicle. We cannot disclose the detail design of the production battery pack due to GM proprietary information. Therefore, the validation results for this battery pack are reported in a non-dimensional format only. The air-cooled battery pack consists of two modules with battery cells are connected in series. The aircooled battery pack is driven by an electric blower, and the air flow distribution at 24 cooling channels is nonuniform as shown in Figure 4. The heat transfer is enhanced by cooling design features in the gap between the cells. The test data available from the GM battery group are a part of the thermal durability test in a controlled thermal chamber. The chamber temperature varied while the battery pack ran with pulsing current loads with different C-rates at a constant blower speed, as shown in Figure 5. The flow distribution and the heat transfer coefficients in the cooling channels are obtained from the field simulation with Fluent computational fluid dynamics package. The non-uniform flow information and the heat transfer coefficients are provided to the system simulation based on a Simplorer. The measured current profile and the chamber temperatures are specified as an input to the system simulation. The electrical sub model based on a 6 parameter ECM model is coupled with the thermal network model to predict the battery cell temperature response during the battery pack level test. Figure 6 and 7 show the unit electrical and thermal models respectively. As indicated in Figure 6 , the battery is represented by a 6P ECM model, and the empirical parameters used in model are in the form of a two-dimensional lookup table as a function of state of charge and temperature. At a given instance, each parameter is estimated based on current loading direction (charging or discharging), state of charge, and cell temperature. The value of the empirical parameters is calculated using the look-up table and bi-linear interpolation. The key thermal properties of the cell are obtained from cell level test data and also from a cell supplier.

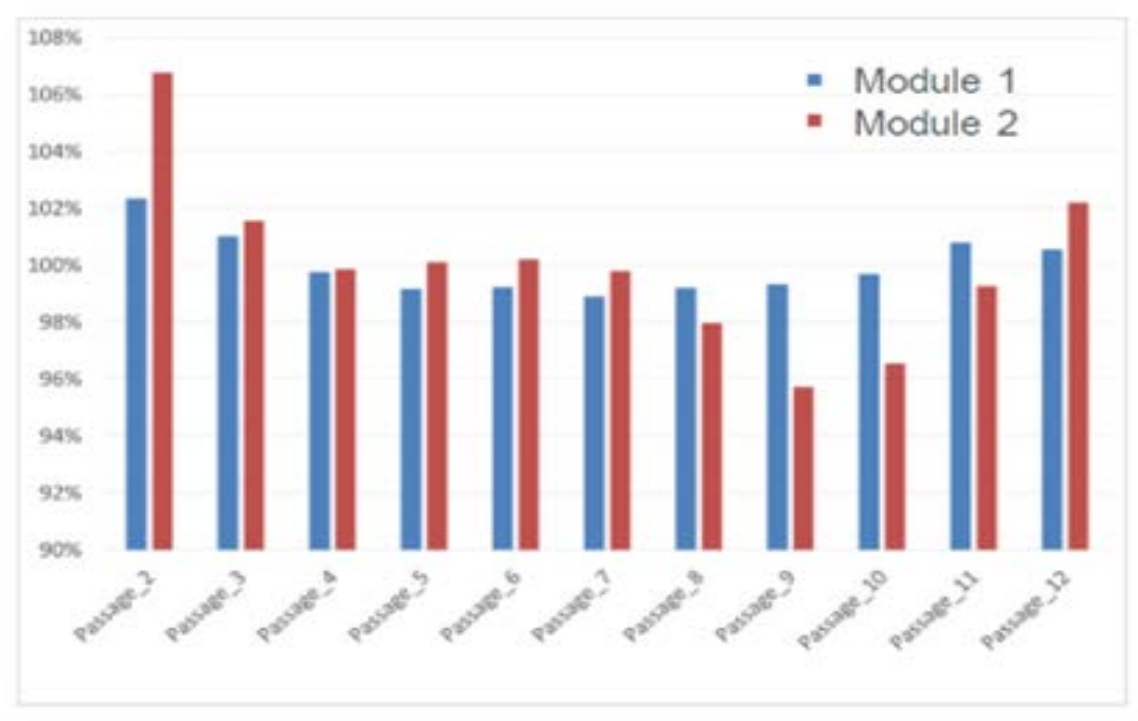

Figure 4. Flow distribution along the cooling channels 

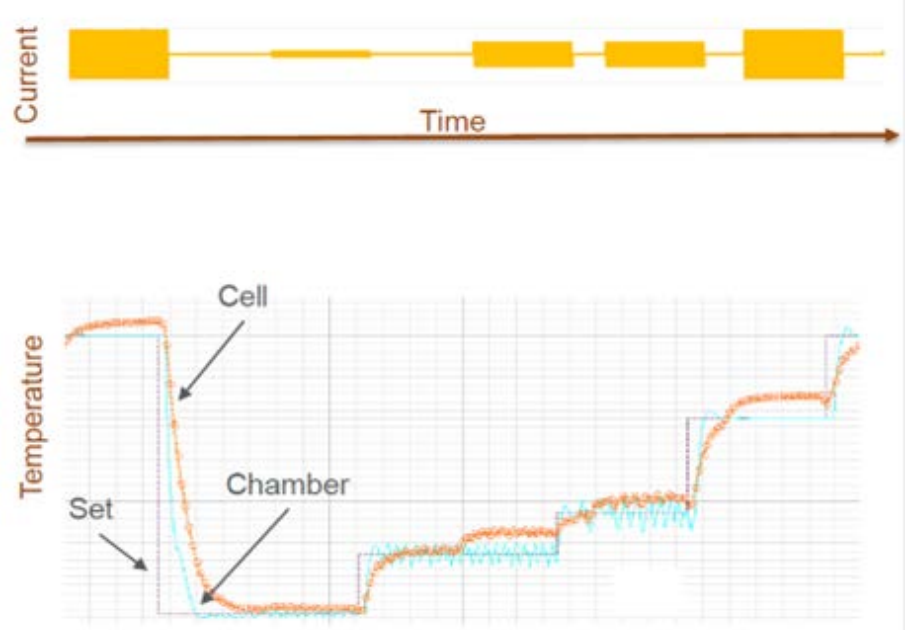

Figure 5. Pack level validation overview

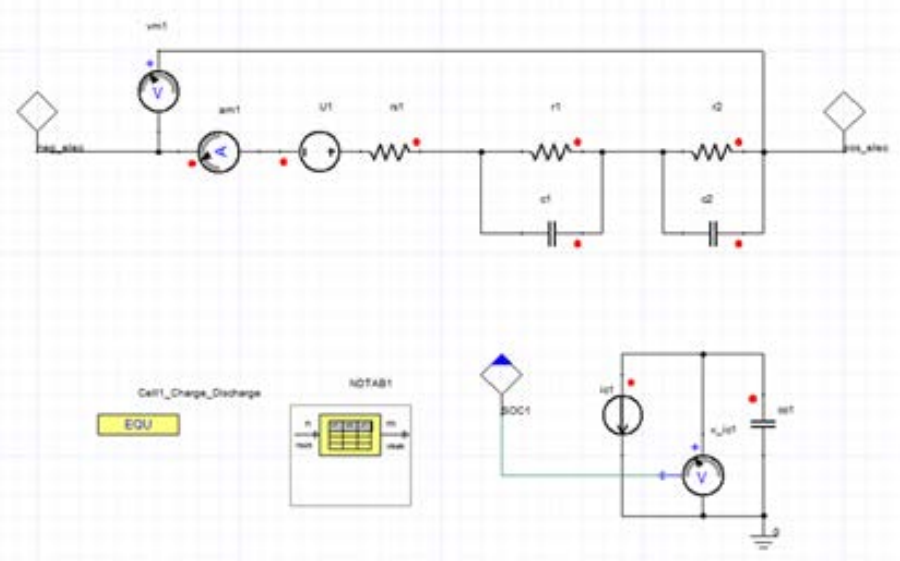

Figure 6. Electrical system model for a unit in a production-intent battery pack

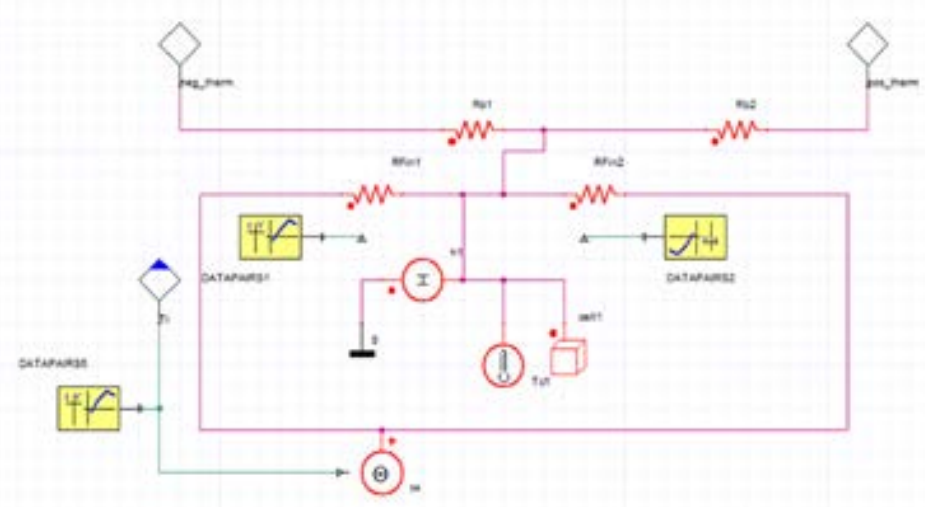

Figure 7. Thermal system model for a unit in a production-intent battery pack

Figure 8 summarizes the results and comparison of system modeling validation using the production-intent battery pack. The test data used for the validation were obtained from testing that involves different current 
loadings under different set temperatures. The validation result for the cell temperature prediction is shown in Figure 8. As shown in Figure 8, the system-level simulation predicted the cell temperature variation fairly well in comparison with the measured cell temperature. The comparison demonstrates that the system modeling is able to capture the transient response of the battery pack. Unlike the previous 24-cell module validation case reported in the previous section, the test data were not designed for a rigorous model validation; however, the available test data for the production-level battery pack helped us to complete the validation of the systemlevel simulation approach. As this is the first attempt for the production battery pack-level validation, GM will continue to gain further experience and will make use of these system simulations for future battery pack applications.

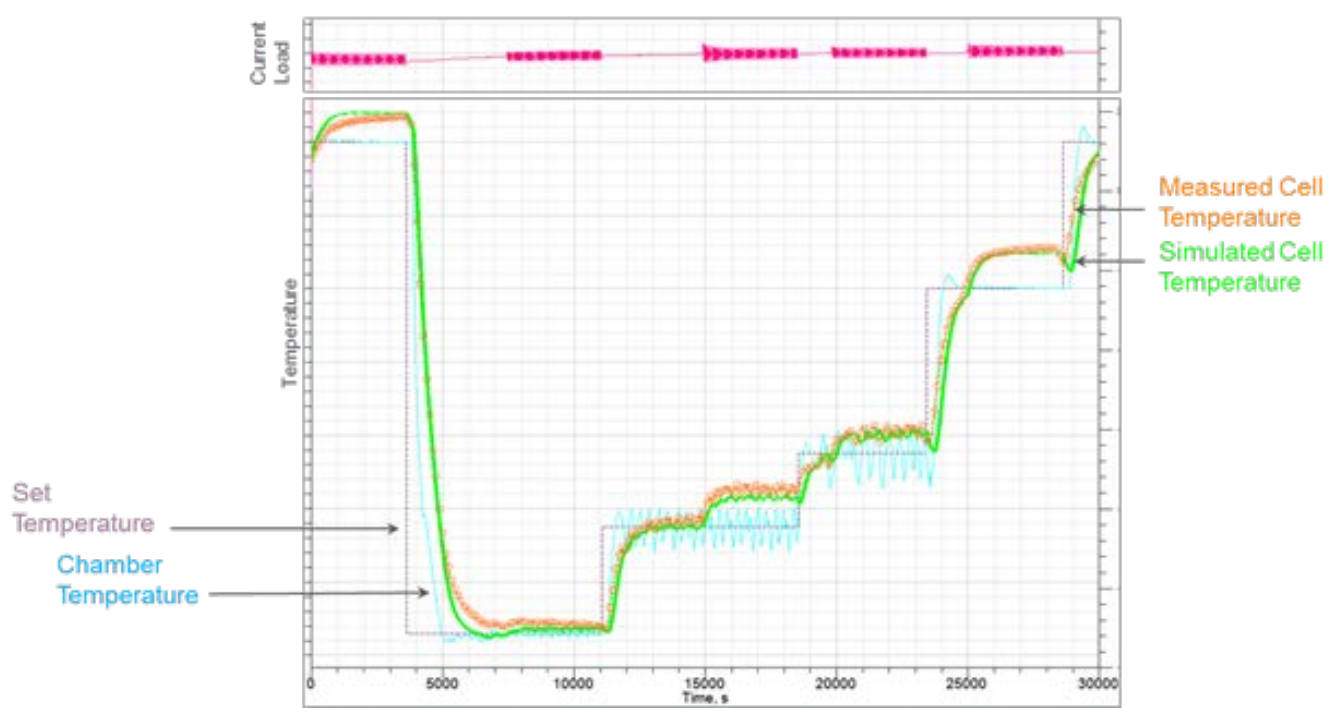

Figure 8. Thermal system model for a unit in a production-intent battery pack

\section{Commercial Software Release}

Many of the simulation tools and models developed under this project have been or are planned to be commercially released by ANSYS as integral feature enhancements to its existing, proven, commercial off-theshelf products. The ABDT customization layer was delivered to NREL in source-code and executable forms with unlimited Government use rights, and is also being test-marketed by ANSYS to explore commercial viability, as discussed further below.

\section{ANSYS Fluent Battery Module}

The field-simulation battery module was first commercially released as a standard Fluent model with ANSYS R15 release in December 2013, and has subsequently been updated as follows:

ANSYS Fluent R15 (December 2013)

ANSYS Fluent R16 (January 2015)

ANSYS Fluent R17 (Planned for early 2016)

These capabilities were documented to commercial CAE standards in a new 112-page user-guide section delivered to every Fluent licensee, which includes two hands-on battery tutorials. Introductory user training materials were also developed and deployed to ANSYS' global technical-services organization. 


\section{Fluent-Simplorer Co-Simulation and ROM}

The Fluent-Simplorer coupling capability was first commercially offered with ANSYS R14.0 in December 2011 and further refined and improved in the R14.5 release in November 2012. An example project distributed with the Simplorer software demonstrates a non-linear control system in Simplorer to control the coolant flow around a single cylindrical battery cell simulated in Fluent. Another new option, released with ANSYS R16.0 in 2015, provides the ability to import a Fluent LTI ROM and include it in the Simplorer system model as a Subcircuit.

\section{ANSYS Battery Design Tool (ABDT)}

ABDT has been distributed to and evaluated by the project team partners since May 2013 and has since been updated and extended many times. Although not yet an official ANSYS product, ABDT is available from ANSYS as a prototype, with customer training, support, and enhancement typically provided under an ad hoc services project.

\section{Other Miscellaneous Code Features or Fixes}

Thanks to the CAEBAT project, some new Simplorer scripting methods were added, and two new custom VHDL-AMS models for lookup of flow rates and drive cycles were developed. All commercial software enhancements were integrated into the ANSYS quality assurance process involving continuous regression testing to ISO 9001 standards, and a number of minor underlying code defects were identified and fixed in both Simplorer and Fluent.

\section{Commercialization Activities}

In addition to the contractually specified progress reports and annual merit review presentations, GM, ANSYS, ESim, and NREL authors on the project team have published a combined total of 11 technical papers in refereed journals and at technical conferences that document the R\&D accomplishments. In addition, although not directly charged to the funded project, software commercialization efforts are an important part of the team's plans and the DOE vision for rapid transfer of the CAEBAT technology to the battery-design community. The following list briefly summarizes those uncharged activities during the project period, which are expected to continue in the future

- Prominent outreach materials and resources were added to the automotive industry section of the ANSYS public website.

- In 2012, the project was featured in a GM-authored article in ANSYS Advantage, a marketing periodical with a global circulation of more than 50,000 CAE specialists (image below). A second article focusing on system simulation is in press for 2015.

- GM and ANSYS presented CAEBAT progress at the ANSYS-sponsored Automotive Simulation World Congress in the United States (2012) and Asia (2014), respectively.

- On August 21, 2014, GM and ANSYS co-presented an SAE-sponsored webcast showcasing CAEBAT to a live audience of 199 people. Several hundred additional registrants could download the recording for the subsequent year from http://www.sae.org/magazines/webcasts/.

- In 2014, ANSYS conducted internal training of its 500-person global salesforce to promote the new capabilities, including exploration of new projects based on the ABDT prototype. A number of presales visits, presentations, and demonstrations to battery teams in industry have taken place.

- The ANSYS technical-support incident database confirms that more than a dozen customers in North America, East Asia, Europe, and India have already begun using the new battery features. These existing licensees span from cell manufacturers to tier suppliers to automotive original equipment manufacturers.

- Most recently (January 2015), ANSYS presented CAEBAT and its potential for accelerating battery innovation to the European battery research community at the prominent AABC conference [2]. 


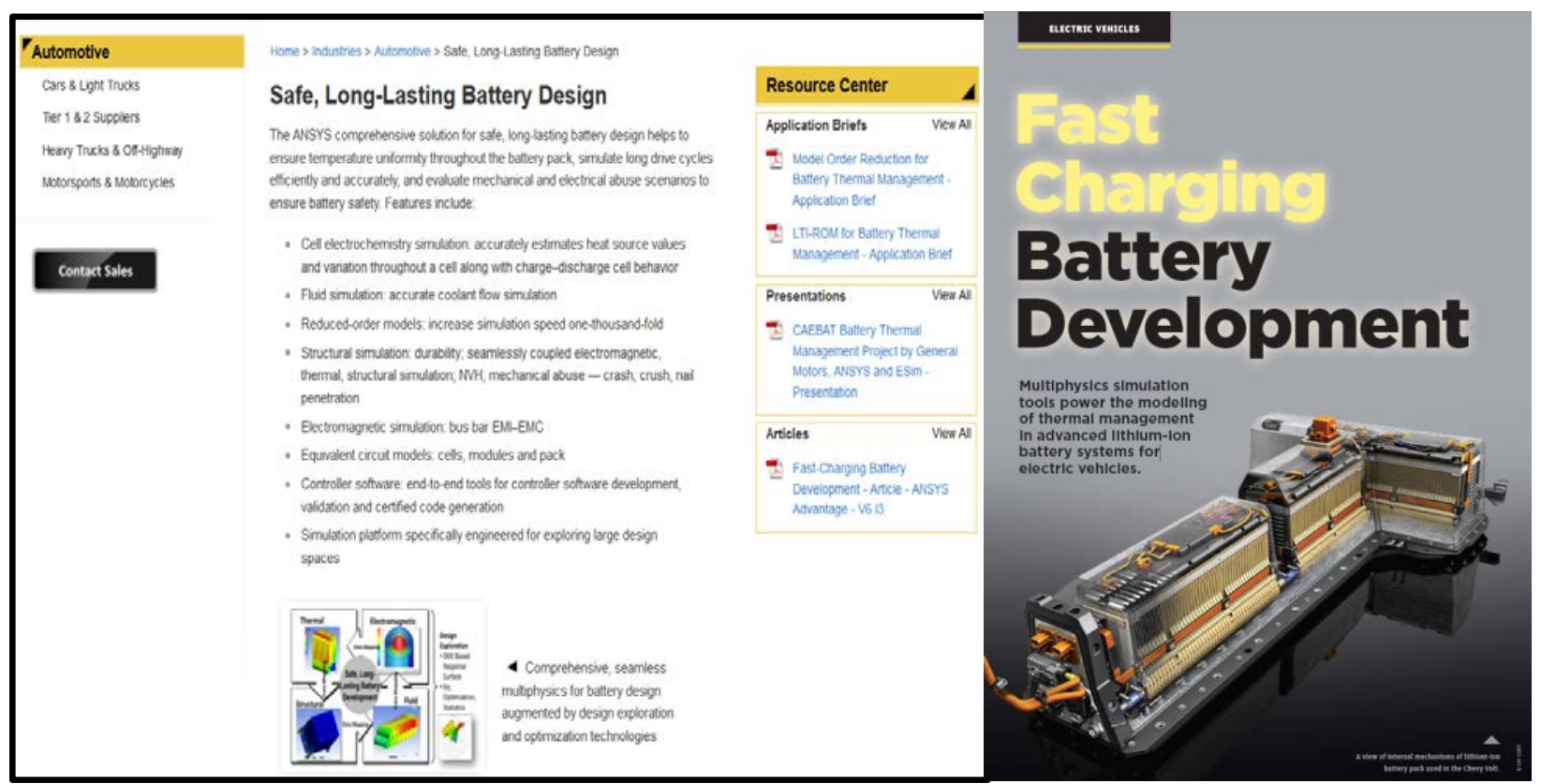

Figure 9: ANSYS website describes the battery simulation capabilities developed under the CAEBAT project

\section{CONCLUSIONS AND FUTURE DIRECTIONS}

The three CAEBAT-1 subcontract teams (CD-adapco, EC Power, and GM) now have successfully completed their projects and released three different battery computer-aided design software tools to simulate the electrochemical-thermal performance of batteries. The GM team completed its project in FY2015 while the other two teams completed theirs in FY2014. The developed and publicly released tools are now in ANSYS Fluent Revision 16 and engineers use full simulation version for cell design and ROM version for back design.

As ANSYS leads the transfer of the newly developed technology to the industry, several logical continuation $\mathrm{R} \& \mathrm{D}$ activities can also be recommended to further increase the software's capability and appeal.

- One clear example is to evolve the cell-aging models into general purpose, integrated features that would connect the deterministic, single-drive-cycle simulations currently emphasized in ABDT to the stochastic service-life prediction that is ultimately needed in design.

- Another would be to integrate a more sophisticated model to address particle morphology, size distribution, surface modification, contact resistances, and mixture composition of active particles.

- The structural analysis capabilities in ANSYS' existing family of commercial products, although automatically tied loosely to the new battery tools through Workbench, were not utilized significantly in this CAEBAT-1 project; a follow-on project in CAEBAT-2 and CAEBAT-3 has leveraged that immense investment by extending the ABDT concept to microstructural models of resolved electrodes and/or macroscopic mechanical battery abuse scenarios.

The MSMD is recognized as an effective model framework for modular architecture linking interdisciplinary battery physics across varied length and time scales. By implementing MSMD in Fluent, the team has overcome challenges in modeling the highly nonlinear multiscale response of battery systems. However, the inevitable nested iteration, ensuring self-consistency at each hierarchical level in the original MSMD, becomes a factor limiting computation speed. In a separate concurrent project in FY15 supported by DOE as part of CAEBAT-2, NREL developed a new quasi-explicit nonlinear multiscale multiphysics framework, the GHMSMD (see Section III.C.8 of this report). The new framework uses time-scale separation and variable decomposition to eliminate several layers of nested iteration and still keeps the modular MSMD architecture 
that is critical to battery behavior simulations. Fast electronic charge balance is differentiated from the processes related to slow ionic movements. During preliminary benchmark tests carried out at the electrode domain model (EDM) level, the GH-MSMD implementation demonstrated significant computational speed improvement compared to the original MSMD. One promising candidate to build on the accomplishments of this project is therefore to implement GH-MSMD into the commercially deployed ABDT tool, potentially increasing computational speed of the pack level simulation by a factor of 100 . These latest developments will be carried into the third phase of CAEBAT to be started in FY16.

\section{REFERENCES}

1. Grimme, E. J., "Krylov projection methods for model reduction," Doctoral dissertation, University of Illinois at Urbana-Champaign, 1997.

2. "Battery Pack Simulation: Multiscale methods that achieve both speed and accuracy," European Advanced Automotive \& Stationary Battery Conference, 26-29, 2015, Mainz, Germany

\section{FY 2015 PUBLICATIONS/PRESENTATIONS}

1. Asgari, S., and Kaushik, S., "A linear parameter varying combined with divide-and-conquer approach to thermal system modeling of battery modules," SAE Int. J. Commer. Veh. 15JAP-0010, 2015. 


\title{
Coupling Mechanical with Electrochemical-Thermal Models Batteries Under Abuse
}

\section{OBJECTIVES}

- The main objective of this project is to develop mathematical models to couple the electrochemical-thermal (ECT) behavior of a lithium-ion (Li-ion) cell to its structural behavior after rapid mechanical deformation, with the eventual goal to predict the onset of a thermal runaway after a crash-induced crush.

- A second objective of this project is to develop validated codes to predict the combined structural, electrical, and thermal responses to a thermal ramp.

\author{
Brian Cunningham (DOE Program Manager) \\ DOE Agreement \# 27041 Recipient: \\ National Renewable Energy Laboratory \\ Ahmad Pesaran (NREL - PI) \\ 15013 Denver West Parkway, M/S 1633 \\ Golden, CO 80401 \\ Phone: 303-275-4441; Fax: 303-275-4415 \\ Email: Ahmad.Pesaran@nrel.gov \\ http://www.nrel.gov/vehiclesandfuels/energystorage/
}

\section{TECHNICAL BARRIERS}

- Concerns regarding potential thermal event by

Subcontractors:

ANSYS

Li-ion batteries in today's plug-in electric vehicles (PEVs) delaying faster adoption of PEVs.

- Poor availability of characterization data that Massachusetts Institute of Technology Start Date: October 2013

Projected End Date: March 2015 identify mechanical limitations of Li-ion cells.

- Unavailability of a standard experimental approach that is widely accepted by the industry to characterize the mechanical response of a Li-ion cell and the resulting implications for battery safety.

- Limited understanding of physical phenomena that take place within a Li-ion cell just before and after a mechanical crush that result in the failure of the battery cell components.

\section{TECHNICAL TARGETS}

The major technical targets for this effort include the:

- Creation of an experimentally validated mechanical deformation model for a $\mathrm{Li}$-ion cell

- Development of a mechanism to understand the interactions among the mechanical effects and the chemical runaway reactions that occur within the cell

- Implementation of the coupling between the mechanical and ECT models on the ANSYS software platform for designing safer cells.

\section{ACCOMPLISHMENTS}

- We developed a representative-sandwich (RS) model to predict the mechanical deformation of Li-ion cells under indentation tests.

- The team developed an analytical method to estimate through-thickness mechanical properties of battery cell components.

- The team proposed a couple of approaches to predict the mechanical-electrical-thermal response during a crush event. 
- We conducted systematic case studies investigating the role of mechanical failure and electrical contact area on the subsequent electrical and thermal responses during a mechanical abuse.

- This report highlights the comparison of the simulation results to experimental data including results from the phenomenological models developed by our team members at Massachusetts Institute of Technology (MIT), the cell-level implementations by ANSYS, and the coupled models built at NREL using this information.

\section{INTRODUCTION}

The safety behavior of Li-ion batteries under external mechanical crush is a critical concern, especially during large-scale deployment. In this report, we present the mechanical response of Li-ion cells under different test conditions and examine the interaction between mechanical failure and electrical-thermal response by developing a simultaneously coupled mechanical-electrical-thermal model. This project as part of the CAEBAT-2 activity started in October 2013 with collaboration between NREL, MIT and ANSYS. The present work utilizes a single representative layer of electrodes (RS) to model the full pouch cell with explicit representations for each individual component, including the active material, current collector, separator, etc. Anisotropic constitutive material models are presented to describe the mechanical properties of the active materials and separator. The model accurately predicts the force-strain response and of the battery structure, simulates the local failure of the separator layer, and captures the onset of the short circuit for the Li-ion battery cell under sphere indentation tests with three different diameters. Electrical-thermal responses to the three different indentation tests are elaborated and discussed. Numerical studies are presented to show the potential impact of the test conditions on the electrical-thermal behavior of the cell after the occurrence of the short circuit.

\section{APPROACH}

Our modeling approach builds upon the capabilities established during the last few years under CAEBAT-1 . In this CAEBAT-2 project NREL, have teamed with ANSYS to take advantage of the Multi-Scale MultiDomain (MSMD) implementation of the ECT model for Li-ion batteries. The mechanical response is simulated using explicit methods available in the commercial finite-element software LS-DYNA. The material properties for the layers under various loads are measured by our partner MIT in the Impact and Crash Laboratory.

\section{Coupled Mechanical-Electrical-Thermal Model}

We use solver modules available in LS-DYNA by default: solid mechanics solver, thermal solver, and electromagnetic (EM) solver. The basic equations for these three solvers are summarized below. The mechanical solver is used to solve for deformation and predict the failure of a structure suffering external or internal loading conditions. The explicit mechanical solver seeks a solution to the momentum conservation equation:

$$
\sigma_{i j, j}+\rho f_{i}=\rho u_{i, t t}
$$

where $\sigma_{i j}$ denotes the components of stress, $u_{i}$ denotes the components of displacement, $\rho$ is the density, $f_{i}$ is the body force density, and $t$ is time. The comma on $\sigma_{i j, j}$ denotes covariant differentiation; similarly, $u_{i, t}$ denotes acceleration. For a solid, the constituent (stress-strain) relationship can be written as follows:

$$
\sigma_{i j}=C_{i j k l} \gamma_{k l}
$$

where $C_{i j k l}$ is the stiffness matrix, and the components of strain $\gamma_{k l}$ are related to displacement by the following relationship: 


$$
\gamma_{k l}=\frac{1}{2}\left(\frac{\partial u_{k}}{\partial x_{l}}+\frac{\partial u_{l}}{\partial x_{k}}\right)
$$

where $x$ is the coordinate. And the indexes $i, j, k$, and $l$ equal 1,2, and 3 corresponding to $x, y$, and $z$ directions. The LS-DYNA EM solver employs the eddy current approximation, which assumes a divergence-free current density and no charge accumulation. Two equations constituting the system response will be solved:

$$
\begin{aligned}
& \nabla(\kappa \vec{\nabla} \varphi)=0 \\
& \kappa \frac{\partial \vec{A}}{\partial t}+\vec{\nabla} \times\left(\frac{1}{\mu} \vec{\nabla} \times \vec{A}\right)+\kappa \vec{\nabla} \varphi=\overrightarrow{j_{s}}
\end{aligned}
$$

where magnetic vector potential, $\vec{A}$, and electric scalar potential, $\phi$, are two unknowns to be solved; $\kappa$ is the electrical conductivity, $\mu$ is the magnetic permeability, and $j_{s}$ is the source current density. After solving the above two equations, the Lorentz force, $\boldsymbol{F}_{\text {Lorentz }}$, and Joule heating energy, $\boldsymbol{E}_{\text {Joude }}$, can be computed as:

$$
\begin{gathered}
\vec{F}_{\text {Lorent }}=\vec{j} \times \vec{B} \\
\mathrm{E}_{\text {Joule }}=\frac{\vec{j} \cdot \vec{j}}{\kappa_{s}}
\end{gathered}
$$

where $\vec{j}$ is the current density.

For the thermal solver, the governing equation of the conduction of heat in a three-dimensional solid is given by:

$$
\rho c \frac{\partial T}{\partial t}=\frac{\partial}{\partial x_{i}}\left[k_{i j} \frac{\partial T}{\partial x_{j}}\right]+Q
$$

where $T$ is temperature, $c$ is specific heat, $k_{i j}$ is thermal conductivity, and $Q$ indicates heat generation rate per unit volume, $\Omega$.

In LS-DYNA, the mechanical, EM, and thermal solvers are fully coupled to each other. Figure 1 shows the interactions among the LS-DYNA mechanical, thermal, and EM solvers. The three solvers have distinct time steps, and generally the mechanical time step is a lot smaller than the EM and thermal time steps. At each mechanical time step, the EM and thermal field values are calculated by linear interpolation. At each EM time step, the EM solver and the mechanical solver interact, during which the EM solver communicates the Joule heating term, $E_{\text {Joule }}$, to the thermal solver while the thermal solver communicates the temperature to the EM solver.

At each EM time step, the EM solver communicates the Lorentz force described in Eq. (6) to the mechanical solver, which results in an extra force in the mechanical governing equation (Eq. (1):

$$
\sigma_{i j, j}+\rho f_{i}+F_{\text {Lorentz }}=\rho u_{i, t t}
$$




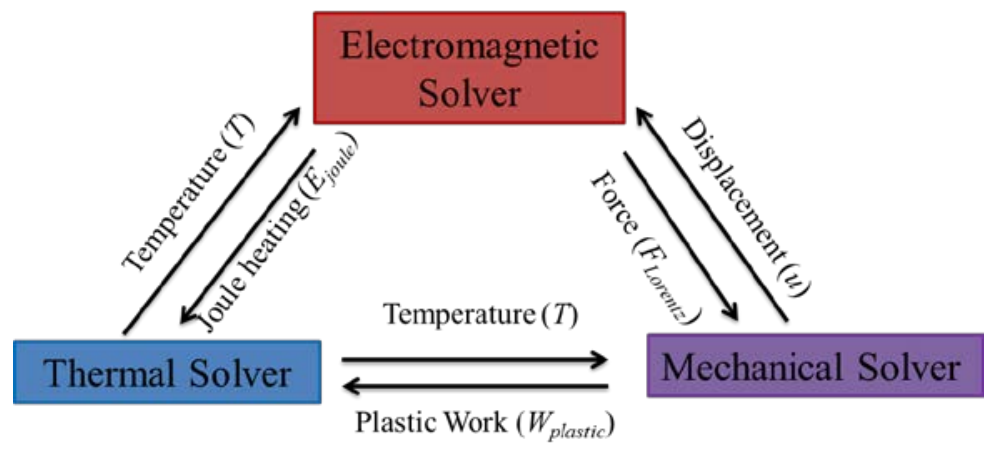

Figure 1: Interactions among the mechanical, EM, and thermal solvers for the simultaneously coupled modeling approach

The mechanical solver returns the displacements and deformation of the structure to the EM solver. Similarly, at each thermal time step the thermal solver communicates temperature to the mechanical solver while the mechanical solver communicates the value of the plastic work, $W_{\text {plastic }}$, to the thermal solver. The plastic work and Joule heating are the predominant sources of heat generation in our case, so Eq. (8) can be rewritten as follows:

$$
\rho c \frac{\partial T}{\partial t}=\frac{\partial}{\partial x_{i}}\left[k_{i j} \frac{\partial T}{\partial x_{j}}\right]+\frac{\dot{W}_{\text {plastic }}+\dot{E}_{\text {Joule }}}{V}
$$

where the dot indicates the time derivative, and $V$ is the volume of the element. Note that there is no explicit representation of temperature in the governing equation for the mechanical and EM solvers. The material properties, such as conductivity, $\kappa$, and stiffness, $C_{i j k l}$, evolve as a function of the temperature. However, due to the limited availability of experimental data, in this work all the material properties are considered to be temperature independent throughout the analysis.

In typical electrochemical battery models, the magnetic field is not considered assuming $\overrightarrow{\boldsymbol{A}}=\mathbf{0}$ all over. Then the electrical potential can be obtained by solving the following two equations:

$$
\begin{aligned}
& \vec{j}=-\kappa_{s} \vec{\nabla} \varphi \\
& \vec{E}=-\vec{\nabla} \varphi
\end{aligned}
$$

where $\vec{E}$ is the electrical field. These are simplified versions of Eqs. (4) and (5). Contributions from the electrolyte to the short circuit are assumed to be negligible ( $\kappa_{s}$ is the solid-phase conductivity) - given that the difference between the electronic and ionic conductivities is four orders in magnitude or larger.

The goal of the model is to predict the initiation of the short circuit and its consequential evolution of the electrical properties (current and voltage) and temperature and, more importantly, the effect of external deformation on the electrical and thermal response of the cell. The information obtained from these simulations is extremely helpful for studying the electrochemical responses.

\section{Numerical Implementation}

The $\mathrm{Li}$-ion battery studied in this work is a $\mathrm{LiCoO}_{2}$ pouch cell that was previously characterized by MIT. The nominal capacity of the cell is $740 \mathrm{mAh}$ with a nominal voltage of $3.7 \mathrm{~V}$. To simulate the local damage and predict the short circuit, it is necessary to model each individual component (separators, collectors, and active materials) of the battery structure. In this work, a finite-element model was built to explicitly model each 
individual component without losing computational efficiency or accuracy. We use the electrical contact between the active materials following the failure of the separator as a criterion for the short circuit.

\section{Representative Sandwich Model}

The detailed stacking and dimensions of the studied pouch cell were reported by Sahraei et al. at MIT. It was found that the pouch cell was composed of two separate laminates; each can be considered a multilayered plate made from cathodes, anodes, and separators. A cross-sectional view is shown in Figure 2(a). A cathode and anode are each composed of collector and active layers. An RS is introduced to define the repeating layout, as shown in Figure 2(a). Each RS contains a cathode active material layer, a cathode current collector layer, an anode active material layer, an anode current collector layer, and one separator layer. The whole pouch cell contains approximately 165 layers, and it can be estimated to be comprised of 40 representative sandwiches. The modeling of all 165 layers (the full pouch cell model) is computationally very costly. One simplifying approximation is to represent the 40 sandwiches as one single equivalent but with thicker RS (shown on the right side of Figure 2(a)), such that each layer has a proportionately larger thickness.

The schematic representation of an indentation model is shown in Figure 2(b). Due to symmetry, and to save computational time, we consider only one-quarter of the actual in-plane domain in our finite-element model. The geometry in our finite-element representation has a length, $l$, of $29.75 \mathrm{~mm}$; a width, $w$, of $17 \mathrm{~mm}$; and thickness, $h$, of $4.6 \mathrm{~mm}$. The bottom surface (i.e., $z=0$ ) of the battery models is constrained in the thickness direction ( $z$-direction). The indentation tests were conducted with rigid spheres with diameters of $12.7 \mathrm{~mm}$, $28.575 \mathrm{~mm}$ and

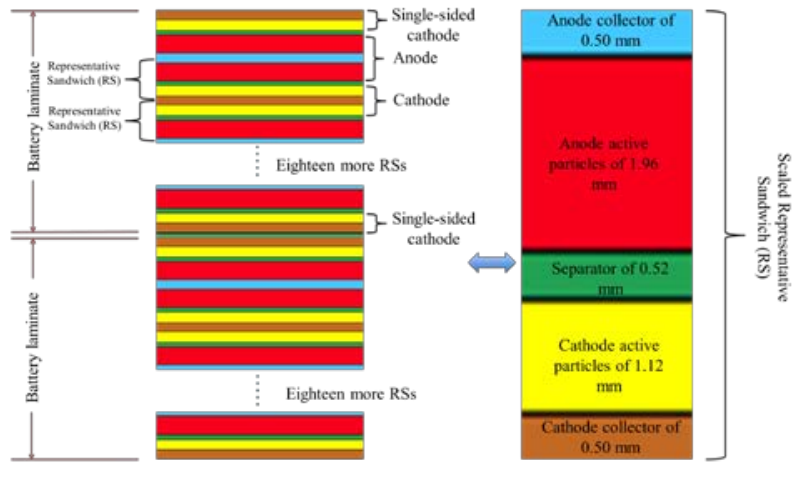

(a)

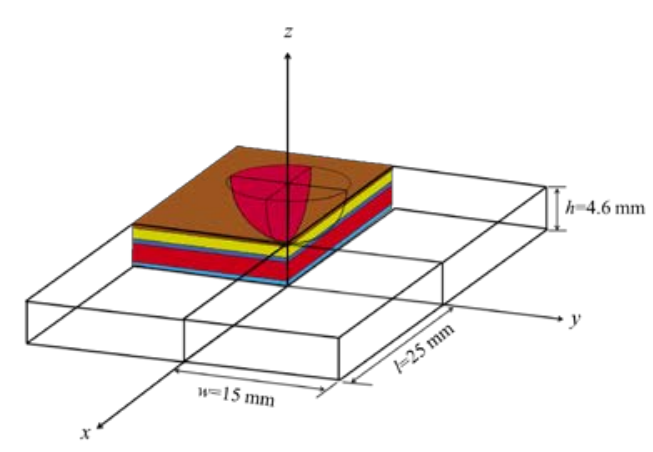

(b)

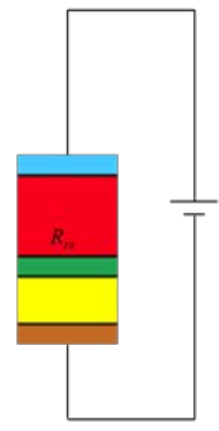

Single RS model

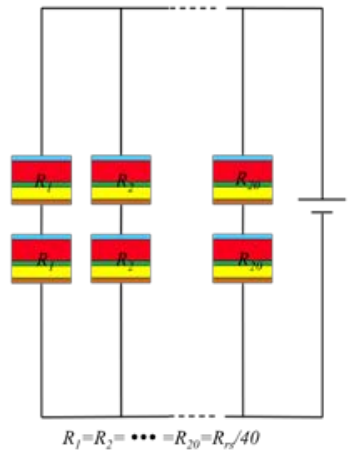

Full pouch cell model

(c)

Figure 2: (a) Cross-sectional view of a pouch cell and schematic of an RS: the pouch cell is represented by a single RS that explicitly represents the thickness proportions of each individual component. (b) Schematic and dimensions of the single RS indentation model: a quarter of the actual domain is utilized in the finite-element model based on symmetry. (c) Schematic of electrical connections for the single RS model and full pouch cell model: in this work, scaled electrical conductivity properties are utilized for each individual component of the single RS model to theoretically match the overall Joule heat. 
$44.45 \mathrm{~mm}$ in three different test cases, respectively, moving downward in the $z$-direction at a constant speed to accomplish the loading process in 0.01 second. Although the loading speed is much higher than that in a typical quasi-static experiment, the simulations are still considered quasi-static because we were able to verify that the kinetic energy was less than $1 \%$ of the total energy.

The battery model was meshed using solid elements, with 18 elements through the thickness (z-direction), 100 elements along the length ( $x$-direction), and 60 elements through the width ( $y$-direction), resulting a total of 108,000 elements for the RS model. The indenter is modeled as a rigid sphere.

\section{Constitutive Models for Battery Components}

The development of an accurate constitutive model is essential for building a predictive model. The preliminary test results by MIT suggest that the electrodes and separator have significantly different tensile and compressive responses due to the presence of porous active materials. The separator is also known to be anisotropic under in-plane tensile loading conditions. Under this effort, MIT built an extensive experimental data set for the cell components (Figure 3 ) and developed anisotropic models.

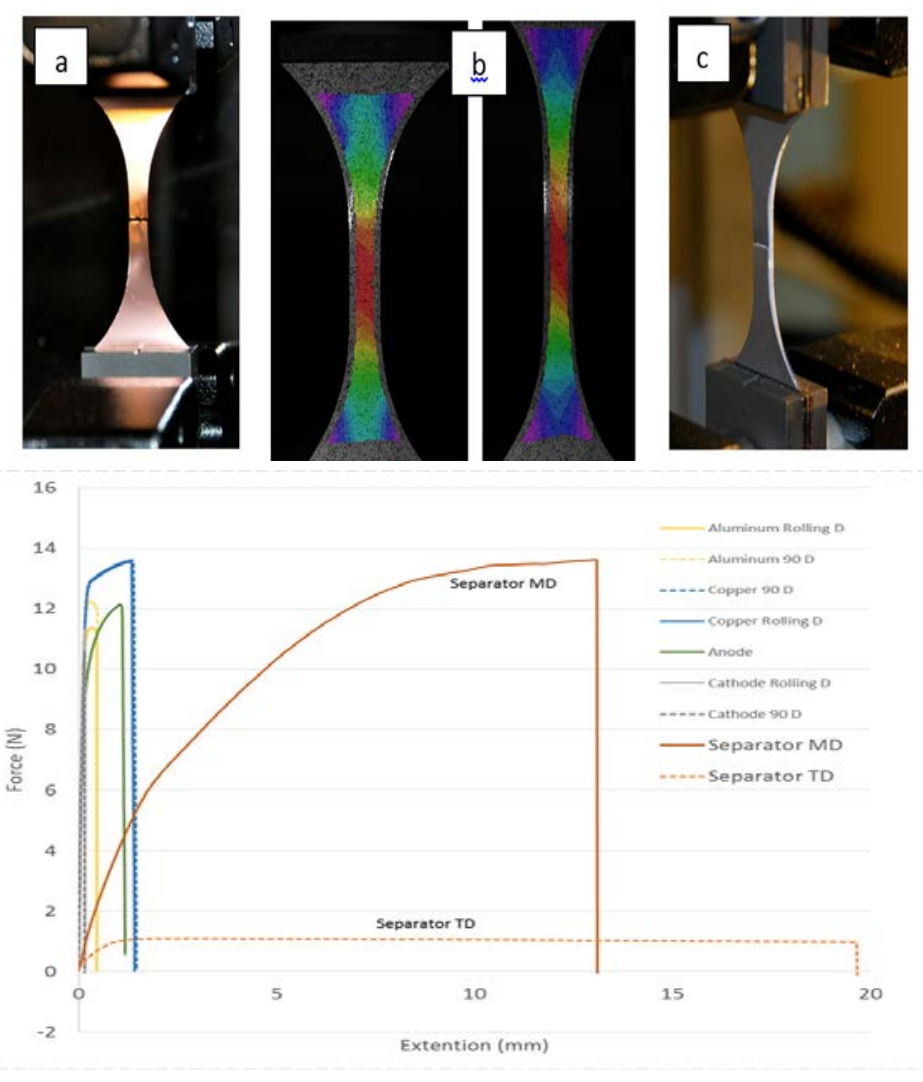

Figure 3: Experimental measurement of material properties

\section{Electrical-Thermal Model}

For the coupled simulations, a constant voltage of $3.7 \mathrm{~V}$ is applied between the top and bottom surfaces of the RS. The evolution of the voltage after the initiation of a short circuit is studied by calculating the internal voltage drop caused by the sudden decrease in resistance due to the short circuit. For thermal simulations, a default adiabatic boundary condition is used for the symmetrical surfaces $(x=0, y=0)$. For the other four external surfaces $(x=-w, y=-l, z=0$, and $z=h$ ), a convection boundary condition is defined to model the heat exchange between the surroundings and the battery cell: 


$$
q=k_{i j} \frac{\partial T}{\partial x_{j}}=h\left(T-T_{\infty}\right)
$$

where $q$ is the heat transferred per unit time and per unit area; $h$ is the heat transfer coefficient, which in this work is defined as $15 \mathrm{~W} /\left(\mathrm{m}^{2} \cdot \mathrm{K}\right)$; and $T_{\infty}$ is the temperature of the surroundings, which is considered constant at $298 \mathrm{~K}$. An initial temperature of $298 \mathrm{~K}$ is applied to all the elements.

\section{Mechanical and Electrical-Thermal Failure Criterion}

The objective of this work is to predict the structure fracture-induced electrical short circuit of Li-ion batteries LIB under quasi-static indentation. Proper failure criteria and failure parameters should be implemented and defined to enable this capability. We used a maximum volume-strain failure criterion earlier to simulate the mechanical failure of the separator, and we carried out a parametric study on the maximum through-thickness volume-strain value of the separators using the single-RS model and found that when the failure strain equals 0.93 (which means that the thickness of the element is compressed to $7 \%$ of the initial thickness), the numerically predicted and the experimentally measured global failure strains match. In this work, the maximum tensile failure criterion was implemented using the Honeycomb Model was utilized to simulate separator failure. The tensile failure strain of the separator varies a lot depending on the polymer component, manufacturing process, and specimen preparation.

We first conducted a mechanical-only simulation to correlate the mechanical indentation test results and recorded the critical global displacement, $u_{f}$, of the indenter at the moment of the cell fracture. Then we conducted the coupled simulation by applying exactly the amount of critical displacement, $u_{f}$, to the indenter and disabling mechanical failure criterion. Through this method we can obtain exactly the same deformed geometry at the instant of the cell fracture. The electrical contact is defined by a distance-based criterion, which means that the electrical contact initiates when the distance between two parts is below a certain threshold value, $d_{c}$. Once the mechanical failure criterion is satisfied, no more loading was added, which corresponds to the test case in that the indenter will be held in place without further movement. No further deformation or relaxation occurred inside the pouch cell beyond the instant of the mechanical failure.

While existing models assume initiation of electrical contact following the mechanical failure of the separator layer, our approach calculates the current flow across the component layers that border the element subjected to the mechanical failure and utilizes the resultant voltage drop to determine the short resistance. This process allows us to introduce additional failure criteria based on the electrical and thermal properties of the different layers coming into contact across the instance of the mechanical failure. For instance, in this work, the criterion for the electrical failure is the instantaneous local current density exceeding a preset value, such as $0.01 \mathrm{C}$, which corresponds to a current density of $13.12 \mathrm{~mA} / \mathrm{mm}^{2}$ for a $740-\mathrm{mAh}$ cell when the area of the elements subject to mechanical failure is $0.785 \mathrm{~mm}^{2}$. Thermal failure is set to initiate when the temperature across the element in question exceeds the melting point of the corresponding material (e.g., $144^{\circ} \mathrm{C}$ or $417 \mathrm{~K}$ for the separator). However, mechanical failure sets in instantaneously compared to the thermal response, which is usually distributed throughout a span of several seconds. Accordingly, in this work we present our methodology for linking the mechanical-failure criterion to the follow-on electrical activity and discuss some preliminary thermal responses.

The numerical models were solved on a high-performance computing system equipped with a total of 31,104 Intel Xeon processors providing a total of approximately 608 TeraFLOPS or trillion floating-point calculations per second. The computational time for the mechanical-only simulation is 8 hours using 60 CPUs (central processing units), while the computational time for the coupled model was 16 hours, also using 60 CPUs.

\section{RESULTS}

An efficient mechanical modeling strategy was established with the capability to predict the onset of the mechanical fracture and enable the coupled modeling of the electrical and thermal behavior. The mechanical model was validated through comparison of the numerically predicted and experimentally measured force and 
global-strain curves (see Figure 4). Utilizing the constitutive and failure models described in the previous section, the mechanical responses of the cell subjected to the indentation using the spherical indenters of three different diameters $(12.7 \mathrm{~mm}, 28.575 \mathrm{~mm}$, and $44.45 \mathrm{~mm}$ named small punch, medium punch, and large punch, respectively) were simulated. Experimental indentation tests corresponding to these results on the pouch cell described above were conducted by MIT using the hemispherical punches at a loading rate of 1 $\mathrm{mm} /$ minute while monitoring the voltage simultaneously. A significant finding of the experimental results was the fact that the electrical short circuit detected from the drop in cell voltage coincided well with the drop in the load due to the mechanical failure.

\section{Coupled Mechanical-Electrical-Thermal Simulation}

In our work the global strain is defined as the applied displacement of the rigid sphere over the initial thickness of the RS model. The force is recorded as the reaction force of the rigid sphere in the through-thickness direction (z-direction). The maximum tensile failure strain of the separator is obtained through a parametric study comparing the numerical predicted force-strain curves to the experimental curves. Figure 4(a) shows the parametric study of the mechanical responses for the small-punch indentation test obtained by varying the tensile failure strain of the separator. It is found that the numerically predicted global failure strain of the battery cell increases with the increase of the tensile failure strain for the separator layer. When the tensile failure strain of the separator equals 0.29 , the numerical predicted and the experimentally measured global failure strain match.

Note that the failure strain value used for the indentation model is much lower than the experimental measured value in a uniaxial tensile test. This is because under a structure-level test some other local premature damage events - for example, cracking of electrodes - may cause earlier failure of the separator. The strain contour of the active materials at the instant before the fracture of the battery cell is shown in Figure 4(a), from which we can see that the maximum tensile strain value of the active materials is about 0.2487 , exceeding the experimental detected tensile failure strain of 0.03 . This suggests that before the failure of the separator, the active material layers were very likely cracked.

The failure shape of the separator layer is also shown in Figure 4(a). The crack initiated at exactly the center of the structure $(x=y=0$, Figure 2(b)) and propagated along the y-direction (machine direction). The cracking behavior is consistent with the characterized fracture image using X-ray CT scanning, which is likely due to the anisotropic feature of the separator and the in-plane aspect ratio (length/width). The successful prediction of the cracking behavior further elaborates the significance of the presented single-RS model.

Figure 4(b) presents a comparison of the numerical and experimental results for the indentation tests using punches of three different diameters. The single-RS model predicts well the force-strain responses under all three indentation conditions, showing the suitability of the material models presented here in capturing the mechanical response of the pouch cell components and the viability of using the single-RS model to predict the global mechanical response of the full pouch cell. The latter observation is important when scaling these models to simulate the response of the multi-cell modules or battery packs. The single-RS model is capable of predicting the onset of failure within the pouch cell under indentation, and it enables a lumped representation of the cell with the ability to incorporate the mechanical properties of the individual cell components.

Note that the onset of the cell fracture under different indentation conditions is predicted through parametric studies of tensile failure strain for the separator layer, shown in Figure 4(a). The parametric study results in different tensile failure strain values for the three indentation conditions, which are 0.29 for the small punch, 0.17 for the medium punch, and 0.15 for the large punch. This is because the tensile strain of the separator is related to the indenter diameter. A smaller indenter produces a sharp deformation and results in a relatively higher maximum tensile strain for the same indentation depth.

In the previous section, the single-RS model presented was correlated to the experimental results to predict the mechanical response and the onset of the structure fracture. The correlated models were then applied to simulate the mechanical-electrical-thermal responses of the battery cell during the indentation tests by incorporating the electrical-thermal model described earlier. 


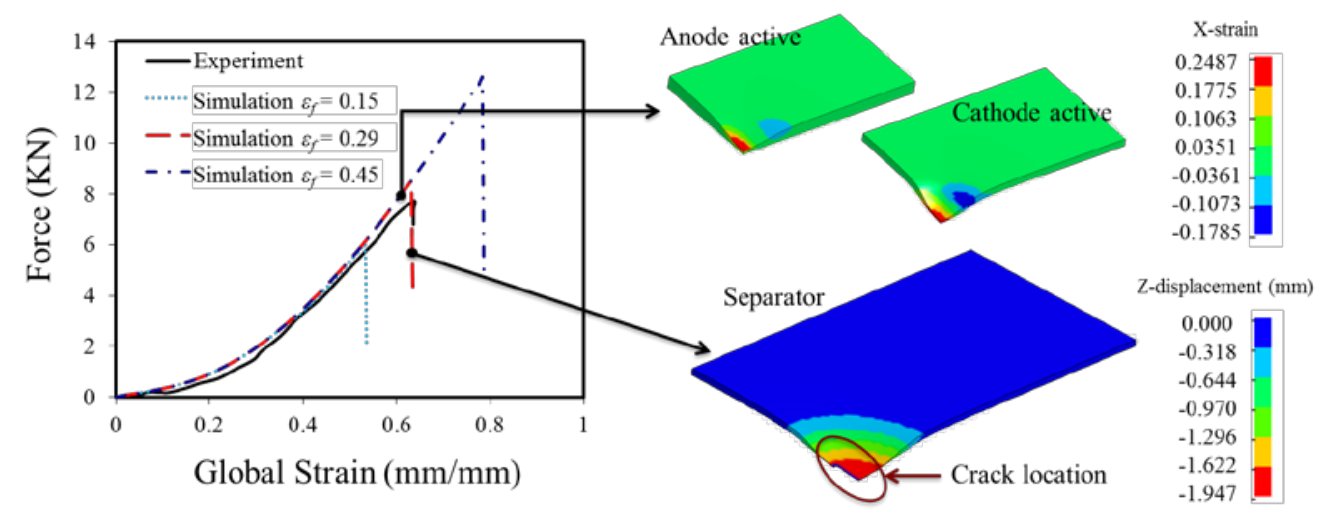

(a)

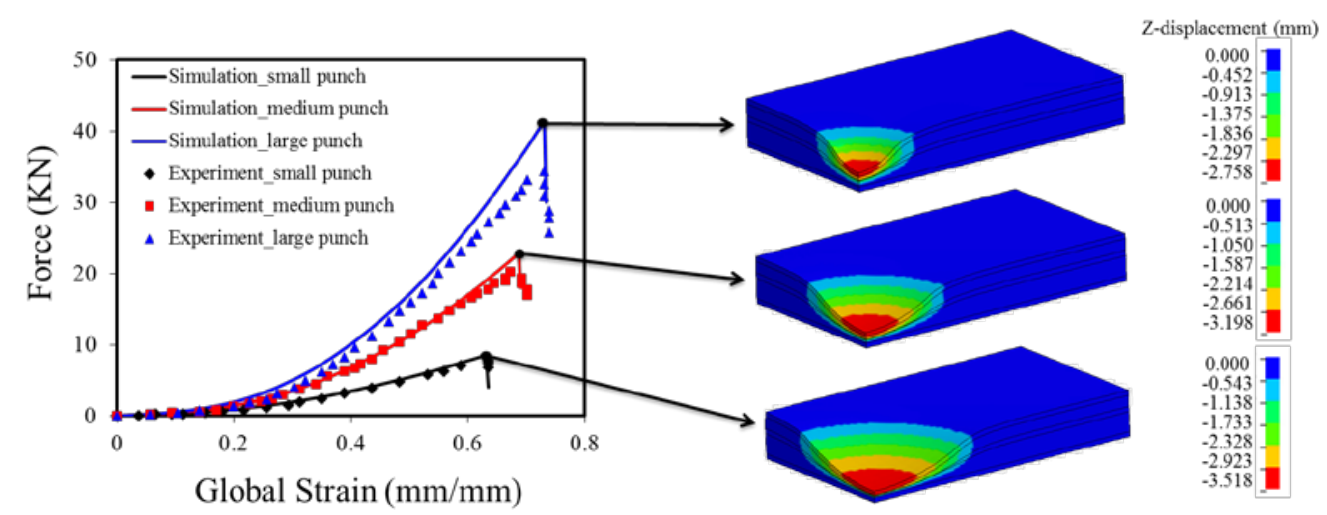

(b)

Figure 4: (a) Correlation of numerically predicted and experimentally measured force-strain curves for the small-punch indentation test and numerically predicted deformation of the separator and active materials at the instant of the cell fracture. The crack in the separator layer propagates along the y-direction, consistent with the experimental observation. (b) Comparison of the numerically predicted and experimentally measured force-strain responses for three different indentation tests and the numerically predicted deformation of the battery cell at the instant of the cell fracture. With an increase in indenter diameter, the maximum indentation depth at the moment of the fracture increases, indicating that the larger-punch test results in a delayed failure of the cell. 


\section{Prediction of Electrical Short Circuit}

One main focus of this work is to predict the onset of the electrical short circuit during a mechanical crush. For

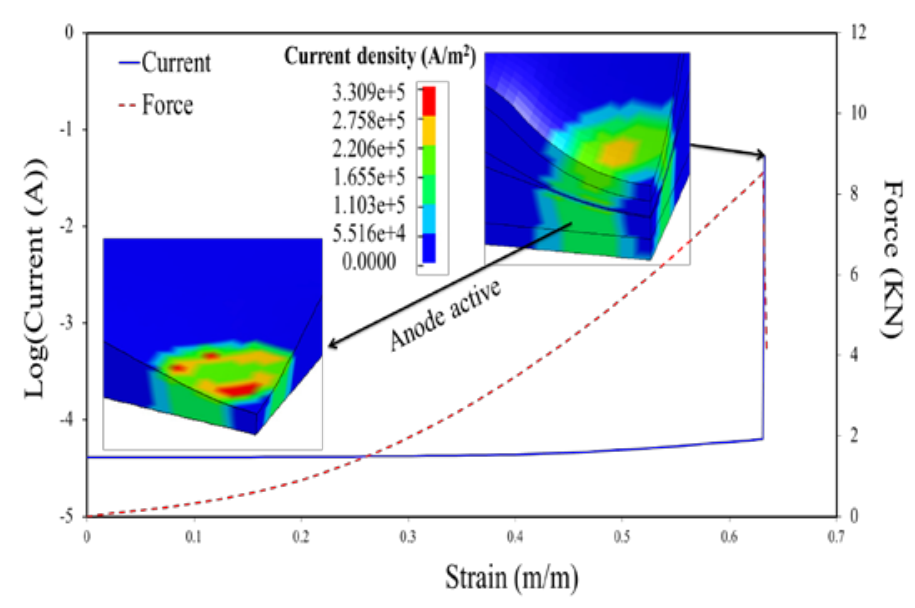

(a)

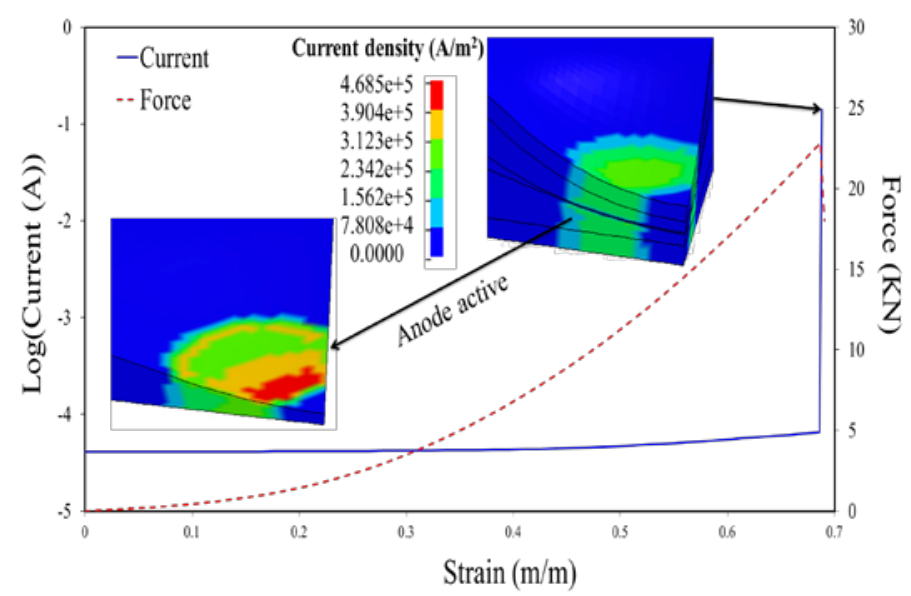

(b)

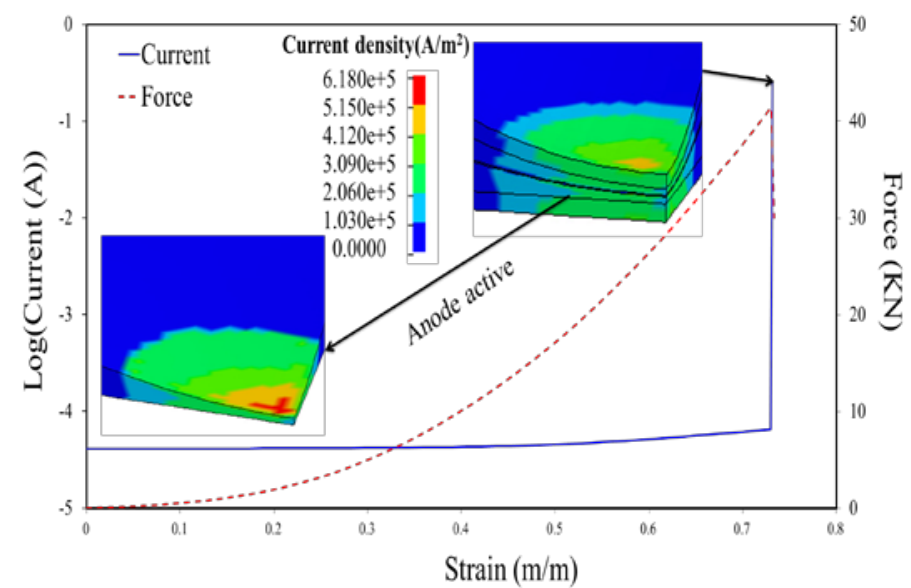

(c) the simultaneous coupled mechanicalelectrical-thermal model, the distance-based criterion is utilized for the electrical contact initiation. Figure 4(b) shows the overall displacement contour of the battery cell at the moment of the fracture, from which we identified that the maximum throughthickness displacement of the battery cell (loading distance of the indenter) is 2.758 $\mathrm{mm}, 3.198 \mathrm{~mm}$, and $3.517 \mathrm{~mm}$ for the three indentation conditions. To predict the electrical short circuit, we assume the indenter stops moving once the structure fails, which means that there will be no further deformation after the mechanical failure of the battery cell. The critical distance, $d_{c}$, of the electrical short circuit of the LS-DYNA model is taken as the minimum thickness of the separator at the instant of the cell fracture (contour plots of Figure 4(b)). Based on the electrical failure criteria, a current larger than $0.0074 \mathrm{~A}(0.01$ C) will be sufficient to create a short circuit in the cell. The battery cell is considered electrically failed based on the detected current value at the moment of the cell fracture. Figure 5 shows the evolution of the current across the electrical contact area for the three different indentation tests. All three cases show the same electrical behavior during the test: there is a small increase in the current before the onset of the short circuit due to the thickness decreasing the induced decrease of the electrical resistance; a sharp increase in the current is detected at the moment of the failure due to the initiation of the short circuit, which corresponds to the current density contour plot for the peak point (cell fracture and electrical failure). Note that the maximum concentration of the current density occurs in the anode active layer due to its relatively higher conductivity than the cathode active material.

Figure 5: Evolution of average current (A) across the active material before and after short circuit at the electrical contact area, and isotropic-view of the current density $(\mathrm{A} / \mathrm{m} 2)$ distribution in the battery cell for the three different indentation tests: (a) small punch, (b) medium punch and (c) large punch. 
Comparing the three different indentation tests, we found that there is an increase of the short-circuit area with the increase of indenter size, which is consistent with the mechanical deformation distribution (Figure 4(b)) and illustrated in the current density contour plots (Figure 5) wherein the current density concentration area is larger for the indentation test with a larger indenter. The electrical contact area has a significant impact on the short-circuit behavior. The current at the moment of the short will be larger due to the relatively lower short resistance when there is a larger electrical contact area. This will then result in a faster voltage drop and a lower local maximum temperature. Note that the short-circuit behavior depends also on the electrical conductivities of the materials in contact.

\section{Prediction of Thermal Ramp After Short Circuit}

Understanding the voltage evolution behavior after the short circuit is of great significance, both for designing a safer battery as well as for the design of post-event containment measures. With the initiation of electrical contact, the voltage and resistance of the cell structure drops to very small values. Simultaneously, there is an evolution of the local cell temperature at the location of the short circuit. For the same cathode-anode short, as expected, the simulated voltage drop for the large-punch indentation test (largest electrical contact area) is faster than the other two tests. This result, when extrapolated, is useful in explaining why short circuits involving very small contact areas do not result in a thermal runaway. The voltage drop is so slow that any heat generated from such shorts is dissipated before a sufficient temperature rise can result in a runaway. On the other hand, when the contact area is exceedingly large, the energy content of the small format cell is released within milliseconds before the current density can rise to sufficiently large values to generate any heat; in contrast, a large-format cell will continue to have sufficient energy available across the same timescale and will generate sufficient heat to result in the follow-on reactions. The predicted temperature ramp is similar to the experimentally observed results reported by MIT. The change in the maximum surface temperature also matches the experimental results ( $10 \mathrm{~K}$ for the small-punch test, $50 \mathrm{~K}$ for the medium-punch test, and $40 \mathrm{~K}$ for the large punch) in a reasonable manner. In the experiments, the medium-punch test produces a higher temperature rise than the large punch test, which is likely due to the variation of the contact area at the moment of the short. At the moment of structural failure, the local deformation or damage event (e.g., cracking, fracture) is a very rapid process, which will result in significantly different contact areas at the instant of the short circuit. For the instant of the short circuit, a large contact area will produce a higher short-circuit current, a faster voltage drop, and a higher local temperature rise.

\section{CONCLUSIONS AND FUTURE DIRECTIONS}

In collaboration with ANSYS and MIT, we developed a coupled mechanical-electrical-thermal model for predicting the mechanical-abuse-induced short-circuit behavior of Li-ion cells under different indentation test conditions. A Representative Sandwich model was used to enhance its accuracy in predicting the short-circuit location and temperature rise as well as to be compatible with the mechanical-electrical-thermal solvers.

The mechanical model successfully predicts the onset of the structure fracture and captures the local cracking behavior of the LIB under three different indentation conditions. The simultaneous coupled model accurately predicts the initiation of the short circuit due to the structural fracture and post-short thermal and electric responses through using distance-based electrical contact criteria. It is identified that the maximum current density located in the anode active material and a larger indenter size creates a larger electrical contact area.

The simultaneously coupled modeling technique is useful in studying the safety behavior of Li-ion cells under mechanical abuse, especially when studying the interaction of the mechanical failure and short-circuit behavior. It is a helpful tool for evaluating the safety performance of a battery cell and designing more efficient and safer battery structures. Future work will focus on investigating more complicated crush conditions (multiaxial crush, impact, and battery module crush, etc.). Implementation of a methodology to transfer the mechanical simulation results to the battery models built in ANSYS Fluent are underway. 


\section{FY 2015 PUBLICATIONS/PRESENTATIONS}

1. "Coupled Mechanical-Electrochemical-Thermal Modeling For Accelerated Design of EV Batteries," A. Pesaran, G-H. Kim, S. Santhanagopalan, $28^{\text {th }}$ Electric Vehicle Symposium, May 2015, Kintex, Korea.

2. "Coupled Mechanical-Electrical-Thermal Modeling for Lithium-ion Batteries," C. Zhang, S. Santhanagopalan, M. Sprague, A. Pesaran, Journal of Power Sources, Vol. 290, p. 102-113, 2015.

3. "Damage of Cells and Battery Packs Due to Ground Impact," Sahraei et al., Journal of Power Sources, Vol. 267, p. 78-97, 2014.

4. "Mechanical Electrochemical Thermal Simulation of Lithium Ion Batteries Subjected to Crush," Pesaran et al., DOE VTO Annual Merit Review, Washington, D.C., June 9, 2015.

5. "A Representative Sandwich Model for Coupled Mechanical-Electrical-Thermal Simulation of Lithium-ion Battery Cell Under Quasi-Static Indentation Tests," C. Zhang, S. Santhanagopalan, M. Sprague, A. Pesaran, Journal of Power Sources, Vol. 298, p. 309-321, 2015.

6. "Modeling of Cracks Developed in Lithium-ion Cells Under Mechanical Loading," Sahraei et al., RSC Advances, Vol. 5, p. 80369-80380, 2015. 


\title{
Significant Enhancement of Computational Efficiency in Nonlinear Multiscale Battery Model for Computer-Aided Engineering
}

\section{OBJECTIVES}

- The objective of the project is to develop a computational methodology for a significant enhancement in computation speed of nonlinear multiscale modeling of plug-in electric vehicle (PEV) batteries while maintaining or improving the solution accuracy from the most advanced state-of-the art models.

\section{TECHNICAL BARRIERS}

- Lack of high-fidelity, fast-running battery simulation tools for battery design studies for PEVs.

- The inevitable nested iterations, ensuring selfconsistency in the state-of-the-art multiscale multidomain (MSMD) model, become a factor limiting further improvement of computation speed.

\author{
Brian Cunningham (DOE Program Manager) \\ DOE Agreement \# 27042 Recipient: \\ National Renewable Energy Laboratory \\ Gi-Heon Kim (NREL - PI) \\ 15013 Denver West Parkway, M/S 1633 \\ Golden, CO 80401 \\ P 303-275-4437 | F 303-275-4415 \\ Email: gi-heon.kim@nrel.gov
}

Subcontractors:

ANSYS

Start Date: October 2013

Projected End Date: December 2015

- A traditional multiphysics approach, collapsing scales into a single, large, differential algebraic equation system, renders the system impractically large and stiff, sacrificing modularity.

- As soon as the reduced-order-model (ROM) basis is acquired in a reduced dimension space, physical interpretations are easily lost. The ROM basis is restricted to reuse in the system where its characteristics are evolving, such as battery aging.

- The ROM build process becomes computationally costly, with an increased number of parameters.

- Most state-of-the-art battery ROMs addressed coupling battery physics only within limited scales.

- The state-of-the-art ROMs suggested for battery models lose validity when severe nonlinearities arise.

- The model applicability can be limited for varied design, environment, and operation conditions.

\section{TECHNICAL TARGETS}

- Develop very fast, accurate electrochemical-thermal models for accelerating development of PEV batteries

- Improve computation speed of state-of-the-art nonlinear multiscale battery model by a factor of 100 while maintaining its solution accuracy

- Develop a new multiscale coupling method using time-scale separation and variable decomposition to eliminate several layers of nested iteration while still keeping the modular framework architecture that is critical to battery behavior simulations

- Establish a new technique to identify a low-order state variable model (SVM) that is adaptive to system evolution

- Construct an application programming interface for multiphysics integration of NREL's custom model library in a commercial software environment. 


\section{ACCOMPLISHMENTS}

- Developed GH-MSMD, a new quasi-explicit, modular, extendable, tightly coupled, nonlinear framework in both the $\mathrm{C}++$ and MATLAB platforms

- Demonstrated that the new GH-MSMD speeds up computations by 1,000 times

- Demonstrated implementation of GH-MSMD cell-domain model (CDM) in ANSYS/Fluent

- Built a custom graphical user interface (GUI) in ANSYS/Fluent for GH-MSMD simulation preprocessing

- Compared options for an adaptive time-stepping algorithm in GH-MSMD versus the existing recursive method

- Constructed the MSMD standard input file structure, facilitating its multiscale simulation

- Refined the numerical method for the final version of the adaptive SVM (A-SVM) model

- Validated and benchmarked A-SVM against other electrode domain model (EDM) MSMD models in MATLAB

- Demonstrated that the A-SVM achieved 50x speed-up with accuracy better than $15 \mathrm{mV}$

- Developed a new time-domain ROM, Error-corrected Time-domain Series solution (ETS) for the solid-phase diffusion equation

- Evaluated the computational speed and the solution accuracy of the ETS

- Performed the first demonstration of wall-clock speed-up for POD/DEIM method for prototype electrolyte equation

- Initiated the MSMD integration with vehicle simulator software.

\section{INTRODUCTION}

NREL pioneered the multiscale multidomain (MSMD) model, overcoming challenges in modeling the highly nonlinear multiscale response of battery systems. The MSMD provides high extent flexibility and multiphysics expandability through its modularized architecture, as well as computational efficiency. However, further improvement of computational speed of the model is greatly desired to promote the application of the high fidelity multiphysics model in various battery engineering problems. In this project, we significantly improve the computation speed and stability of multiscale model framework by eliminating several layers of nested iteration through innovative multiscale coupling methodology, while still keeping the modular framework architecture, and provide a new reduced order model (ROM) that is adaptive to system evolution and identifiable with fewer compound parameters.

\section{APPROACH}

Framework \& Component: The project target is achieved through complementary parallel efforts in framework efficiency improvement and component efficiency improvement. We developed a new quasi-explicit nonlinear multiscale model framework, GH-MSMD, using time-scale separation, variable decomposition, and partial linearization procedures (Figure 1). GH-MSMD eliminates several layers of nested iteration, significantly improve the speed and stability upon the original MSMD, and retain the modular framework architecture that is critical to battery behavior simulations. We also develop advanced ROMs for the component models. Computational time is often invested in advance to find a reduced order basis in a much lower dimension than that of the full ordinary differential equation systems derived from spatial discretization of the partial differential equation systems. The ROM basis is typically restricted to reuse in the system where its characteristics are evolving, such as the battery aging process. In this project, we developed the A-SVM, a new ROM that adapts to system evolution and identifiable with fewer compound parameters. For enhancing usability of the model, we constructed the MSMD-Fluent application programming interface for multiphysics integration of NREL's custom model library in a commercial software environment - ANSYS/Fluent. 


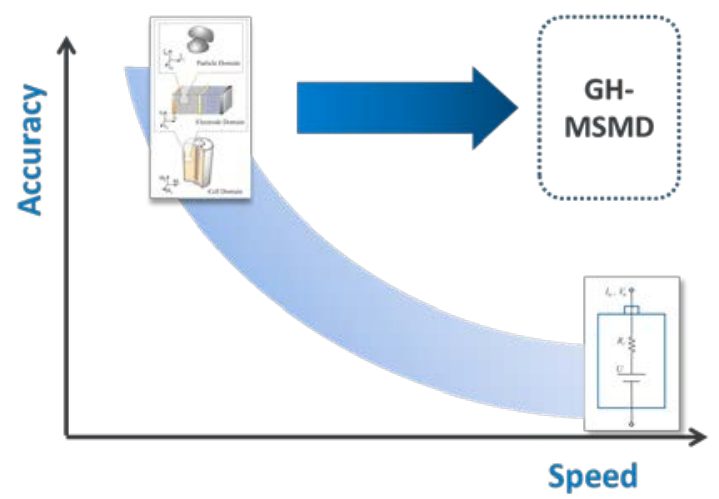

Figure 4: GH-MSMD significantly improves the computational speed of nonlinear multiscale battery model without compromising accuracy

\section{RESULTS}

We have achieved the following progress:

\section{New Model Speeds Up Computations by 1,000 times}

Last year, NREL met the 100-fold computational speed-enhancement target for its multiscale multiphysics battery model (MSMD) one year ahead of schedule. In FY15, we significantly exceeded the projected target by further improving the code structure and by extending the model to a larger scale. Figure 2 presents the comparison of the electrical and thermal response of a battery for a mid-size sedan plug-in hybrid electric vehicle (PHEV10) on the US06 20-minute driving power profile. While the model outputs are shown to be very close to each other, the new quasi-explicit, modular, extendable, tightly coupled, nonlinear MSMD framework, GH-MSMD, demonstrates that the most efficient electrode-scale battery-cell model option can run a 1,200-second driving profile simulation in only 0.74 seconds using a personal computer - an approximate 1,000 -fold improvement over previous capabilities. In contrast, the original MSMD runs the same simulation in 654 seconds. When the model is extended to its full-scale, three-dimensional, larger cell domain, the speedenhancement factor reaches 1,000 to 10,000 , depending on the choice of sub-model.
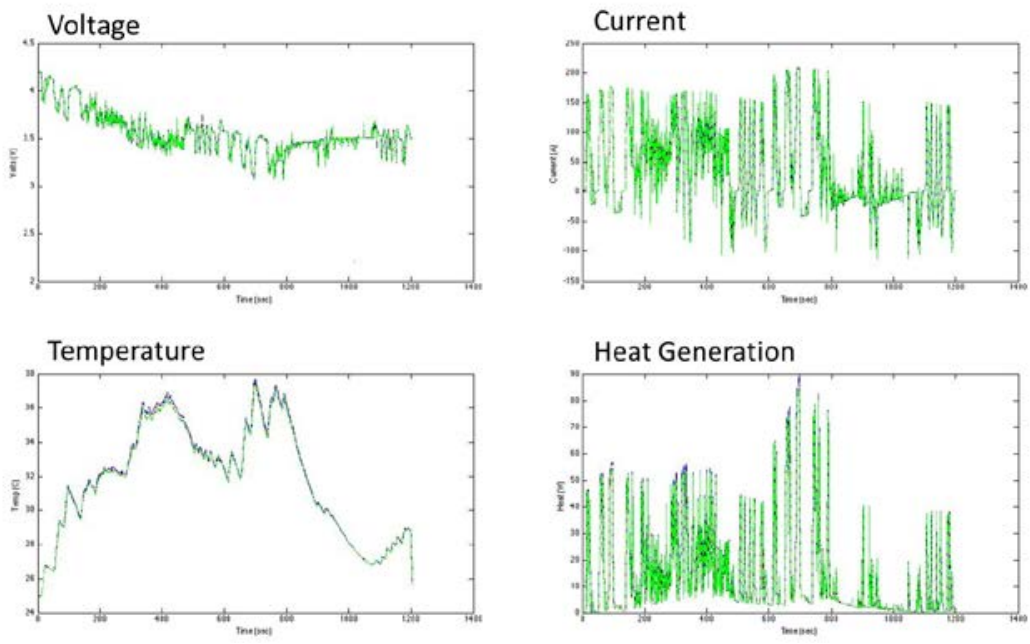

Figure 5: Comparison of electrical and thermal response of a battery for a mid-size sedan plug-in hybrid electric vehicle (PHEV10) on the US06 20-minute driving power profile from the GH-MSMD and the original MSMD

Enhancement of Computational Efficiency in Nonlinear Multiscale Battery Model for Computer-Aided Engineering (Kim - NREL)54 
Figure 3 compares the model solution variables in each computational domain and the coupling variables exchanged between the adjacent length scale domains in MSMD (left) and in GH-MSMD (right). Even though the solution algorithms are significantly different between the two, the model structures are similar. This comparison signifies the modularity of model framework that the GH-MSMD inherited from the MSMD. The new GH-MSMD framework retains the flexibility needed for application to various lithium battery chemistries and designs. It still integrates a sophisticated particle model to address particulate morphology, size distribution, surface modification, contact resistances, and mixture composition of active particles. The model simulates all major cell form factors with variable electrode compositions and designs.
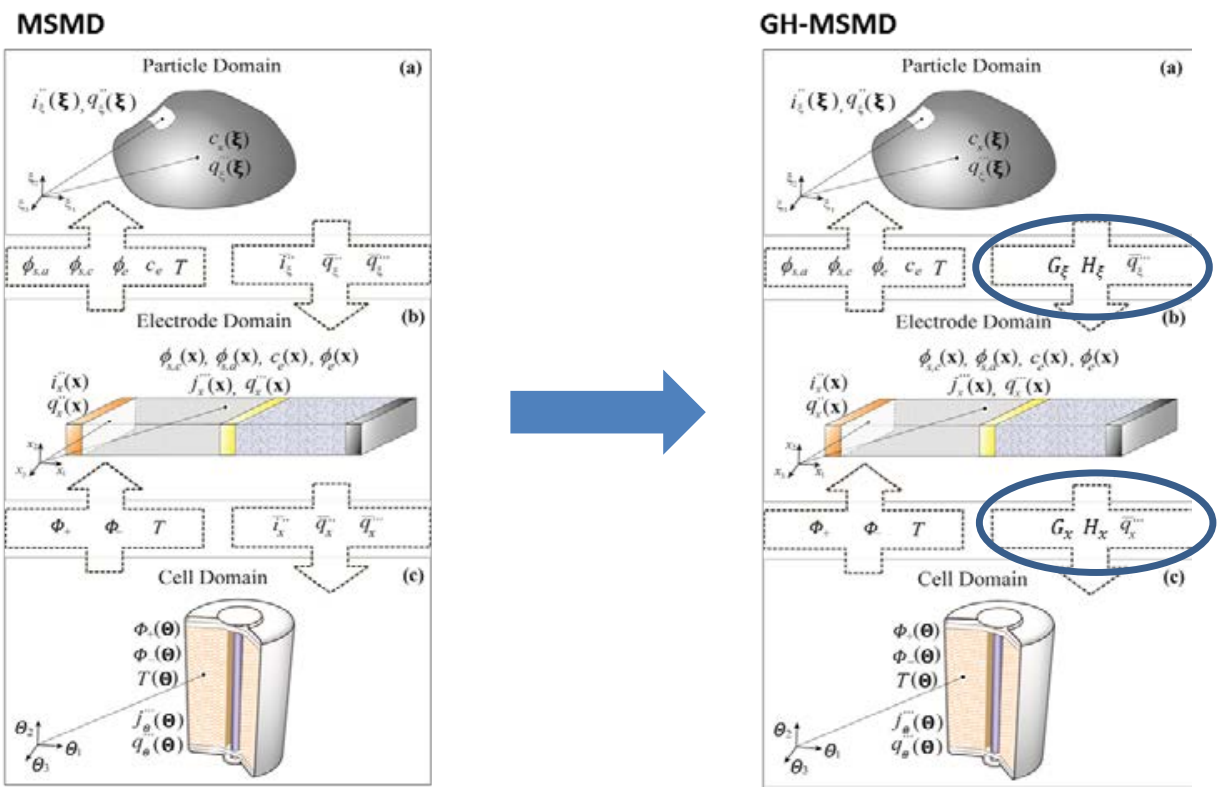

Figure 6: Comparison of the original MSMD and the GH-MSMD framework structure and main changes in the GH-MSMD

\section{Reduced Order Electrochemical Model Becomes Adaptive}

NREL developed an accurate, computationally efficient realization of the Newman electrochemical model that runs 100 to 1,000 times faster than typical numerical solutions in modern commercial software. Although spectral model order-reduction techniques are available to achieve speed enhancement, previous efforts that applied these methods to the Newman model required a cumbersome preprocessing step to identify a model versus a few selected parameters of interest. To overcome this limitation, NREL eliminated the preprocessing step so that a simulation could run immediately, and NREL fully populated the ROM so that it is extendable to all possible lithium-ion porous electrode designs and states of health. This achievement will enable the rapid optimization of lithium-ion cell chemistries and the use of the model for aging studies. The new A-SVM was validated and benchmarked against other EDM MSMD models (two MSMD-EDMs and two GH-MSMDEDMs) in MATLAB. The compared MSMD EDM combinations are edLPD/pdPLLM, edPLM/edLPD, edSEG/pdPLM, and edSEG/pdSEG. Figure 4 presents the model output comparisons for a $5 \mathrm{C}$ and 10C pulse profile and constant current discharge in 1,2,5, and 10C. Accuracy is generally greater than $99 \%$, and the speed-up factor of A-SVM against the highest-order segregated solver option is about 50 . The unconditional stability of A-SVM enables a large time-step size, and additional speed-up is expected in practical situations. A-SVM shares the common input and output file structure with the MSMD/GH-MSMD.

Enhancement of Computational Efficiency in Nonlinear Multiscale Battery Model for Computer-Aided Engineering (Kim - NREL)55 
Pulse: $5 C,-5 C, 10 C,-10 C$

Constant Current Discharge: 1,2,5,10C
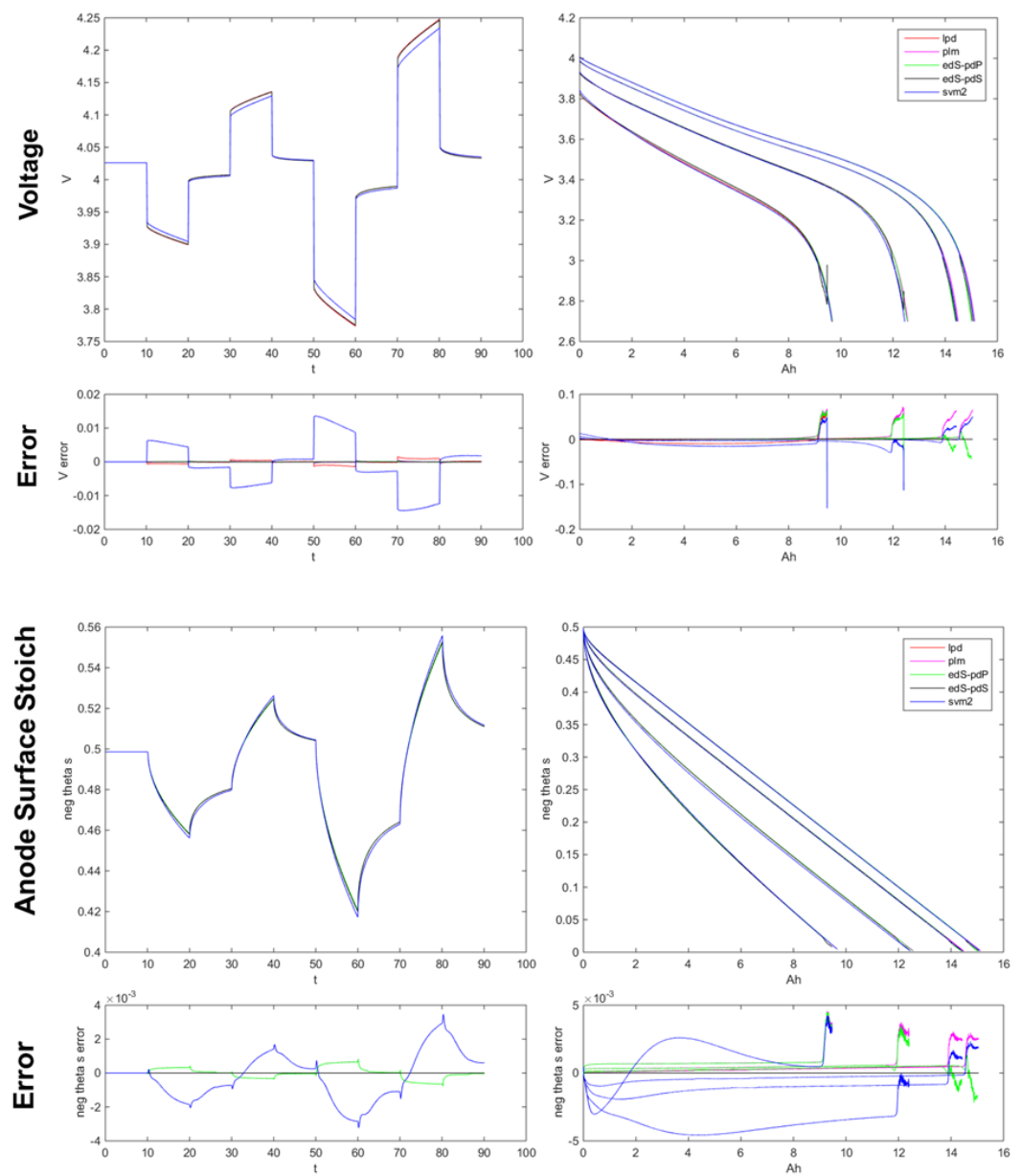

Figure 7 A-SVM verification and benchmark results against various MSMD/GH-MSMD models

\section{Efforts To Promote Industry Access to New Models}

The successful development of GH-MSMD is expected to shift the paradigm in using a model for electricdrive vehicle battery system design and evaluation, potentially revolutionizing the standard development process for the entire industry. NREL's GH-MSMD baseline model codes are developed in both the MATLAB and $\mathrm{C}++$ platforms. These NREL custom models are planned to be available to external users in the future. In the meantime, it is desired to implement GH-MSMD in commercial computer-aided engineering software to make it available immediately to a large number of users in the electric vehicle industry. In this regard, NREL developed a manual procedure for GH-MSMD implementation in ANSYS Fluent and built a GUI using scheme programing and the user codes. Figure 5 is a captured image of NREL's custom GUI of GH-MSMD. The current GUI is similar to that in the ANSYS/Fluent MSMD Battery Module. The customized GUI enables us to practice and test GH-MSMD implementation into Fluent. Unique features could be added for the GHMSMD methodology to link different domain levels and improve simulation efficiency. NREL's implementation of the GH-MSMD CDM in Fluent has been verified by comparing the model outputs against the commercially available and existing MSMD model option in Fluent. The results are shown in Figure 6. 

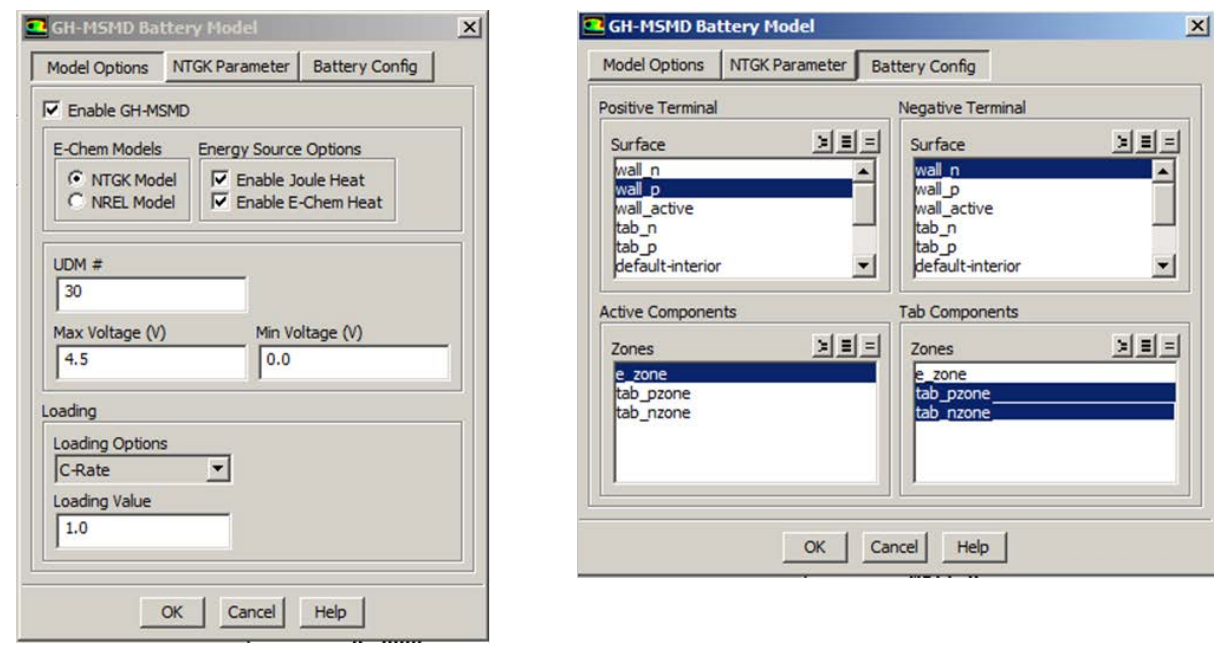

Figure 8: Custom GUI of GH-MSMD set up in ANSYS/Fluent
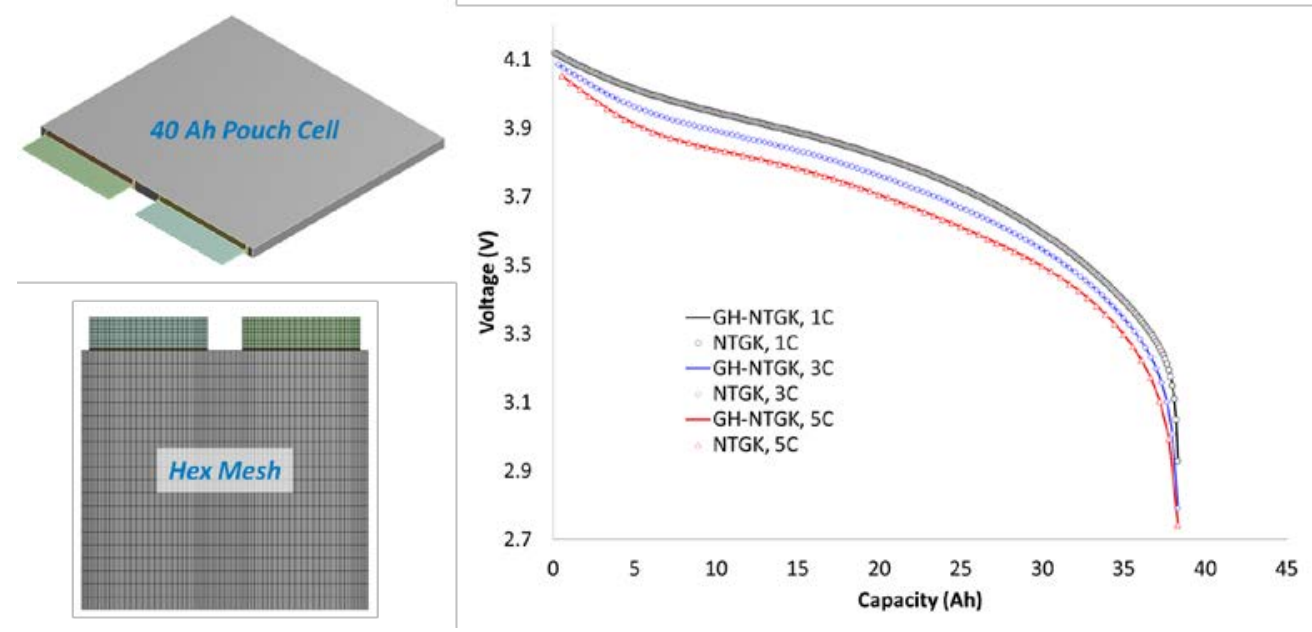

Figure 9: NREL's custom implementation of GH-MSMD in Fluent is verified. Solid lines are the cell voltage response of NREL custom GH-MSMD model simulations, and the symbols are corresponding outputs from the Fluent MSMD Battery Simulation Module.

\section{CONCLUSIONS AND FUTURE DIRECTIONS}

We successfully accomplished the project goal and improved the computation speed of state-of-the-art nonlinear multiscale battery model by a factor of 100 while maintaining its solution accuracy. The new GHMSMD demonstrates a 1,000-fold speed up compared with the original MSMD during vehicle driving profile benchmark simulation tests. The remaining challenges and the future directions that we expect to address in the third phase of the CAEBAT project are identified below.

\section{Remaining Challenges}

- GH-MSMD demonstrates significant speed up. The remaining challenge, however, is to enhance the applicability of the new model to various battery engineering problems. 
- To address varied problems in the industry, interdisciplinary constituent models relating material/ design/ process/ operational parameters with physicochemical parameters of the GH- baseline models are needed.

- Electrochemical Impedance Spectroscopy is one of the frequently used methods for battery characterization and diagnostics. Since the current GH-MSMD has been developed in time-domain, it is difficult to utilize the information produced in frequency domain.

- The modular architecture of GH-MSMD facilitates participation of external expertise across the battery community. Independently developed submodels can be plugged in the framework to extend the simulation capability. However, unlike the original MSMD, the GH-MSMD protocol is not intuitively understandable.

- Identification of a physics-based battery model is known to be difficult. This anticipated difficulty for development of a physics-based constituent model comes from the fact that characterization of a battery is intrinsically solving an under-determined problem.

\section{Future Direction}

- There have been strong needs in the industry to use purely predictive physics-based models for design, evaluation, and control of batteries and systems. In the pursuit of providing such models, we will develop physics-based interdisciplinary constituent models working in the GH-MSMD framework.

- A frequency-domain GH-MSMD model will be developed from the identical governing equation sets used in the time-domain model, running with the standard input files.

- We will summarize the GH-MSMD principles and implementation and publicize them to encourage contributions from outside experts.

- We will develop sequential optimization procedures to break the under-determined parameter estimation problem of the whole system into a sequence of fully determined fits to subsets of the parameters and advanced model-based battery characterization.

\section{FY 2015 PUBLICATIONS/PRESENTATIONS}

- G.-H. Kim et al., "Significant Enhancement of Computational Efficiency in Nonlinear Multiscale Battery Model for Computer Aided Engineering,” DOE Annual Merit Review, June, 2015, Washington DC.

- Annual Milestone Reports, September 2015.

- G.-H. Kim, C. Yang, A. Pesaran, "Integrated Multiscale Multiphysics Modeling of Dynamic Short Circuit Behavior in Large Lithium-ion Batteries," $228^{\text {th }}$ Electrochemical Society Meeting, October, 2015, Phoenix, AZ.

- C. Yang, G.-H. Kim, M. Keyser, A. Pesaran, "Numerically Characterizing Nail Penetration Testing for Safety Evaluation of Li-Ion Cells," $228^{\text {th }}$ Electrochemical Society Meeting, October, 2015, Phoenix, AZ. 


\section{Crash Propagation in Automotive Batteries: Simulations and Validation}

\section{OBJECTIVE}

- The objective of this work is to build simulation tools with adequate fidelity on commercial software platforms that the industry can use to simulate the electrical, thermal, and mechanical responses of a lithiumion battery subjected to a sudden mechanical impact, such as a crash, focusing largely on the module- to pack-level phenomena.

\section{TECHNICAL BARRIERS}

- Concerns regarding potential thermal event by lithium ion batteries in today's plug-in electric vehicles (PEVs) could delay increased adoption of PEVs.

- Battery safety when a vehicle is subjected to crash is not well characterized. Recently, several experimental investigations have been conducted by different regulatory agencies and the original equipment manufacturers (OEMs); but there is no systematic understanding of the propagation of failure from when an individual cell within a battery pack fails, to whether or not the mechanical crash will be followed by thermal events.

- Criteria relating design of cells (e.g., format, packaging, chemistry) to performance at the module level are difficult to build due to limited understanding of the complex interactions among the different physical phenomena that take place during the crash. This leads to overdesigning for safety of battery packs resulting in heavier and more expensive systems.

- Limited experimental studies on the modes of propagation, as well as the arbitrary nature of the test conditions, limit the understanding of how failure at the individual cell level translates to implications for the safety of the module or the pack.

\section{TECHNICAL TARGETS}

- This effort aims to develop mechanical models that can be coupled with thermal and electrochemical aspects of failure propagation in lithium-ion batteries. The emphasis is on single-cell to multi-cell propagation.

- The technical target is to develop simulation capabilities in this area for individual cells and cell strings that show good agreement with experimental data for coordinates of the origin of failure and maximum surface temperature.

- Such a validated simulation capability will aid designing safer, less expensive, and lighter PEV batteries. 


\section{ACCOMPLISHMENTS}

- We have developed the first-ever simulation tool that includes physics-based models for mechanical, electrochemical and thermal response of a multi-cell unit.

- Several test cases were simulated to demonstrate versatility of the models from the single-cell case and cell strings to modules in different configurations.

- Experimental validation of mechanical models across these geometries were demonstrated and summarized in this report.

- For the single-cell and cell-string levels, the models capture the force response to within 15$20 \%$ accuracy and predict the location for the origin of failure based on the deformation data from the experiments.

- At the module level, there is some discrepancy due to spacing between the cells in the test article that we are addressing now.

- The cells within packaging volume of a module experienced about $60 \%$ less force under identical impact test conditions: so the packaging on the test articles is robust. However, under slow-crush simulations, we found that the maximum deformation of the cell strings with packaging is about twice that from cell strings without packaging.

- Thus, we have identified a sweet spot between balancing damage prevention during an impact test and forced deformation during a slow crush. This information will provide insight to pack assemblers to design better modules by providing sufficient spacing between cells within the modules/cell-strings. An alternate approach is to design packaging material with better elastic properties while maintaining adequate failure strength.

\section{INTRODUCTION}

This effort builds upon our work in FY14 to develop a simulation tool that captures the propagation of thermal events following mechanical impact from a single cell across a multi-cell module. Ford Motor Company is our partner in this project, providing insight on packaging of cells in modules and overseeing crush testing. In the previous year's report, we demonstrated simulation capabilities across multiple form factors for individual cells (e.g., prismatic vs pouch cells, wound vs stacked, cylindrical vs prismatic). These models are chemistry agnostic, and leverage the battery module available from ANSYS based on previous work under the first phase of Computer-Aided Engineering for Electric-Driven Vehicle Batteries (CAEBAT) project.

\section{APPROACH}

The key distinguishing feature in our current approach is that our mathematical treatment of batteries accounts for the energetics that follow a mechanical deformation. Previously reported battery crash simulations treated batteries as passive materials similar to air-bags or structural elements of the vehicle. These models considered the mechanical aspects only, and did not capture the electrochemical effects. On the other hand, the state-ofthe-art electrochemical-thermal models assumed that the contributions from the mechanical constraints imposed on the cells were limited. Physical deformation of the cells due to thermal/electrochemical events was not considered. In the present work, we present a new approach that combines the effect of deformation or mechanical failure of the different components in a battery with electrochemical models to simulate the thermal propagation response. 


\section{Geometry and Meshing}

The models implement realistic geometries from computer-aided design (CAD) images for the actual test article hardware. We integrate the mechanical response from explicit simulations performed in LS-DYNA to the battery-abuse models available in ANSYS to perform different case studies of interest. One of the key challenges in simulating performance of large battery modules in three dimensions is the mathematical complexity and computational demand that scales with the size and shape of the different features associated with the geometry. In our case, in the geometry for the 20-cell module shown in Figure 1, for example, there were more than 800 individual parts that must be meshed to adequate detail before any simulation effort begins. Identification of the critical components that contribute to the propagation events and subsequent defeaturing of the geometry was streamlined as the first step towards extending the coupled thermal/ mechanical simulation capability to CAD geometries reflective of actual hardware. This was accomplished using a shell script to

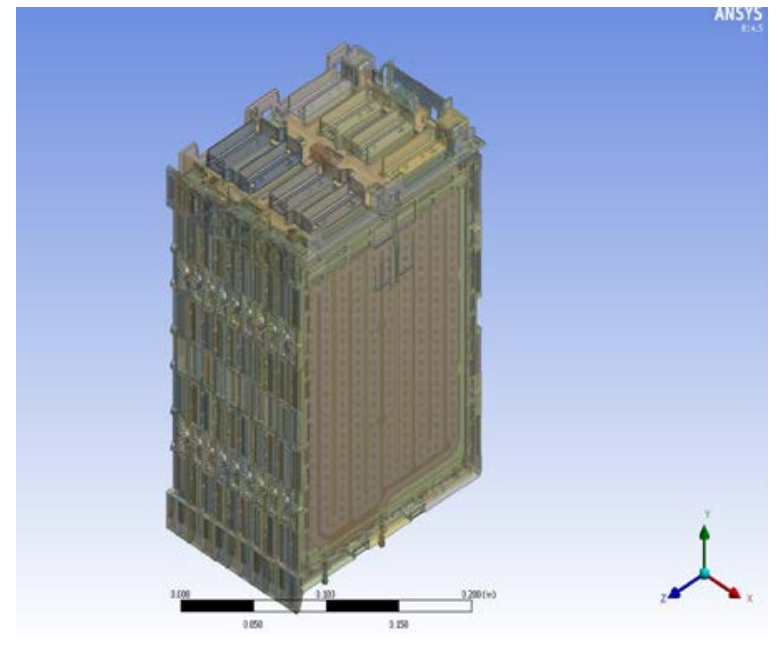

Figure 1. CAD image of a 20 cell module complete with packaging and heat-exchange fins (geometry courtesy of Ford): the hardware uses the same $15 \mathrm{Ah}$ cells and has more than 800 small parts meshing of which results in more than 16 million elements, making it challenging to run efficient simulations. identify contact faces that must be retained to capture the physics adequately. We are still evaluating the limits of the current approach and making refinements to the scalability with the size of the geometry.

\section{Mechanical Models}

We implemented the anisotropic material properties of the active materials and separator into the LS-Dyna Honeycomb Model. The model enables different tensile and compressive stressstrain responses and tensilestrain-based failure criteria. The LS-Dyna damage model is used together with the other models to describe damage of current collectors. The model parameters were calibrated using quasi-static cylindrical indentation test data. Figure 2 shows an example of calibration of the component properties in the mechanical models.

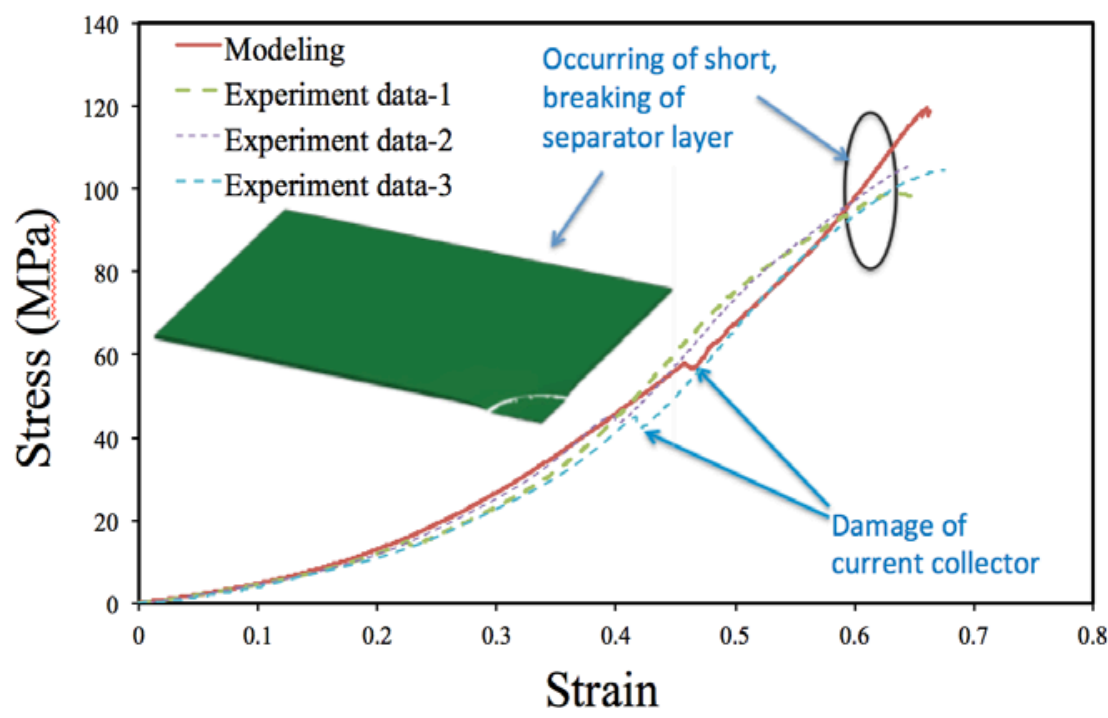

Figure 2. Illustration of obtaining parameters in the constitutive models by calibration against component-level test data. This information is then used as input to the cell-level and larger scale simulations.

\section{Electrochemical-Thermal Models}

The results from the mechanical simulations (such as deformation or localized resistance values) are fed as input into the thermal/electrochemical simulations. Under the scope of this phase of the project, a one-way coupling is implemented; the contributions of the thermal or reaction parameters to the change in mechanical properties are not accounted for. This approach is valid for the impact (e.g., drop-test-type scenario) loading 
studied in our experimental test matrix. The results of the slow-crush simulations are less accurate because the one-way coupling methodology limits the validity to very slow (quasi-static) simulation cases.

Table 1. Sample list of parameters and variables exchanged across the different domains

\begin{tabular}{|c|l|l|l|}
\hline Scope & \multicolumn{1}{|c|}{ Cell-Level } & \multicolumn{1}{c|}{ Cell-Strings } & \multicolumn{1}{c|}{ Module-Level } \\
\hline & $\begin{array}{l}\text { Electrical, thermal, and } \\
\text { mechanical data on cell } \\
\text { components } \\
\text { - Cell assembly } \\
\text { information }\end{array}$ & $\begin{array}{l}\text { - Mechanical models for } \\
\text { individual cells } \\
\text { - Heat-generation model } \\
\text { for the cell under short- } \\
\text { circuit }\end{array}$ & $\begin{array}{l}\text { - Mechanical models for individual } \\
\text { cells } \\
\text { - Heat-generation model for the cell } \\
\text { under short-circuit } \\
\text { - Properties of packaging material, } \\
\text { module configuration }\end{array}$ \\
\hline \multirow{E}{*}{$\begin{array}{l}\text { Constitutive } \\
\text { mechanical models } \\
\text { representative of the } \\
\text { cell-level response }\end{array}$} & $\begin{array}{l}\text { - Origin and propagation of } \\
\text { electrical/thermal } \\
\text { phenomena, when } \\
\text { multiple short-circuit } \\
\text { events occur across the } \\
\text { string during crush }\end{array}$ & $\begin{array}{l}\text { - Origin and propagation of } \\
\text { electrical/thermal phenomena } \\
\text { under crush } \\
\text { Identification of weak spots on the } \\
\text { module to monitor /take } \\
\text { preventive measures }\end{array}$ \\
\hline
\end{tabular}

One feature worth mentioning in our approach to modeling cells, strings and modules is that the input for any of these domains can be obtained from simulation results, or in the absence of that, from test data at a lowerlength scale. In this sense, the models at the different domains are fairly independent of each other. This is in line with the modular framework implemented across all of NREL's battery simulation tools. It enables the end user to exercise some flexibility in the choice of models for the different domains; at the same time, it enables practical use of models at a given domain of interest without the need to build the entire suite. Table 1 describes the inputs and outputs across the different domains.

\section{RESULTS}

Simulations were performed at the cell, string and module levels. Validation hardware was assembled accordingly for each level. The following section summarizes a few test cases and examples of key observations.

\section{Cell-Level Simulations}

Cell-level mechanical simulations predict no breach of the packaging; this is in line with the experimental observations. The strain-based failure criterion we use, together with the lumped representation of the individual layers, does not adequately capture the dynamic effects or internal pressure events. The maximum force during the impact test is captured to within $20 \%$ of the experimental value in the simulation results. There is a rebounding of the thickness of the lumped separator layer from $0.076 \mathrm{~mm}$ to $0.096 \mathrm{~mm}$, corresponding to recovery of the voltage drop observed experimentally. 

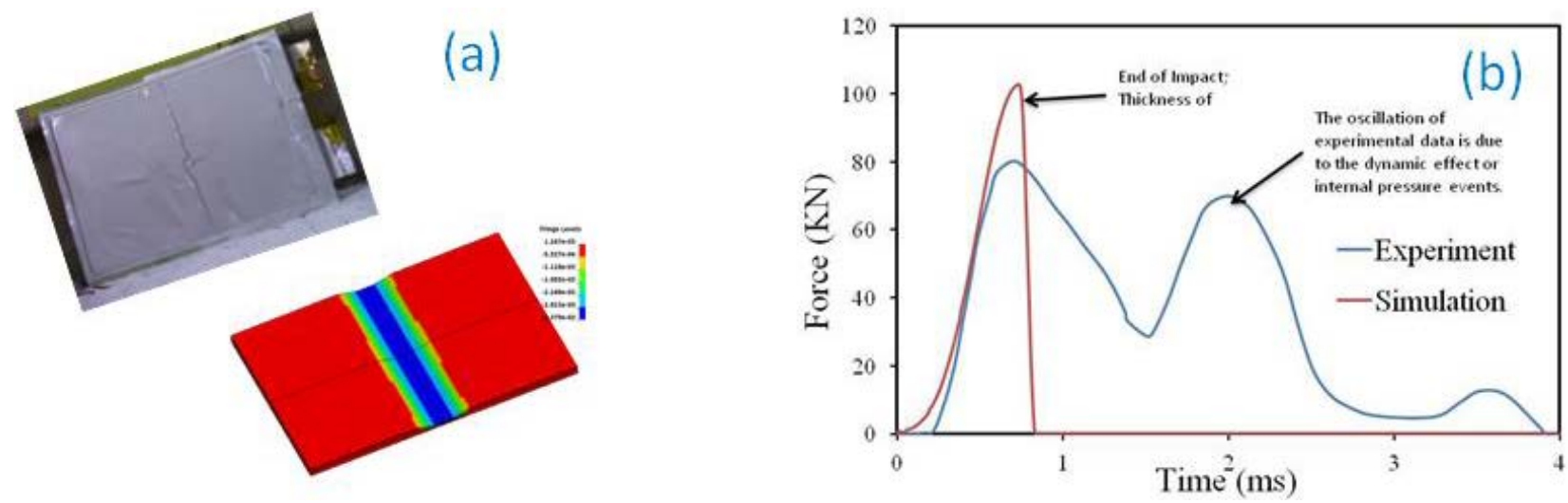

Figure 3. a) Comparison of experimental and simulated geometry showing no breach of packaging material under the impact load conditions tested; the model results for this test case compare well with the EUCAR-2 response observed in the tests. b) A detailed comparison of the force vs time shows that the test data suffer from oscillations of the indenter upon impact. The simulation results do not capture this because the models do not account for factors such as elasticity of the indenter material and fixtures to hold the cell.

Four repeats under identical test conditions showed different voltage drops from the initial $4.15 \mathrm{~V}(80 \%$ state of charge, SOC). High-speed video results indicated the source of variability to be different contact times between the impact load and the cells. Different contact times were simulated to compare with the experimental results. Resistance of the short varies with the duration of contact. This metric is predictive and it can be used as an indicator of the remaining energy in the battery at any given time after the crash. This result has significant implications toward safety assessment of battery packs after crash. Figure 4 shows a comparison of the voltage drop and temperature rise as a function of contact duration between the indenter and the cell.

\section{Simulation of Cell Strings}

For the cell-string crush, the 1S5P test configuration was used. A hemi-cylindrical indenter was used, as specified in the USABC test procedure. The simulation results for the $\mathrm{x}$-plane crush are shown in this report (see Figure 5). The mechanical response of the cell string to the crush along the x-plane captured the test results for maximum deformation both along the axis of indentation and along the edges of the test structure, accurate to within $15 \%$. With the packaging, the deformation was twice that for the cells-only simulation case, indicating that the mechanical properties of the string packaging induce significant deformation under slowcrush conditions.
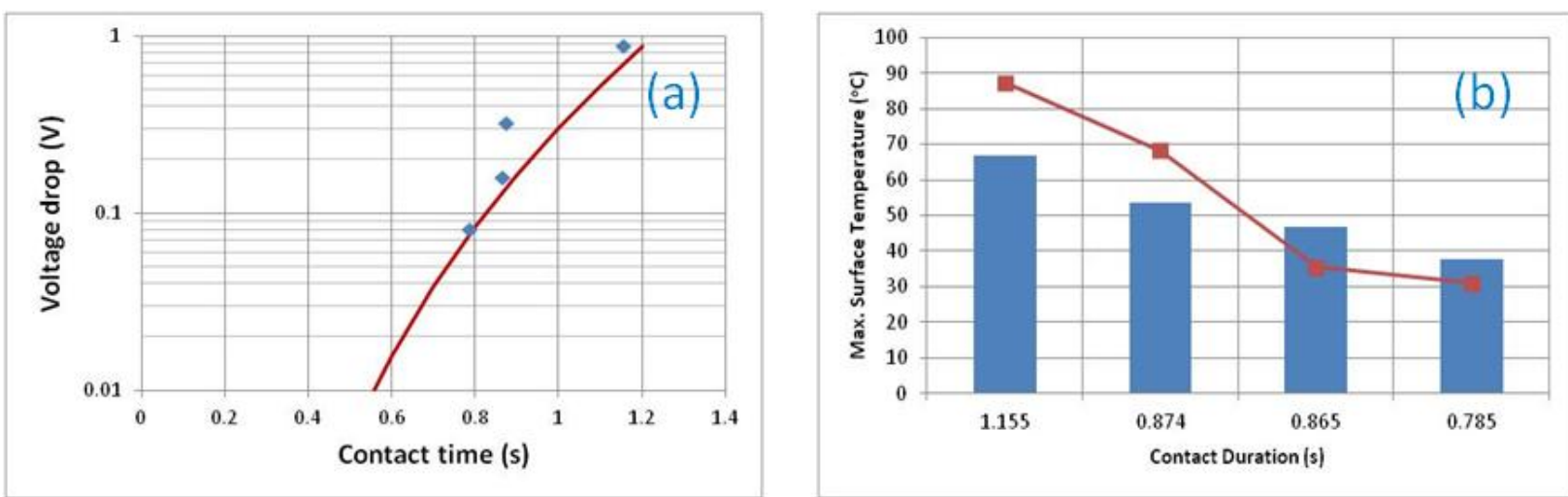

Figure 4. Electrical and thermal responses of the cell: a) Model predictions (solid line) vs experimental data from high-speed imagery (dots), b) Comparison of the experimentally observed maxima for the surface temperatures (dots) against the model predictions (bars). In general, the experimental results are consistent with the simulation: the initial voltage drop varies directly as a function of contact time with the load and the maximum temperature decreases with a decrease in the contact duration. 
These results counter the benefits of having a robust packaging system under an impact (sudden-drop) test. The cells within the packaging likely have some buffer space to accommodate for such conditions. More work is under way in this area to investigate the effect of spacing among cells in the string. Previous models assuming constant resistance throughout the short circuit predict propagation along the current collectors 25 seconds into the short. Evolution of resistance with mechanical deformation predicts localized thermal events within the first few seconds of impact.

\section{Module-Level Simulations}

Two different sets of simulations were set up with the impactor approaching from the $\mathrm{x}$ - and z-planes (see Figure 6). The impact was simulated as a drop of a pre-determined mass from a height of $2 \mathrm{~m}$ (impact velocity of $6.26 \mathrm{~m} / \mathrm{s}$ ). Based on the experimental test plan previously developed from Ford, the loads on the impactors were set to $22 \mathrm{~kg}$ for the $\mathrm{x}$-plane and $14 \mathrm{~kg}$ for the $\mathrm{z}$-plane.

For the impact along the x-plane, the cell frame considerably reduces the propagation of mechanical damage across multiple cells. The maximum deflection of the end plate is limited to less than $2 \mathrm{~mm}$, which is a reduction of more than $15 \%$ in the maximum deformation for identical test cases with and without the cell frame. Structural damage is concentrated along the edges of the structure, particularly near the holes on the frame. The maximum strain $(0.0829$, front panel) is far less than the failure strain of steel. For the z-plane, the evolution of damage to the structure is strictly confined to the holes. These results are quite similar to those for the x-plane simulations. The inner frame acts as a shock absorber and takes in much of the deformation; also, as noted under the test conditions, the mass of the impactor also influenced the maximum deflection to some extent. Regardless, the overall damage observed in this case is lower than x-plane impact; the maximum plastic strain $(0.395)$ is higher due to the structural design of the inner frame. The indenter reaches zero velocity after impact along the x-plane in about $50 \%$ of the time compared to the impact along the z-plane, due to a larger contact area. In a previous report, we discussed the thermal response of the module under the two cases: the temperature rise for the $\mathrm{x}$-plane impact was much higher compared to the z-plane, primarily due to the presence of the spacing between the cells and the end frames along this direction.
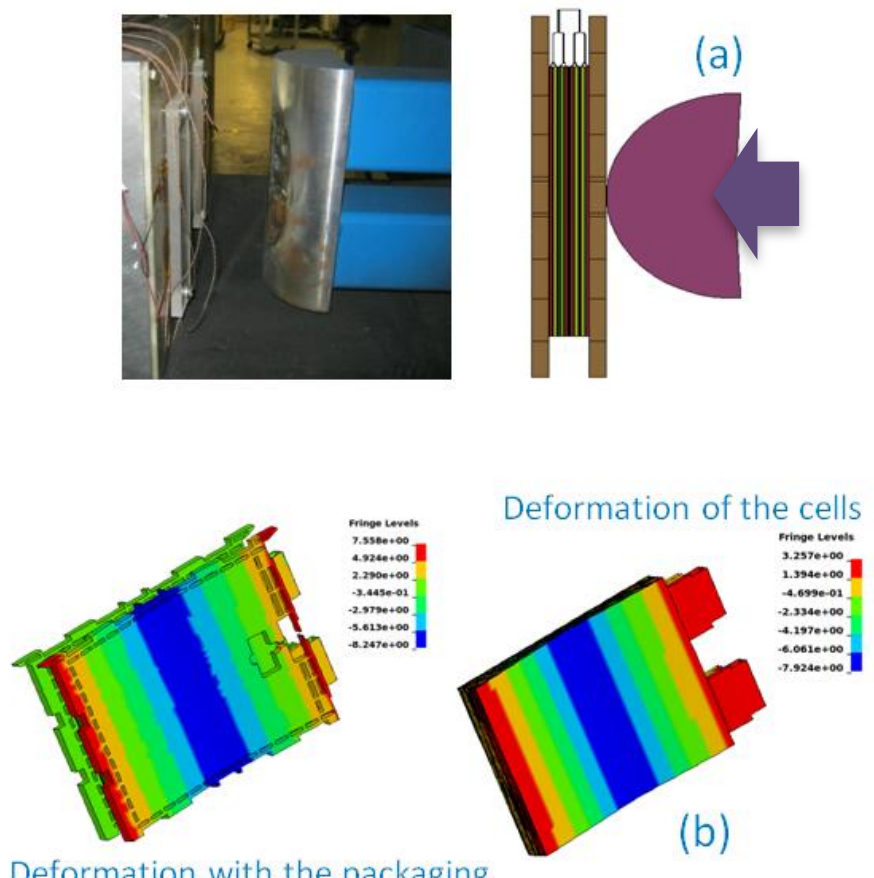

Deformation with the packaging

Figure 5: (a) Experimental test set up for X-plane crush of a cell string and (b) Sample simulation results comparing deformation with and without the packaging 


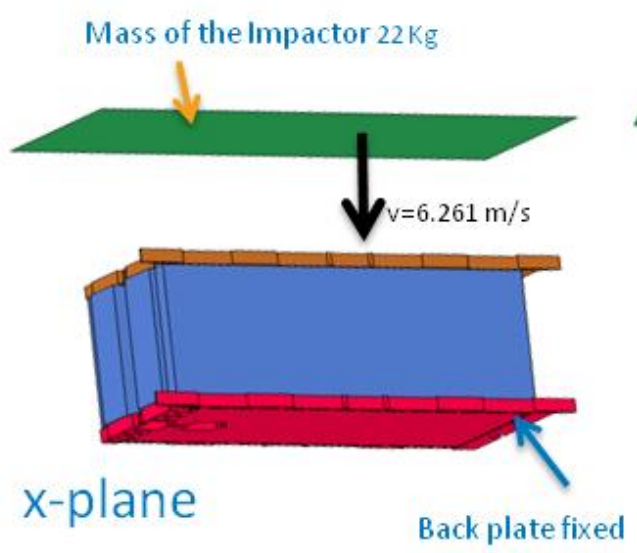

von Mises stress contour plot

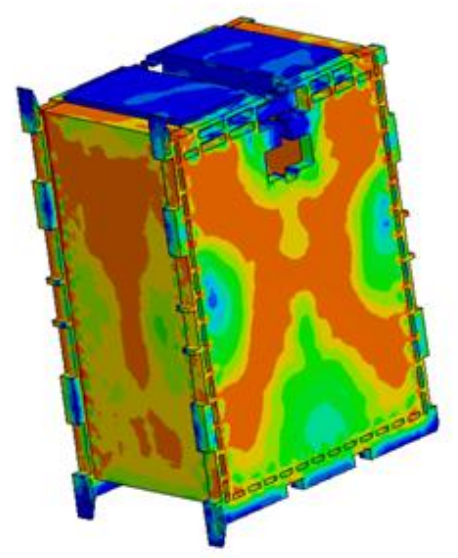

Mass of Impactor $14 \mathrm{Kg}$

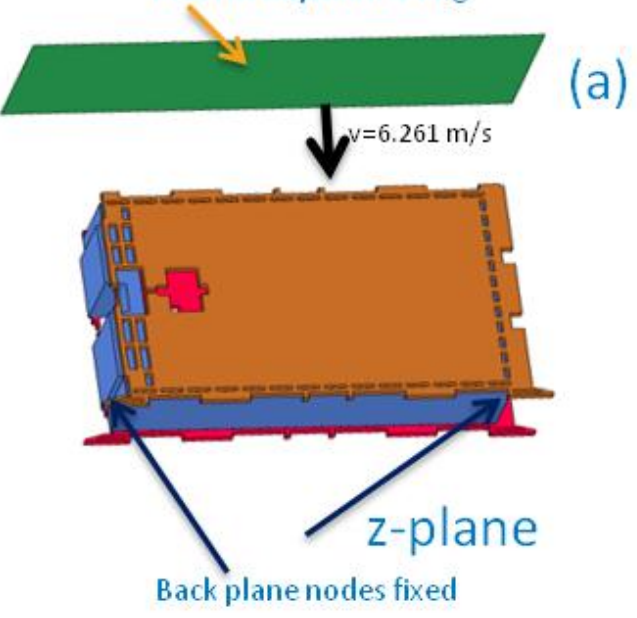

Deformation of front plate

(b)

a)

)

Maximum deflection is $1.723 \mathrm{~mm}$

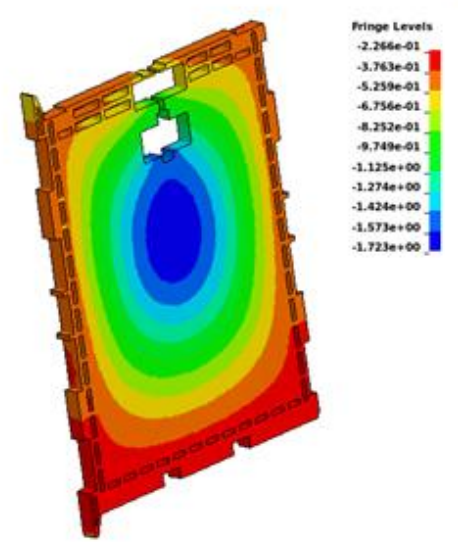


The test articles were also instrumented with shunts to monitor the currents across the cells. The test setup will then enable us to monitor the propagation of failure across different cells within the module. Comparison against experimental results is under way.

\section{CONCLUSIONS AND FUTURE DIRECTIONS}

Under this project, NREL developed the first-ever coupled mechanical-electrochemical-thermal model for batteries after a crush. We presented several examples of simulation results showing crash propagation response of automotive batteries alongside experimental validation. The effort over the last two years has enabled us to identify the critical gaps in test data available and to quantitatively interpret the experimental results.

A good example is the test case showing the effect of duration of contact between the cells and the indenter. Previously, the variability among the test results could not be traced back to sensitivity of individual testing parameters without trial and error. Insights such as the ones described in this report help minimize such iterations and improve the quality of test results, as well as maximizing value gained from the limited test data available. The validation of the electrical signals as a function of time is under way for the cell strings and modules. These results will provide additional insights on preventive measures and trade-off between designing efficient and light battery modules while addressing safety concerns. The experimental results reported here point to key differences in the damage intensity and duration of impact between the drop test and the slow crush: for the same peak force $(\sim 80 \mathrm{kN})$, the slow crush was more damaging than the drop test, which is a relatively fast crush test. The implications of these results for the safety of the battery are yet to be assessed. The swelling of the cells under slow-crush tests (versus no swelling during the drop test) points towards the need for strain-rate-dependent models and incorporating pressure build-up into the mechanicalabuse models. We will continue improving the fidelity of the model to simulate different experimental conditions and use the lessons learned in the next phase of CAEBAT project.

\section{FY 2015 PUBLICATIONS/PRESENTATIONS}

1. "Coupled Mechanical-Electrical-Thermal Modeling for Lithium-ion Batteries," C. Zhang, S. Santhanagopalan, M. Sprague, A. Pesaran, J. Power Sources, vol. 290, pp. 102-113, 2015.

2. "Crash Propagation in Automotive Batteries: Simulations and Validation (NREL)," S. Santhanagopalan, et al., DOE VTO Annual Merit Review, Washington DC, June 9, 2015.

3. "Mechanical Abuse Simulations for Lithium Ion Batteries," S. Santhanagopalan, et al., Advanced Automotive Battery Conference (LLIBTA), Detroit, MI, June 2015.

4. "Abuse Modelling and Testing for Battery Safety," S. Santhanagopalan, Invited as Panel Moderator at the Battery Show, Novi, MI, Sept. 2015.

5. "A Representative Sandwich Model for Coupled Mechanical-Electrical-Thermal Simulation of Lithium-Ion Battery Cell under Quasi-Static Indentation Tests," C. Zhang, S. Santhanagopalan, M. Sprague, A. Pesaran, J. Power Sources, vol. 298, pp. 309-321, 2015. 


\section{Development of Industrially Viable Electrode Coatings}

\section{OBJECTIVES}

- The objective of this work is to develop a system for deposition of thin protective electrode coatings using a novel "in-line" atomic layer deposition (ALD) reactor design that can be integrated into manufacturing to address needs for improvement in rate capability, cycle life, and abuse tolerance in a cost-effective manner.

\section{TECHNICAL BARRIERS}

- Limited calendar and cycle life

- Abuse tolerance

- High cost.

\section{TECHNICAL TARGETS}

- Design and construction of prototype inline ALD coater for deposition on porous substrates.

\section{ACCOMPLISHMENTS}

- The National Renewable Energy Laboratory (NREL) and the University of Colorado at Boulder (CUBoulder) demonstrated the ability to coat ALD alumina on flexible substrates using an in-line rotary reactor system at effective line speeds of approximately $300 \mathrm{ft} / \mathrm{min}$.

- The team developed a model system to assess the ability to coat porous materials using the in-line rotary reactor.

- We performed initial coating of battery electrode materials and are currently assessing coating performance at both NREL and Argonne National Laboratory (ANL).

- NREL initiated new partnerships with ANL, Oak Ridge National Laboratory, and Lawrence Berkeley National Laboratory in support of their High Energy/ High Voltage project to provide ALD coatings as required.

\section{INTRODUCTION}

In previous work, NREL, in partnership with the University of Colorado, has shown that extremely thin, conformal coatings deposited with the Atomic Layer Deposition (ALD) technique are capable of dramatically improving cycleability of lithium-ion cells. Current technology for performing ALD is not amenable to high throughput manufacturing methods and thus represents a high priced bottleneck in the implementation of ultrathin electrode coatings at a commercial scale. This project seeks to convert the common ALD processing format into a new reactor geometry that is compatible with battery electrode manufacturing.

In earlier work, NREL and CU-Boulder successfully completed design and construction of a new in-line ALD reactor. Work in this area has focused on modification of previous reactor designs to build a system capable of assessing the ability to obtain ALD-type coating processes in an in-line format and under acceptable battery manufacturing conditions. Work reported here focuses on demonstrating successful coating of aluminum oxide 
on flexible form factors using the in-line reactor system. Special emphasis has been placed on designing a

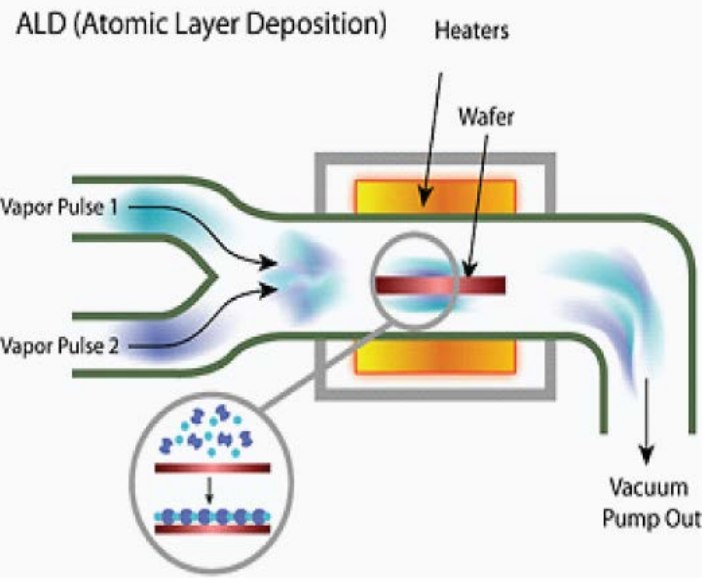

Figure 1: Standard "static" ALD chamber reactor system to understand the impact of coating on porous substrates including battery electrode materials.

\section{APPROACH}

ALD coating methods are conducted by sequential and separate exposure of a sample substrate surface to gas phase precursors that react to form a film. Deposition is typically performed in a closed reactor system at mild vacuum as shown in Figure 1. Precursor exposure steps are conducted in a single chamber and are separated in time. In a typical exposure "cycle," a sample is exposed to one precursor. The chamber is then purged with inert gas prior to exposure to the second precursor that completes the coating reaction. The "cycle" ends with another extensive inert gas purging step before the process can be started again. Film growth takes place by repeating this cycling precursor exposure process multiple times. The sequential and separate

\section{In-line ALD for Manufacturing}

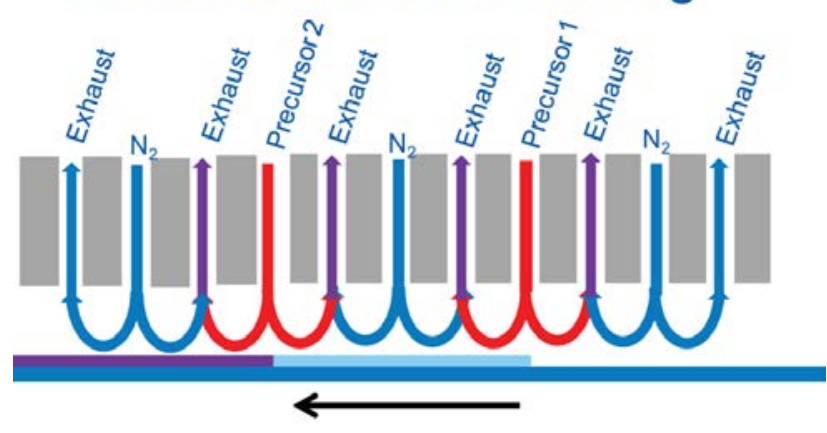

\section{Electrode slurry coated foil translates under multiport "AP-ALD" deposition head}

Figure 2: Conceptual example of a spatial "in-line" ALD reactor exposures are key to achieving the excellent conformal film deposition on highly textured substrates for which the ALD technique is known. As an alternative to the temporal separation of precursor exposure in the same reaction chamber, our work proposes a spatial separation of precursor exposure steps that is more consistent with "in-line" processing techniques. Figure 2 shows a simplified conceptual schematic of our proposed apparatus. Our "spatial" ALD approach employs a multichannel gas manifold deposition "head" that performs sequential exposure of precursor materials as an electrode foil translates beneath it. It is important to note that similarly designed deposition heads are currently employed by glass manufacturers for production of a variety of coated glass products using high-volume, in-line atmospheric pressure chemical vapor

deposition (AP-CVD). Our approach leverages this existing knowledge base as well as our ALD expertise to enable in-line ALD coating that will allow the transfer of our previously demonstrated ALD-based performance improvements to larger format devices.

\section{RESULTS}

\section{Demonstration of ALD Alumina Deposition on Flexible Substrates using Rotary In-Line ALD}

A simple schematic of our in-line ALD reactor system is shown in Figure 3. We refer to the reactor as a "drum-in-drum" design system that consists of a rotating inner drum on which substrates are mounted and is set inside a fixed outer drum that contains all gas sources as well as purge and exhaust lines. The inner drum rotates the web radially while maintaining sufficient tension on the line to ensure accurate gas head to substrate spacing. 


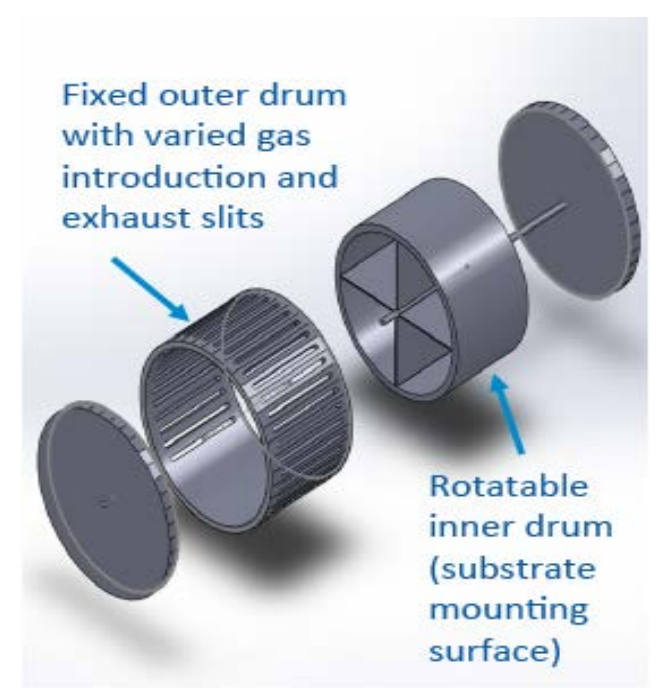

Figure 3: Computer rendering of "drum-indrum" reactor format
To maximize reactor flexibility and enable extensive deposition condition optimization work, we have adopted what we term a "digital modular" system design. Figure 4 shows a more detailed schematic of the drum-in-drum reactor design and demonstrates the digital modular design. To implement the "digital modular" design, the fixed outer drum of the reactor is faceted and has slots drilled every $2.5 \mathrm{~cm}$. Precursor introduction as well as reactant exhaust takes place through the attachment of specific "modules" to these slots. Precursor dosing and vacuum exhaust modules have been fabricated that are able to fit to any of the slots in the external drum. This design will allow the modules to be moved interchangeably on the external drum to allow the maximum amount of variability in dosing and vacuum modules spacing. This enables extensive experimentation across a broad range of deposition conditions in order to optimize performance. Initial depositions of aluminum oxide were conducted on flexible plastic films (PET) with an existing metal coating. These experiments were used to demonstrate the ability to perform a controlled ALD deposition process within the rotary reactor system. Metal- coated samples were employed to eliminate penetration of the flexible plastic model sample with the precursor reactors and ensure that accurate film growth measurements were obtained. Our initial reactor configuration was set to allow one cycle of the ALD deposition process to be conducted per rotation of the sample. Figure 5 shows photographs of a metal-coated PET film prior to being loaded into the reactor (A) and immediately after deposition of $\sim 650 \mathrm{~nm}$ of alumina (B). The color change of the sample is indicative of film growth and does show some degree of non-uniformity on the edges of the sample surface, which appears as blue/gray lines. Figure 6 shows film thickness across the sample surface as measured using spectroscopic ellipsometry. The data show that the edges of the samples are showing slightly higher thickness $(\sim 670$ $\mathrm{nm})$ as compared to the center portion. This may be caused by some mixing of reactants near the edges of

the sample reactor zone; however, the overall thickness does not vary across the sample more than $3 \%$, which represents excellent uniformity for initial characterization. 

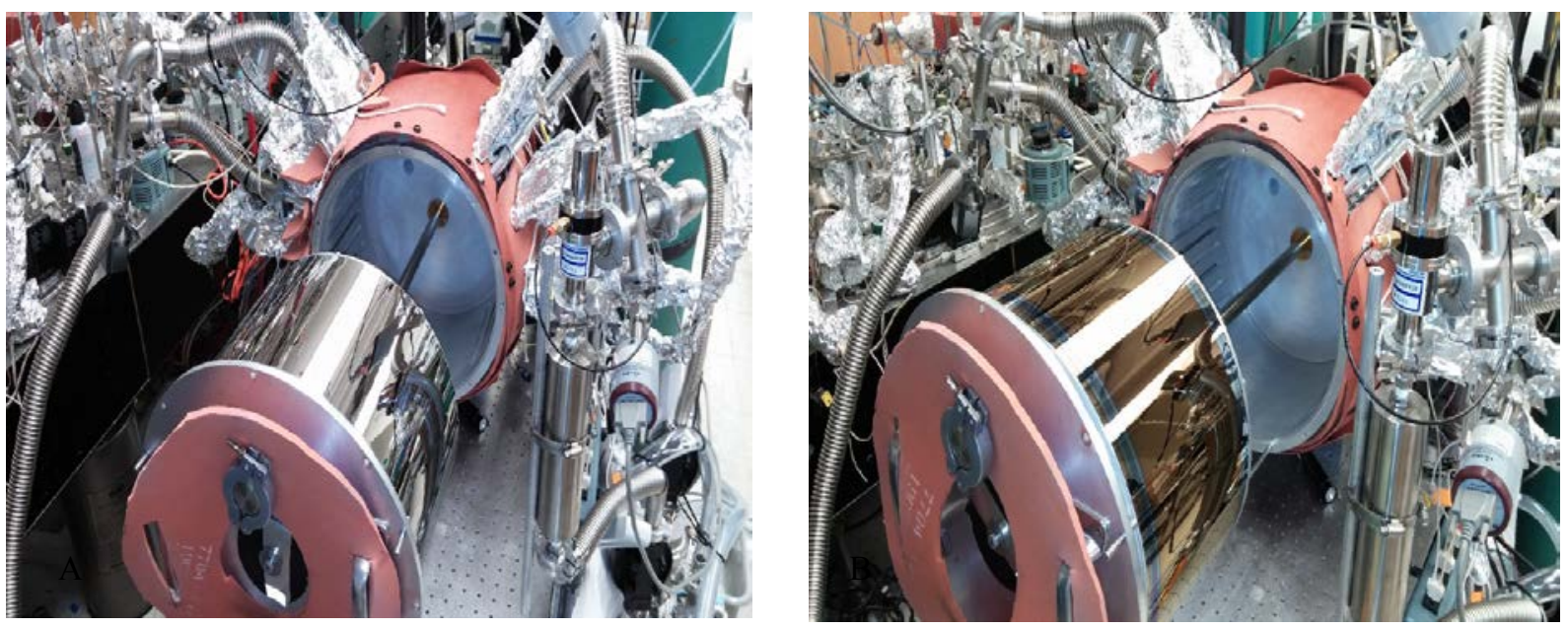

Figure 5: Photographs of a flexible metal-coated plastic film before loading (A) into the rotary reactor and (B) after deposition of $\sim 650 \mathrm{~nm}$ of alumina.

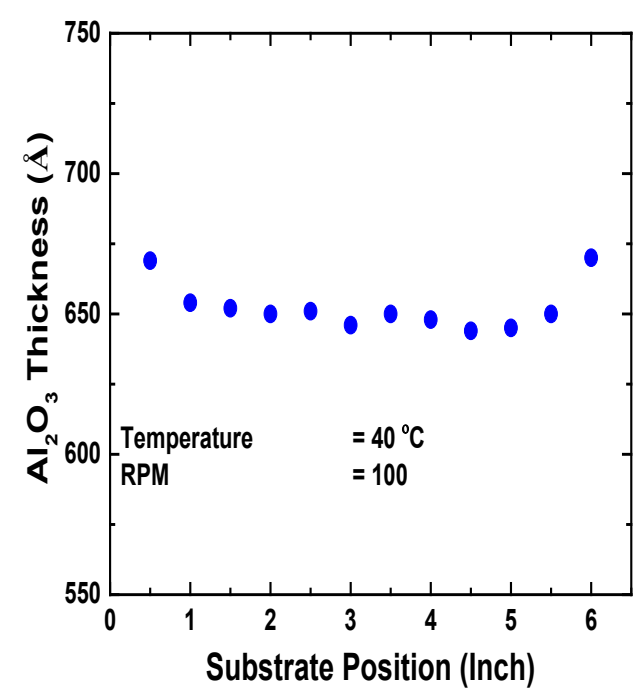

Figure 6: Thickness measurement for alumina coatings deposited across metal coated plastic sample.

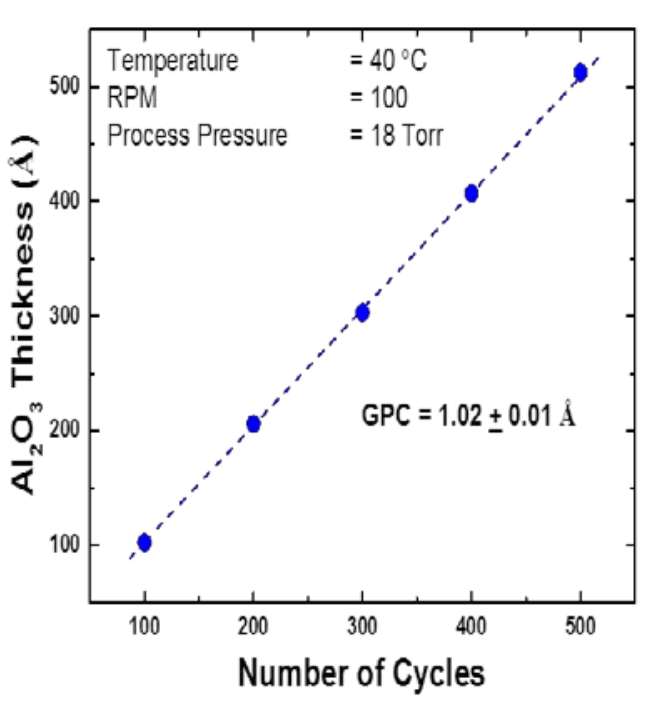

Figure 7: Plot of measured alumina film thickness as a function of number of ALD cycles, which is equivalent to the number of reactor rotations.

Figure 7 shows data for film thickness growth as a

function of number of rotation cycles for the aluminum oxide growth chemistry conducted with the in-line ALD reactor design using optimized deposition conditions. Note that the film thickness increases linearly as is expected for the ALD sequential reaction cycle conducted under a well-controlled condition. The growth rate per rotation cycle (GPC) was determined from the slope of this line to be $\sim 1.02$ Angstroms per cycle. This growth rate is consistent with that observed for well-controlled ALD alumina deposition using standard reactors. The linear growth rate as a function of cycle and consistency with standard reactor deposition rates indicates that under the selected conditions we appear to be achieving a well-controlled ALD deposition process using the in-line reactor design. 
Further experiments were conducted to assess the ability to obtain a well-controlled ALD process as a function of rotation rate and "effective" line speed. The effective line speed is simply calculated based on the rotation rate and the circumference of the inner reactor drum and gives an estimate of what practical manufacturing conditions may be feasible with our reactor design. It is crucial that the ALD chemistry be able to be conducted not only on an in-line format, but also at relevant manufacturing process line speeds in order for this technology to be adopted by industrial partners.

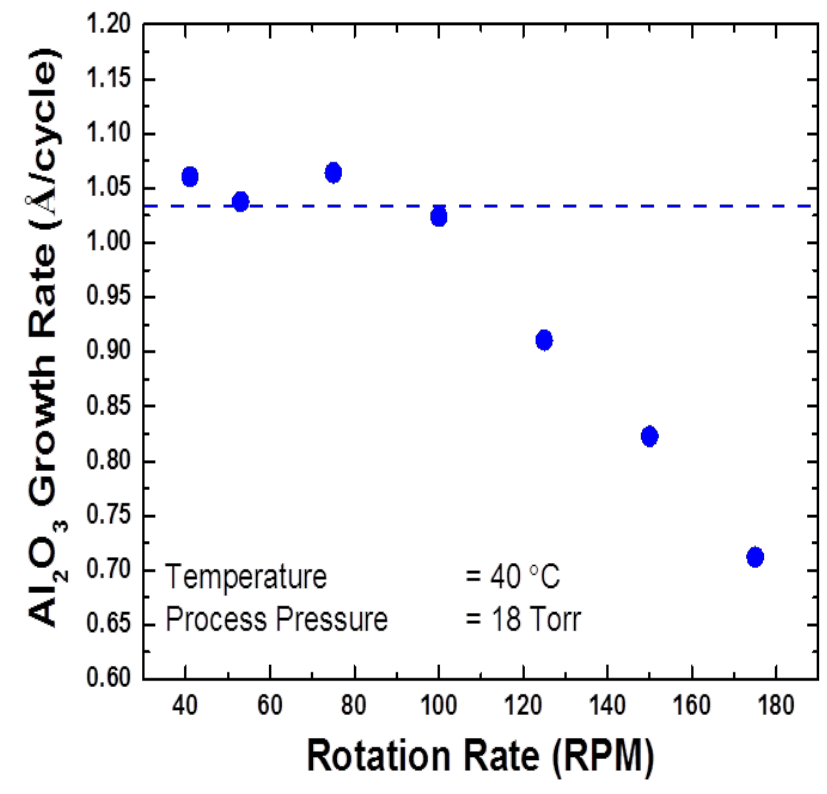

Figure 8: Measured ALD growth rate for alumina as a function of reactor rotation rate
Figure 8 shows the measured ALD growth rate (GPC, in Angstroms/cycle) as a function of the rotation rate of the internal reactor cylinder. Note that up to a rotation rate of $\sim 100 \mathrm{RPM}$, the measured growth rate remains constant at just over 1 Angstrom per cycle; however, as rotation speed increases, the GPC begins to decrease. This is likely due to a combination of the limited "residence" time of the reactants near the sample surface and limitations of the reaction kinetics at our current processing temperatures $\left(40^{\circ} \mathrm{C}\right)$. In more recent experiments, the impact of reactant residence time was explored by reconfiguring the spacing between reactant introduction and exhaust zones, which increased the deposition rate further and is currently under continued study.

It is important to note that while we are pushing the ability of the reactor to enable controlled deposition at higher rotation rates, the 100-RPM limit with the current configuration translates to an effective line speed of $\sim 300 \mathrm{ft} / \mathrm{min}$, which is roughly twice the current rate of state-of-the-art lithium-ion battery electrode manufacturing lines.

\section{Determination of the Ability to Coat Porous Substrates}

While earlier results indicated the ability to obtain a controlled ALD deposition at effective line speeds nearly twice that of current manufacturing, this work was conducted with flat substrates and is not representative of battery electrodes. We have further developed a model system to assess the ability to perform quality and wellcontrolled ALD alumina deposition on porous samples to optimize conditions for eventual battery electrode coatings. Figure 9 shows a simple schematic of anodic aluminum oxide (AAO) materials that we have chosen

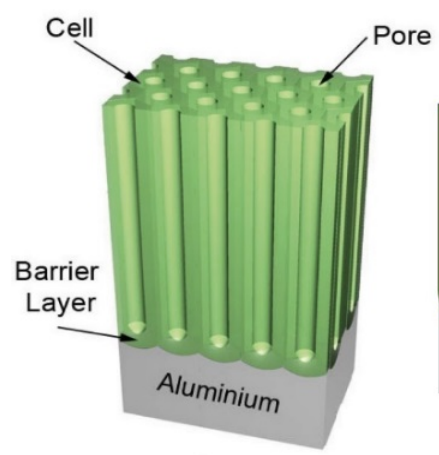

(A)

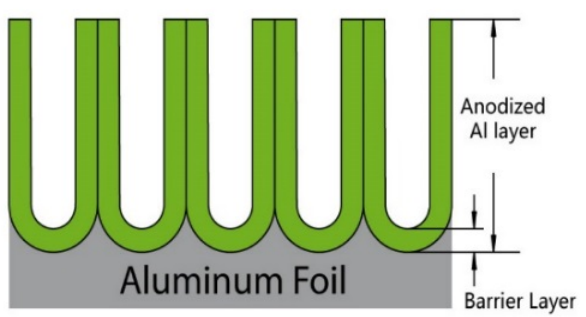

(B)

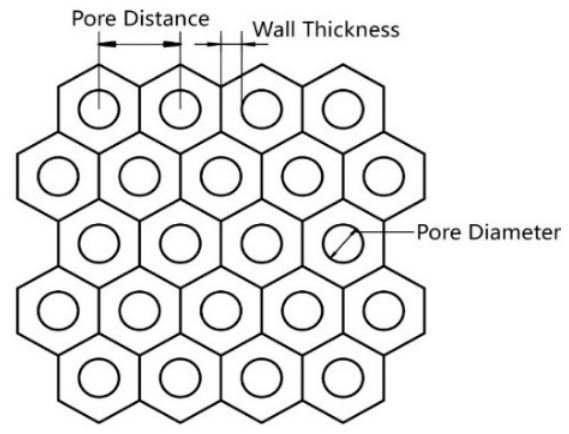

(C)

Figure 9: Schematic of anodic aluminum oxide samples. 
as our model porous substrate. These samples consist of a highly uniform distribution of well-controlled pore structures over large sample areas with pore sizes in the nanometer size regime. This sample format allows detailed experimentation for performing ALD alumina deposition on a wide variety of pore sizes and at a variety of rotation rates.

In order to characterize the ability to perform ALD processing on the anodic alumina samples, a new ALD process was developed to allow deposition of zinc oxide to enable characterization of the coating on the AAO sample which would not be possible with the deposition of ALD aluminum oxide on the already existing AAO material. Significant efforts were placed on development of a well-controlled ALD ZnO chemistry, although

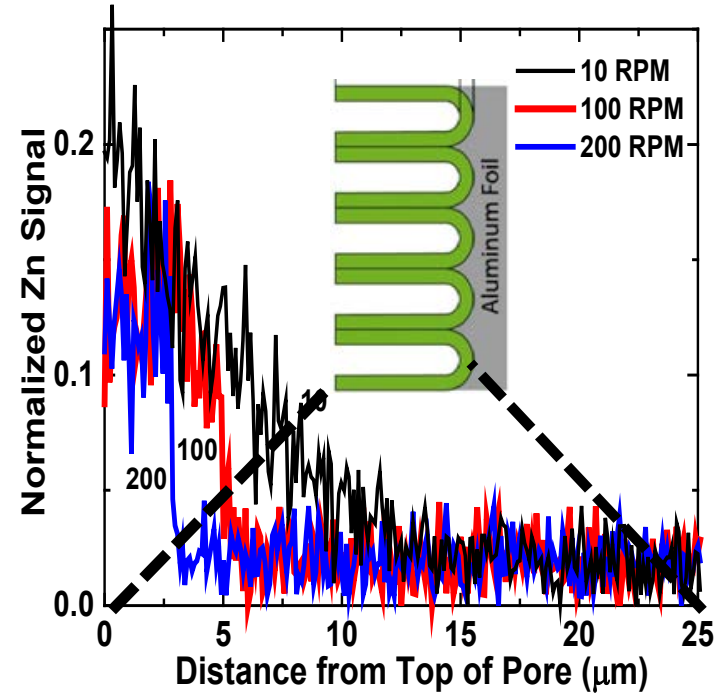

Figure 10: Plot of normalized Zn concentration EDX signal across porous $A A O$ sample structure

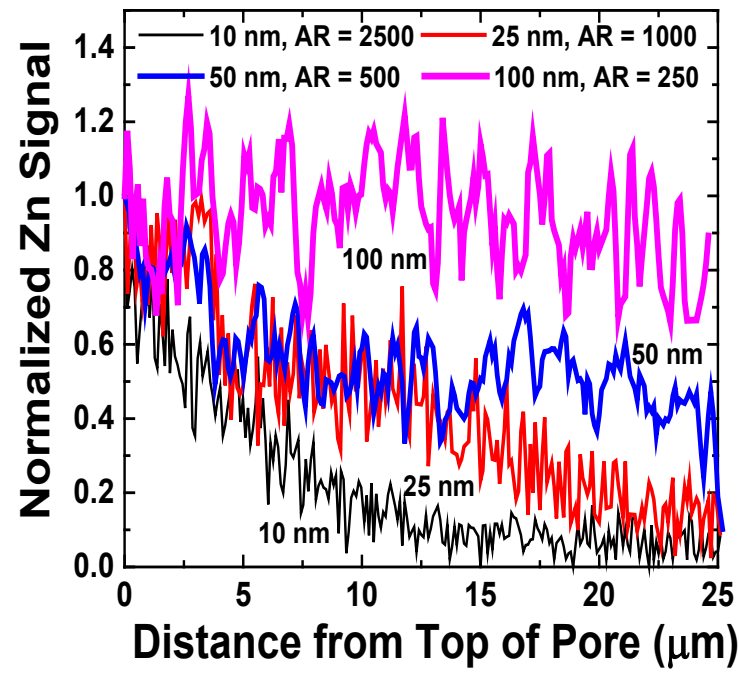

Figure 11: Plot of normalized Zn concentration EDX signal across AAO samples with varied porosity the data are not shown here. Analysis of the ability to coat the highly porous AAO samples was conducted by a combination of electron microscopy and energy dispersive $\mathrm{x}$-ray spectroscopy (EDX). Figure10 shows an example of data collected using this technique as well as an example schematic of the AAO sample showing areas in which measurements were made. The plot in Figure 10 shows the $\mathrm{Zn}$ signal measured by EDX as moving across the AAO structure from the surface that was in closest proximity to the ALD reactant gases in the in-line system to the bottom of the pore structure. This gives an assessment of the amount of $\mathrm{ZnO}$ deposited near the top of the pore structure as compared to the bottom. A uniform coating of $\mathrm{ZnO}$ across the entire structure would give roughly the same signal for $\mathrm{Zn}$ moving across the pore length while a nonuniform deposition would show distinct differences between the $\mathrm{Zn}$ signal as a function of distance from top of the pore. The data in Figure 10 clearly show the impact of rotation rate on the $\mathrm{Zn}$ concentration profile across the pore structure for an average pore diameter of 10 $\mathrm{nm}$. The data also clearly show non-uniformity with a high $\mathrm{Zn}$ concentration near the top of the structure, indicating the inability of the $\mathrm{ZnO}$ precursors to penetrate into the film under these conditions and also indicating the ability to detect changes in $\mathrm{Zn}$ concentration profiles under varied conditions. Note that at 10 RPM, the $\mathrm{Zn}$ concentration clearly reaches further into the pores than at the 100 RPM or 200 RPM rotation rates. NREL and CU-Boulder are in the process of conducting extensive studies to optimize in-line ALD deposition on porous substrates. Figure 11 shows an example data set for deposition on a series of different pore size samples at a 100-RPM rotation rate. These data show that at 100 RPM, it appears to be feasible to obtain a uniform $\mathrm{Zn}$ concentration profile for 
a 100-nm pore structure with decreasing uniformity as pore diameter decreases. Experiments to further understand the limitations of coating of porous samples are ongoing with further optimization.

In parallel with the continued optimization of coating of porous materials, NREL, CU-Boulder, and ANL are now collaborating to begin assessment of in-line ALD coatings on standardized battery electrodes through the Applied Battery Research program with samples currently under test.

\section{CONCLUSIONS AND FUTURE DIRECTIONS}

In FY15, the NREL/CU-Boulder team successfully demonstrated the ability to deposit alumina using a new inline ALD reactor under well-controlled conditions at an effective line speed of $\sim 300 \mathrm{ft} / \mathrm{min}$. In addition, experiments were initiated to determine optimum conditions for coating of porous materials through controlled experiments using standard porous substrate models. Further work is beginning to assess the impact of early coating processes on battery electrode performance through a partnership between NREL and ANL.

Moving into FY16, the NREL team has been tasked with a new role of serving as an ALD coating resource for the Applied Battery Research program as a whole. Work in FY16 will focus on the development of standardized ALD coating processes using both status and in-line spatial ALD in order to provide partners will well characterize materials for further studies. NREL will be partnering with ANL both through the Cell Analysis, Modeling, and Prototyping (CAMP) effort as well as with the High Energy / High Voltage research teams to provide coated materials. Further work will focus on also providing support to additional commercial partners with the longer term goal of achieving integration of the in-line ALD process within manufacturing processes.

\section{FY 2015 PUBLICATIONS/PRESENTATIONS}

1. "Development of Industrially Viable Electrode Coatings," ES159_Tenent_2015_p, US DOE Vehicle Technologies AMR, 2015.

2. "Spatial Atomic Layer Deposition on Flexible Porous Substrates: $\mathrm{ZnO}$ in Anodic Aluminum Oxide Membranes and Al2O3 in Li Ion Battery Electrodes," K. Sharma et al., J. Vac. Sci. Technol. A 33, 01A132 (2015). 


\section{Atomic Layer Deposition for Stabilization of Silicon Anodes}

\section{OBJECTIVES}

- Develop a low-cost, thick and high-capacity silicon ( $\mathrm{Si}$ ) anode with sustainable cycling performance by advanced surface modification

- Synthesize novel stable and elastic coatings for Si anodes using Atomic Layer Deposition (ALD) \& Molecular Layer Deposition (MLD)

- Demonstrate durable cycling performance of thick $\mathrm{Si}$ anodes by using new ALD/MLD coatings and electrode designs

- Identify the mechanical properties and the impact of the MLD coating material on the electrochemical cycling performance.

\section{TECHNICAL TARGETS}

- Stabilize the high-capacity Si anodes by employing the advanced surface coating techniques, ALD and MLD

- Demonstrate the stable high-rage cycling performance of $\mathrm{Si}$ anodes

- Relevant to U.S. Advanced Battery Consortium (USABC) goals: $200 \mathrm{Wh} / \mathrm{kg}$ (EV requirement); $96 \mathrm{Wh} / \mathrm{kg}, 316 \mathrm{~W} / \mathrm{kg}, 3,000$ cycles (PHEV 40 miles requirement). Calendar life: 15 years. Improve abuse tolerance.

\author{
Tien Duong (DOE Program Manager) \\ DOE Agreement Number 16645 Recipient: \\ National Renewable Energy Laboratory
}

\author{
Chunmei Ban (NREL - PI) \\ 15013 Denver West Pkwy \\ Golden, CO, 80401 \\ Phone: (303) 384-6504 \\ E-mail: Chunmei.ban@nrel.gov
}
Steve M. George and Sehee Lee Department of Chemistry and Department of Mechanical Engineering University of Colorado Boulder 914 Broadway, Boulder, CO, 80309 Phone: (303) 493-7471
E-mail: steve.george@colorado.edu and sehee.lee@colorado.edu

Start Date: October 2010

Projected End Date: September 2015

\section{ACCOMPLISHMENTS}

- Developed a new polymeric hybrid inorganic-organic coating, cross-linked aluminum dioxybenzene, that is covalently bonded to the surface of Si particles via molecular layer deposition

- Resolved the chemistry of the hybrid coating during crosslinking reactions

- Demonstrated a high-performance and high-rate-capable lithium-ion Si anode enabled by this robust, conductive surface coating

- Characterized the morphology and structure evolution of both uncoated and MLD coated Si anodes during cycling.

- What was the capacity and cycle life you achieved, that is important?

- By applying new hybrid coating on conventional Si electrodes, the coated electrode is enabled to provide sustainable cycling with capacities of nearly $1500 \mathrm{mAh} \mathrm{g}^{-1}$ after 100 cycles and Coulombic efficiency (CE) in excess of $99 \%$. 


\section{INTRODUCTION}

Major barriers to wider adoption of plug-in electric vehicles include battery cost, performance, life, and safety. Utilization of $\mathrm{Si}$ in lithium ion anodes provides a path toward achieving the DOE targets for energy density of batteries for use in plug-in electric vehicles. However, progress towards a commercially viable Si anode has been impeded by Si's rapid capacity fade caused by the large volumetric expansion and complicate interfacial reactions. As part of the U.S. Department of Energy's advanced Battery Material Research (BMR) activity, we addressed the following barriers in this project:

- Cost: Inexpensive processing techniques are employed to fabricate conventional thick electrodes

- High Capacity: Si is predominantly being explored as a high capacity anode material. There is also a collaborative emphasis to enable high capacity cathode materials

- High Rate: Both ALD and MLD coatings are being developed such that high-rate capability is demonstrated for emerging materials

- Safety: The ALD/MLD coatings are targeted to improve safety for a variety of electrode materials.

- Life: The ALD/MLD coatings are targeted to improve life for a variety of Si anode.

The overall goal of this project is to stabilize the $\mathrm{Si}$ anodes with conformal ultrathin coatings. Both ALD and MLD have been developed to fabricate the nanoscale coatings. Unlink cathode materials with negligible volumetric changes, Si particles are enveloped with Si oxide, as well as suffer from the phase and volumetric changes during $\mathrm{Li}$ intercalation-deintercalation. Therefore, in addition to the requirement for chemical stability, a functional coating with the control of thickness and mechanical properties is required.

This project has demonstrated success in utilizing MLD to grow mechanically robust and flexible surface coatings to address the challenges associated with Si's dramatic volumetric changes from FY11 to FY14. In FY15, we have concluded this work to investigate the properties of the hybrid coating materials. Most importantly, we have applied the knowledge to develop the materials with desirable elastic properties and good conductivity in order to accommodate the volumetric expansion and protect the surface from the reactive electrolytes.

\section{APPROACH}

An aromatic organic diol, hydroquinone (HQ), was used recently for synthesis of the cross-linked aluminum dioxybenzene coating (AlHQ). The coating integrated aluminum oxides into cross-linked dioxybenzene matrix, resulting in products containing electronically conductive bonding environments. MLD method has been applied to synthesize the hybrid inorganic-organic coatings. Both aluminum glycerol (AlGL) and ALHQ films were grown directly on the nano-Si composite electrodes using a pancake reactor.

The nano-Si based composite electrodes were prepared by spreading nano-Si powder ( $50 \mathrm{~nm}$, Alpha Aesar), acetylene black (AB), and PVDF (polyvinylidene fluoride, binder) mixed in N-methyl pyrolidinone solvent (60:20:20 weight ratio) on a piece of copper $(\mathrm{Cu})$ foil. The electrochemical measurements were all normalized based on the mass of nano-Si in each electrode (typically $0.5-0.8 \mathrm{mg} / \mathrm{cm}^{2}$ ).

The hybrid coating (denoted by AlHQ) was deposited conformally onto the nano-Si anodes using the sequential, self-limiting reaction of trimethyl aluminum (TMA) ( $\mathrm{Al}(\mathrm{CH} 3) 3)$ and hydroquinone (HQ) (C6H4(OH)2) according to:

(A) $\mathrm{Si}-\mathrm{OH}^{*}+\mathrm{Al}(\mathrm{CH} 3) 3 \rightarrow \mathrm{Si}-\mathrm{O}-\mathrm{Al}(\mathrm{CH} 3) 2 *+\mathrm{CH} 4$

(B) $\mathrm{Si}-\mathrm{O}-\mathrm{Al}(\mathrm{CH} 3) 2 *+\mathrm{HOC} 6 \mathrm{H} 4 \mathrm{OH} \rightarrow \mathrm{Si}-\mathrm{O}-\mathrm{Al}-\mathrm{OC} 6 \mathrm{H} 4 \mathrm{OH}^{*}+\mathrm{CH} 4$

where asterisks indicate surface species and Si represents the underlying Si electrode. In this work, MLD coating has been applied on the laminated electrode to maintain the original electrode structure. The growth rate of this MLD reaction is measured to be $7.5 \AA$ per $\mathrm{AB}$ cycle at a substrate temperature of $150^{\circ} \mathrm{C}$. 


\section{RESULTS}

Mechanical properties have been improved in the cross-linked AIHQ coating. During the MLD reaction, the aluminum oxide was connected with dioxybenzene via a conjugated chain in the form of (Al-O-benzene-O-Al)n. ${ }^{[1]}$ Further dehydrogenation occurs when annealing the as-deposited film under both inert and air atmosphere. Dehydrogenation induces a longitudinal crosslinking reaction of the aluminum-dioxybenzene chains. The three-dimensional cross-linked structure leads to improved mechanical properties.

The effect of the crosslinking reaction on the evolution of thickness and density in the MLD film has been evaluated and summarized in Figure 1. Results confirm the densification of the AlHQ coating associated with the longitudinal crosslinking of aluminum-dioxybenzene chains. In addition to improving the film's

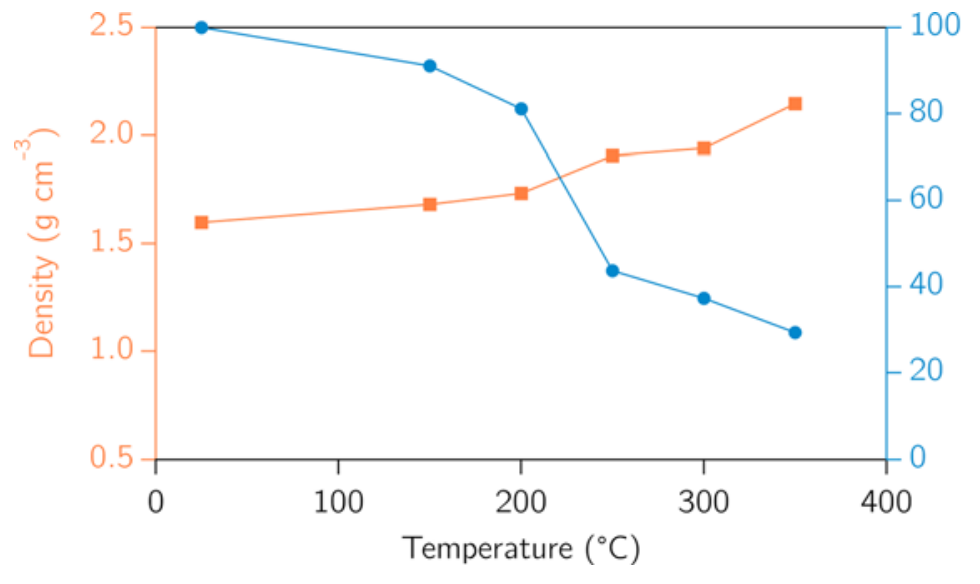

Figure 1: Density (orange profile) and percent thickness (blue profile) of the AlHQ films in relation to temperature. Results reveal the densification (thickness reduction) of the AlHQ films with increasing temperature treatments. conductive properties, such crosslinking was expected to improve the mechanical properties of the AlHQ coating. To study the mechanical effects of heat treatment, we focused our attention on 100-nmthick AlHQ coatings on Si wafers. The heat treatments were all conducted in air, after the deposition process, for a span of 12 hours. Nanoindentation was used to study the ratio of hardness to Young's modulus $\left(H / E^{*}\right)$, which allows determination of the film's wear resistance as a function of temperature. Results reveal the highest $H / E^{*}$ for the AlHQ coating heat-treated at $150^{\circ} \mathrm{C}$, suggesting a more elastic than plastic deformation under contact, with negative returns at $200^{\circ} \mathrm{C}$ (Table 1$)$. Materials
Table 1: Nanoindentation results of AIHQ thin films treated at various temperatures in air revealing the highest $H / E^{*}$ for the $A H Q$ coating heat-treated at $150^{\circ} \mathrm{C}$.

\begin{tabular}{|c|c|c|c|}
\hline $\begin{array}{c}\text { AlHQ } \\
\text { Temperature } \\
\text { Treatment } \\
{\left[{ }^{\circ} \mathrm{C} \text { in air] }\right.}\end{array}$ & $\begin{array}{c}\text { Elastic } \\
\text { Modulus } \\
\text { [E*, } \\
\text { GPa] }\end{array}$ & $\begin{array}{c}\text { Hardness } \\
\text { [H, GPa] }\end{array}$ & $H / E^{*}$ \\
\hline 25 & 29.2 & 1.24 & 0.0425 \\
\hline 150 & 34.9 & 1.82 & 0.0522 \\
\hline 200 & 60.2 & 2.50 & 0.0415 \\
\hline
\end{tabular}
with higher $H / E^{*}$ are expected to have smaller accumulative strains and strain energies; therefore, they are expected to have better wear resistances, which are the indications of the durability of materials under severe mechanical loading. Additionally, the much lower Young's modulus than ALD ceramic coatings (34.9 $\mathrm{GPa}$, compared to $170 \mathrm{GPa}$ for $\mathrm{ALD} \mathrm{Al}_{2} \mathrm{O}_{3}$ ) makes the coating much more flexible and able to accommodate the volume expansion and contraction of Si nanoparticles. The cross-linked AlHQ coatings show improved mechanical properties that ensure the structural integrity of the nanocomposite electrodes.

Furthermore, the crosslinking structure enabled by the polydentate Lewis acid creates strong covalent bonding to the surface of $\mathrm{Si}$ particles, but also provides chemical stability of the coating film. 


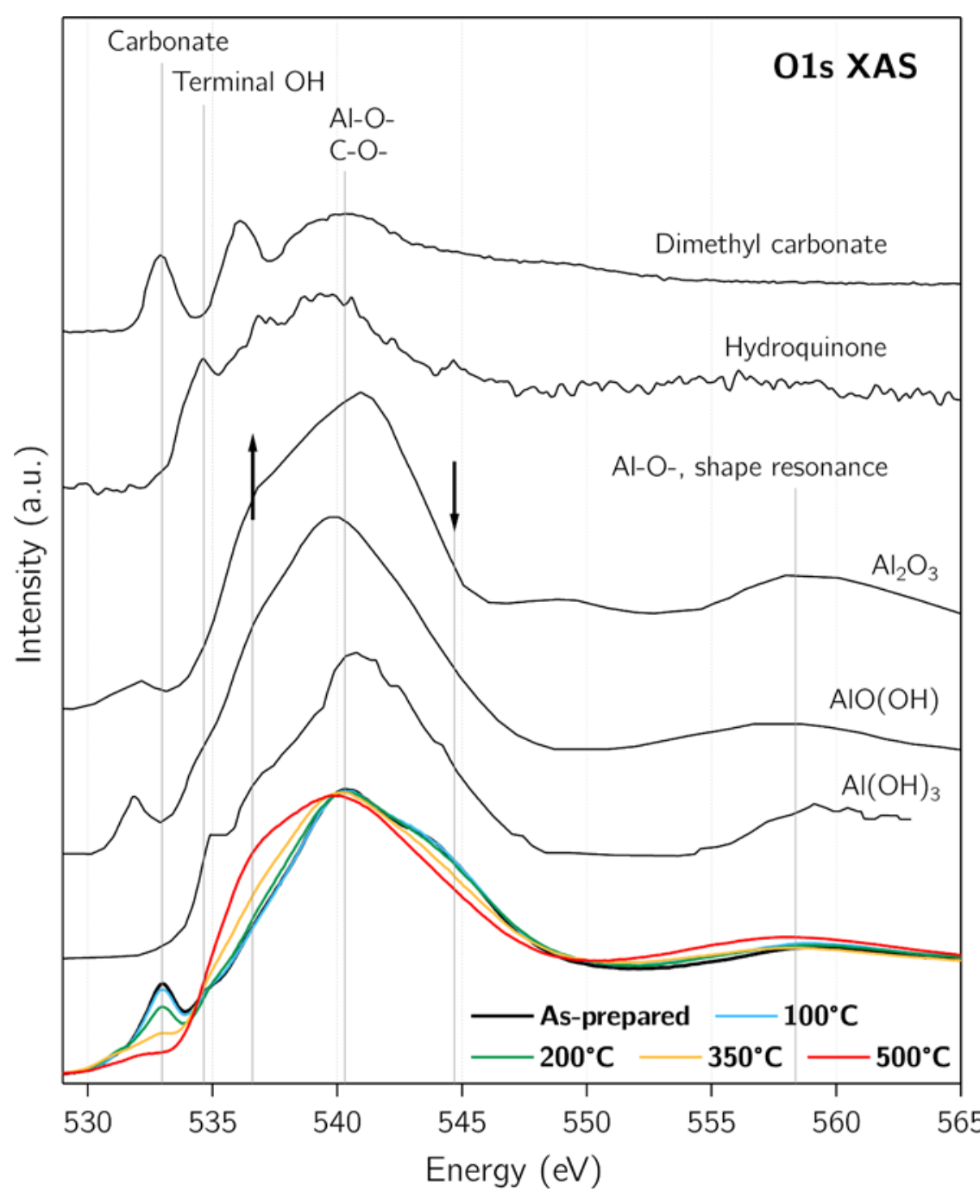

Figure 10: XAS spectra of O K-edge (TEY modes) in AlHQ thin films treated at 25, 100, 200, 350 , and $500^{\circ} \mathrm{C}$ under Ar environment.
Chemistry in the crosslinking process of the AlHQ coating has been characterized by using XAS spectra X-ray absorption spectroscopy (XAS). By monitoring the oxygen bonding environments as a function of temperature and atmosphere, we are able to determine the optimal annealing condition for the MLD layer. Figure 2 shows the O K-edge XAS spectra for the samples annealed under $\mathrm{Ar}$ atmosphere. We note that overall, the O K-edge XAS spectra resemble that of aluminum oxyhydrides $(\mathrm{AlO}(\mathrm{OH}))$, with slightly broader features than that of gibbsite $\left(\mathrm{Al}(\mathrm{OH})_{3}\right)$, as depicted in Figure 2. This indicates that the as-prepared AlHQ-MLD film has a similar electronic structure to both Al-O- and Al$\mathrm{OH}$ functionalities in $\mathrm{AlO}(\mathrm{OH})$. Apart from the $\sigma$ resonance around $540 \mathrm{eV}$ (associated with the single oxygen bond in Al-O- and Al$\mathrm{O}-\mathrm{C}$, as well as $\mathrm{C}-\mathrm{O}-$ ), there is a relatively well-defined shape resonance near $560 \mathrm{eV}$ in the as-prepared MLD film; this shape resonance closely matches that found for the Al-O- bond in $\mathrm{AlO}(\mathrm{OH}){ }^{[2]}$ The AlHQ coating was synthesized from the reaction between TMA and HQ, as summarized in reactions A and B. However, the signature of the terminal $-\mathrm{OH}$ group from hydroquinone (at about $535 \mathrm{eV}$ ) is greatly suppressed in the AlHQ film. The quenched peak confirms the self-limited and sequential reaction between the - OH in HQ and TMA, which is consistent with previous results. ${ }^{[3]} \mathrm{We}$ also notice a low-energy peak around $533 \mathrm{eV}$ that cannot be associated with the saturated bond of the AlHQ framework. Based on careful alignment with the core-excitation database of Hitchcock and co-workers, the resonance lines up with carbonate functionalities. Based on the established reaction pathway of carbonates on an oxygen-covered surface, we speculate that during the processing of the AlHQ film, residual $\mathrm{CO}_{2}$ reacts with the surface oxide to form carbonates. ${ }^{[4]}$ As shown in Figure 2, the peak (around $533 \mathrm{eV}$ ) undergoes gradual decomposition as the annealing temperature rises, indicating that the carbonate species decompose at high temperatures.

In regard to the chemistry evolution of the AlHQ coating upon post-deposition heat treatments, we used two energy spans of the $\mathrm{O}$ K-edge XAS spectra (535-540 eV, upward arrow, and 542-548 eV, downward arrow in Figure 2) to track the transition of $\mathrm{AlHQ}$ to $\mathrm{Al}_{2} \mathrm{O}_{3}$ as a function of annealing temperature. When the annealing temperature is above $200^{\circ} \mathrm{C}$, we clearly observed the changes of electronic structure toward $\mathrm{Al}_{2} \mathrm{O}_{3}$ for the samples heat-treated in both air and argon (Ar) environments. The conversion to $\mathrm{Al}_{2} \mathrm{O}_{3}$ following pyrolysis is 
obvious at $350^{\circ} \mathrm{C}$. However, a slower transition was observed when using Ar in comparison to the air-annealed sample. The oxygen deficiency in an Ar environment limits oxygen functionalization, resulting in slower kinetics for the crosslinking reaction and the following pyrolysis. Based on these observations, we determined to use a higher temperature, $200^{\circ} \mathrm{C}$, for Ar annealing to induce crosslinking reactions in AlHQ coating with no electronic structure changes toward $\mathrm{Al}_{2} \mathrm{O}_{3}$.
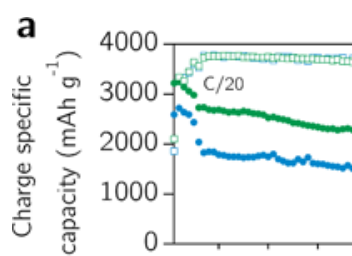

50

b

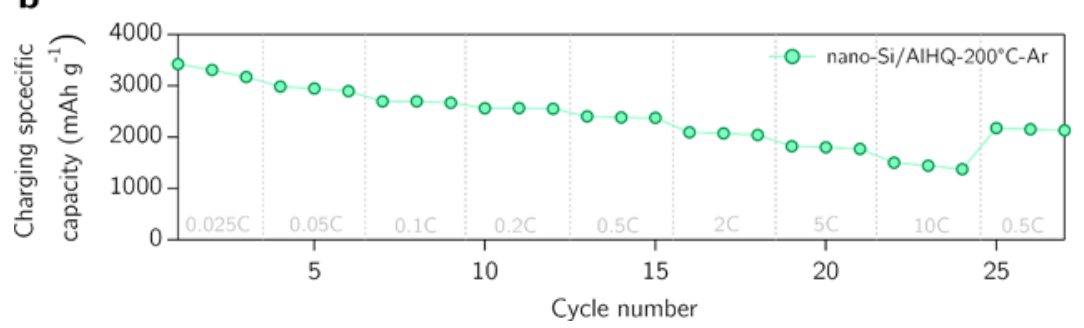

Figure 11: (a) Cyclic capacity and CE of a Si anode coated with as-deposit AIHQ (blue symbols) compared to the cyclic capacity and CE of a Si anode coated with Ar-treated AIHQ (green symbols). (b) A rate test demonstrates that the Ar-treated electrode can achieve an average specific charge capacity of $1798 \mathrm{mAh} \mathrm{g-1}$ at a rate of $5 \mathrm{C}$ and specific charge capacities of about $1500 \mathrm{mAh} \mathrm{g}-1$ at a rate of $10 \mathrm{C}$. All the capacities were normalized based on total Si-active material in each electrode.
MLD AlHQ coating has improved the cycling performance of the conventional Si-CPVDF based electrodes, as shown in Fig. 3a. The Si anodes were prepared by using PVDF as a binder additive. Previous work has confirmed that PVDF fails to accommodate the volumetric changes in Si electrodes. Thus,

PVDF has been selected in this work to distinguish the effect of coating on mechanical integrity and electrochemical performance of Si anodes. Both electrodes with the as-deposited AlHQ coating and the cross-linked AlHQ coating (treated under Ar) were run at a rate of C/20 (175 mA g-1) for the first five cycles and then at a rate of $\mathrm{C} / 10\left(350 \mathrm{~mA} \mathrm{~g}^{-1}\right)$ for all subsequent cycles, as plotted in Figure 3a. At cycle 200, the AlHQ-coated electrode exhibits a specific charge capacity of nearly $1500 \mathrm{mAh} \mathrm{g}^{-1}$ and CE values in excess of $99 \%$, whereas the as-deposited AlHQ-coated electrode achieves a stable capacity of about $1000 \mathrm{mAh} \mathrm{g}^{-1}$. The specific charge capacity of $1500 \mathrm{mAh} \mathrm{g}^{-1}$ of the coated $\mathrm{Si}$ anode corresponds to an electrode areal capacity of $0.581 \mathrm{mAh} \mathrm{cm}^{-2}$ and a volumetric capacity of $1020 \mathrm{mAh} \mathrm{cm}^{-3}$. The Si electrode coated with Ar-treated AlHQ coating, as compared to the non-heat-treated AlHQ coating, has exhibited the improvements. Both of these electrochemical performances significantly outperform the rapid degradation of an uncoated Si electrode, which fails by its $30^{\text {th }}$ cycle. Moreover, the capacity retention of the AlHQ-coated electrode at 200 cycles nearly triples that of previous attempts to use MLD aluminum-glycerol coatings on Si electrodes. ${ }^{[4]}$

Electrochemical rate test was performed to study the transport properties of the Ar-treated AlHQ coating, as shown in Figure 3b. At a rate of 5C $\left(17.5 \mathrm{~A} \mathrm{~g}^{-1}\right)$, the AlHQ-coated electrode exhibited an average specific charge capacity of $1798 \mathrm{mAh} \mathrm{g}^{-1}$ - more than $750 \mathrm{mAh} \mathrm{g}^{-1}$ the capacity of our previous AlGL surface coating. Also, at a rate of 10C (35 A g-1), the AlHQ-coated electrode is still able to deliver specific charge capacities of about $1500 \mathrm{mAh} \mathrm{g}^{-1}$. Returning then to a rate of $\mathrm{C} / 2\left(1.75 \mathrm{~A} \mathrm{~g}^{-1}\right)$, the electrode recovered $91 \%$ of its specific charge capacity. This result attests to the maintenance of the electrode's structural integrity but also suggests that the cross-linked AlHQ coating provides very impressive ionic and electronic transport properties.

\section{CONCLUSIONS AND FUTURE DIRECTIONS}

By applying this new hybrid coating on conventional Si electrodes, the coated electrode is enabled to provide sustainable cycling with capacities of nearly $1500 \mathrm{mAh} \mathrm{g}^{-1}$ after 100 cycles and Coulombic efficiency (CE) in excess of 99\%. Diagnostic techniques including X-ray absorption spectroscopy, electrochemical impedance, and nanoindentation have been performed to reveal chemical and physical properties of the hybrid coating and 
its effect on the electrochemical performance of the Si anodes. The MLD-enabled chemistry overcomes many impediments in wet-chemistry fabrication for surface modification and also greatly extends the compositional possibilities of surface modifiers on lithium-ion battery electrodes.

The favorable combination of mechanical and electrochemical properties achieved with AlHQ conformal coatings on Si anode could present a major advancement in lithium-ion battery technology. Surface modification with many chemicals had previously been deemed unsuitable for materials with large volume changes due to the mechanical failure of the coatings under large stresses. However, here we have demonstrated the remarkable capability of the AlHQ electrode coating to not only maintain a reversible Sibased anode structure with stable and high capacities for hundreds of cycles, but to also allow electron and ion exchange at very high rates. At a rate of $10 \mathrm{C}\left(35 \mathrm{~A} \mathrm{~g}^{-1}\right)$, the AlHQ-coated electrode is still able to deliver specific charge capacities of about $1500 \mathrm{mAh} \mathrm{g}^{-1}$. This back-end surface modification process is also compatible with a range of Si-based electrode configurations. While this work has been focused on enhancing the electrochemical performance of conventionally prepared Si anode structures with PVDF and conductive additives, the AlHQ surface chemistry is not limited to these structures. Preliminary work on AlHQ coated Si anodes utilizing a carboxymethyl cellulose binder and conductive additives shows great promise. This research may also be adaptable to a range of other high-capacity materials, representing an important advancement in high-energy LIBs applications. Future work, moving to the Applied Battery Research program, will look into an in-depth study of this particular aromatic framework to fully understand its electrochemomechanics, in addition to improving the early cycling coulumbic efficiency through electrolyte modifications.

\section{FY 2015 PUBLICATIONS/PRESENTATIONS}

1. D.M. Piper, Y. Lee, S.B. Son, T. Evans, F. Lin, D. Nordlund, X. Xiao, S.M. George, S.H. Lee, C. Ban, "Cross-Linked Aluminum Dioxybenzene Coating for Stabilization of Silicon Electrodes", submitted.

2. Y. Ma, J.M. Marinex de la Hoz, I. Angarita, J.M. Berrio-Sanchez, L. Benitez, J.M. Seminario, S.B. Son, S.H. Lee, S.M. George, C. Ban and P.B. Perla, "Structure and Reactivity of Alucone-Coated Films on Si and LixSiy Surfaces", ACS Appl. Mater. Interfaces, 2015, 7 (22), pp 11948-11955.

3. L. Luo, H. Yang, P. Yan, J. J. Travis, Y. Lee, N. Liu, D.M. Piper, S.H. Lee, P. Zhao, S.M. George, J.G. Zhang, Y. Cui, S. Zhang, C. Ban and C. Wang, "Surface-Coating Regulated Lithiation Kinetics and Degradation in Silicon Nanowires for Lithium Ion", ACS Nano, 2015, 9 (5), pp 5559-5566.

4. D.M. Piper, S.B. Son, J. J. Travis, Y. Lee, S.M. George, S.H. Lee, C. Ban, "Mitigating irreversible capacity losses from carbon agents via surface modification", Journal of Power Sources, 2015 275, 605-611.

5. Y. He, D.M. Piper, M. Gu, J.J. Travis, S.M. George, S.H. Lee, A. Genc, L. Pullian, J. Liu, S.X. Mao, J.G. Zhang, C. Ban and C. Wang, "In Situ Transmission Electron Microscopy Probing of Native Oxide and Artificial Layers on Silicon Nanoparticles for Lithium Ion Batteries" ACS Nano, 2014, 8 (11), pp 11816-11823.

6. S.B. Son, B. Kappes, C. Ban, "Surface Modification of Silicon Anodes for Durable and High-Energy Lithium-Ion Batteries", Israel Journal of Chemistry, 2015, 55 (5), 558-569. (Review paper)

7. 249th ACS National Meeting, Denver, Colorado, 2015: Investigation of atomic/molecular layer deposition coatings for Li-ion electrode. (Invited)

8. International Battery Association and Pacific Power Source Symposium Joint Meeting 2015: Investigation of Molecular Layer Deposition Coatings for Silicon Anodes. (Invited)

9. 40th Annual symposium AVS, East Lansing, Michigan, 2014: Surface modification of silicon anodes for advanced Li-ion batteries. (Invited)

\section{Reference:}

1. (a) B. Yoon, Y. Lee, D. Derk, C.B. Musgrave, S.M. George, ECS Trans. 33 (2011) 191-195; (b) Y. Lee and S.M. George, "Molecular Layer Deposition of Alucones and Zincones Using Hydroquinone", AVS 59TH International Symposium \& Exhibition, Tampa, FL (Oct. 2012). 
2. (a) Y.F. Hu, R.K. Xu, J.J. Dynes, R.I.R. Blyth, G. Yu, L.M. Kozak, P.M. Huang, Geochim. Cosmochim. Acta 72 (2008) 1959-1969; (b) R.K. Xu, Y.F. Hu, J.J. Dynes, A.Z. Zhao, R.I.R. Blyth, L.M. Kozak, P.M. Huang, Geochim. Cosmochim. Acta 74 (2010) 6422-6435.

3. J.T. Francis, A.P. Hitchcock, J. Phys. Chem. 96 (1992) 6598-6610.

4. D. Molina Piper, J.J. Travis, M. Young, S.-B. Son, S.C. Kim, K.H. Oh, S.M. George, C. Ban, S.-H. Lee, Adv. Mater. 26 (2014) 1596-1601. 